\title{
EFFECT OF SHORT-TERM SEPARATION ON BEHAVIORAL HEALTH OF MILITARY WIVES
}

by

Pedro Nombrefia Oblea, Jr.

Copyright (C) Pedro Nombrefia Oblea, Jr. 2014

A Dissertation Submitted to the Faculty of the COLLEGE OF NURSING

In Partial Fulfillment of the Requirements

For the Degree of

DOCTOR OF PHILOSOPHY

In the Graduate College

THE UNIVERSITY OF ARIZONA

2014 


\section{THE UNIVERSITY OF ARIZONA}

GRADUATE COLLEGE

As members of the Dissertation Committee, we certify that we have read the dissertation

prepared by Pedro Nombrefia Oblea, Jr. entitled "Effect of Short-Term Separation on Behavioral Health of Military Wives" and recommend that it be accepted as fulfilling the dissertation requirement for the Degree of Doctor of Philosophy

Date: November 17, 2014

Terry A Badger, PhD, RN, PMHCNS-BC, FAAN

Date: November 17, 2014

Judith A. Berg, PhD, RN, WHNP-BC, FAAN, FAANP

Date: November 17, 2014

Elaine G. Jones, PhD, RN

Date: November 17, 2014

Denise L. Hopkins-Chadwick, PhD, RN, COL

U.S. Army Corps - Special Member

Final approval and acceptance of this dissertation is contingent upon the candidate's submission of the final copies of the dissertation to the Graduate College.

I hereby certify that I have read this dissertation prepared under my direction and recommend that it be accepted as fulfilling the dissertation requirement.

Dissertation Director: Terry A Badger, PhD, RN, PMHCNS-BC, FAAN

Date: November 17, 2014 


\section{STATEMENT BY AUTHOR}

This dissertation has been submitted in partial fulfillment of requirements for an advanced degree at The University of Arizona and is deposited in the University Library to be made available to borrowers under rules of the Library.

Brief quotations from this dissertation are allowable without special permission, provided that accurate acknowledgment of source is made. Requests for permission for extended quotation from or reproduction of this manuscript in whole or in part may be granted by the copyright holder.

SIGNED: Pedro Nombrefia Oblea, Jr. 


\section{ACKNOWLEDGMENTS}

First and foremost, I want to thank my dissertation committee members for their expertise in research: Dr. Terry A. Badger, Dr. Judith A. Berg, Dr. Elaine G. Jones, and Colonel (Dr.) Denise L. Hopkins-Chadwick. Without their assistance and dedicated involvement in every step of the process, this dissertation would never have been accomplished.

I would like to further express appreciation to my dissertation chair, Dr. Terry A. Badger, for her teaching, mentoring, and most especially her encouragement and motivation, which helped me complete this research.

To my parents and my sisters-it would be an understatement to say that, as a family, we have experienced some ups and downs in the past four years. Every time I was ready to quit, you would not let me and I am forever grateful. This dissertation stands as a testament to your unconditional love and encouragement.

I would like to express my appreciation to John Ross T. Sablan, my best friend, who has always been there for me, for his continuous words of encouragement and belief in me.

Last, my thanks go to my son, Paul David T. Oblea, who has served as my constant reminder that I must finish this research so I can graduate. 


\section{DEDICATION}

I dedicate this dissertation to my family, especially...

my parents, Pedro Sr. and Isabel, for instilling in me the importance of hard work and higher education

my sisters Marcela, Eufemia, Leona, Magin, and Glory for their encouragement my adopted brother, Efren Tabonares

my son, Paul David T. Oblea for being an understanding and loving son all the military wives... 


\section{TABLE OF CONTENTS}

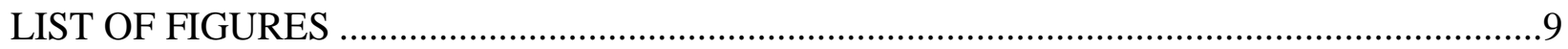

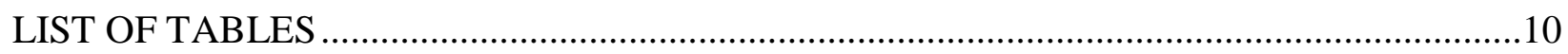

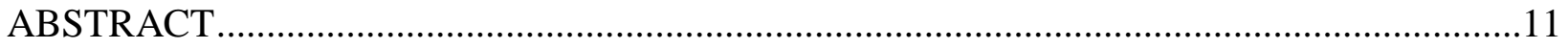

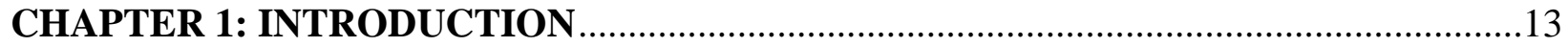

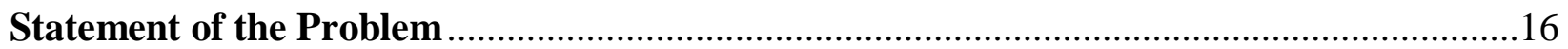

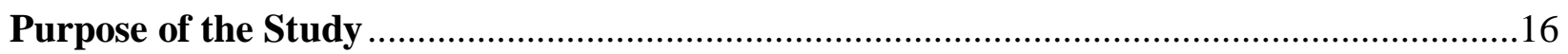

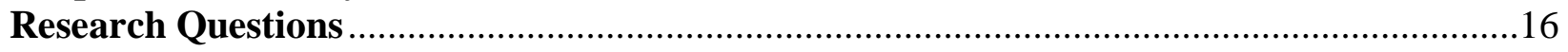

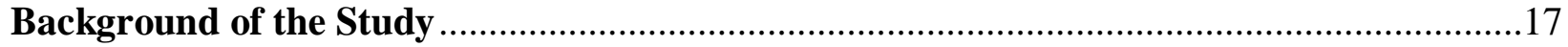

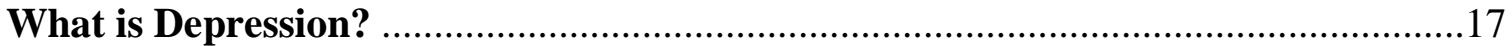

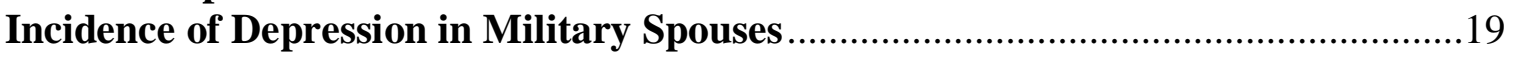

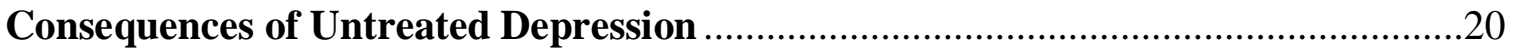

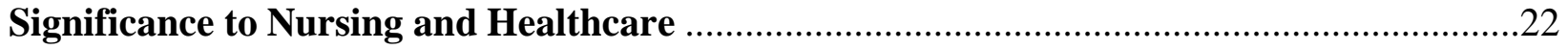

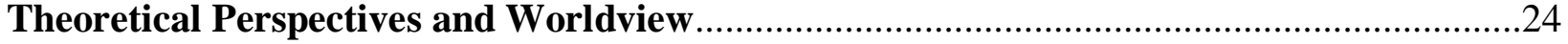

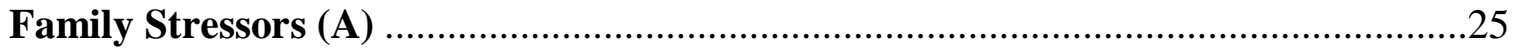

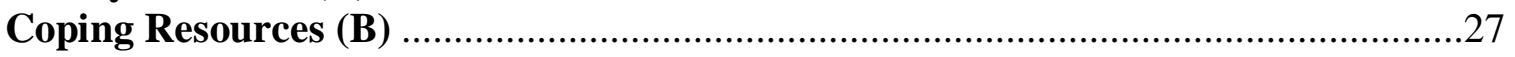

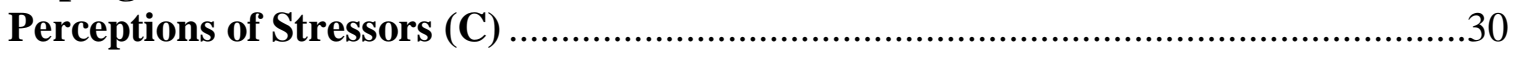

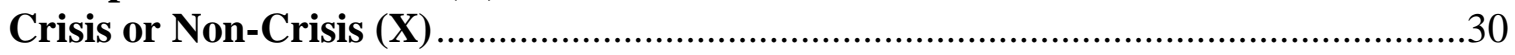

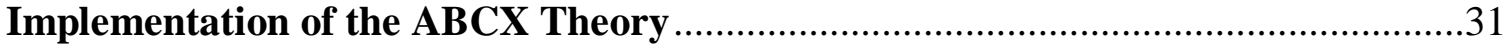

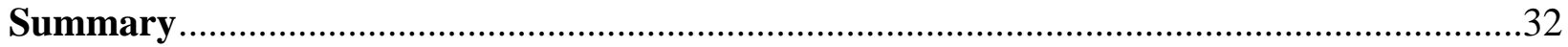

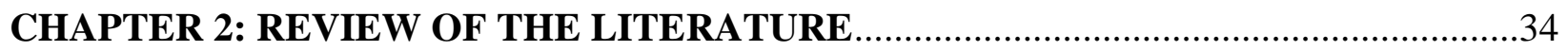

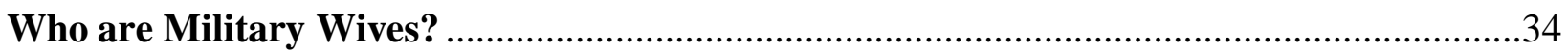

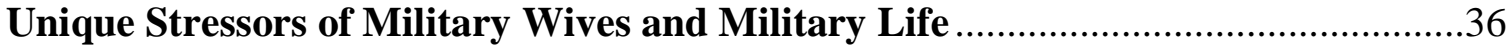

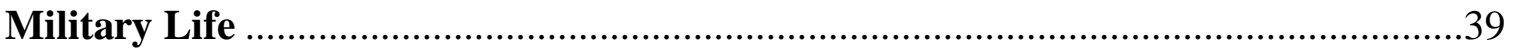

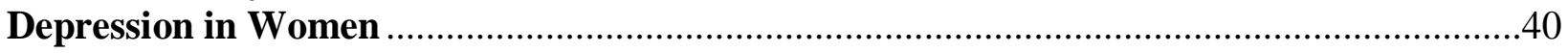

Depression as it Applies in This Study ....................................................... 42

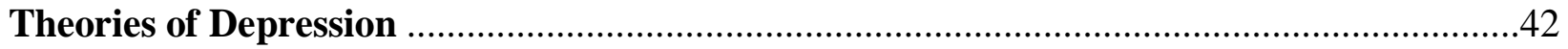

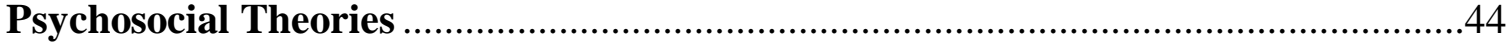

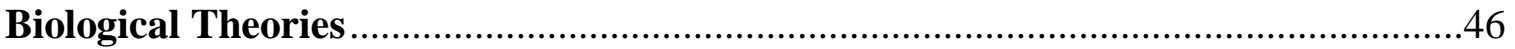

Separation Related to Deployment and Military Wives' Mental Health............................48

Understanding the Impact of Short-Term Separation Results in a New Generation

of Learning About Military Wives and Depression ............................................53

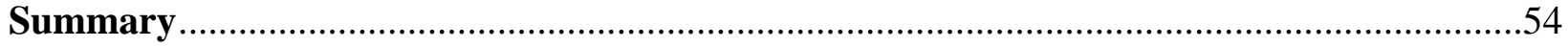

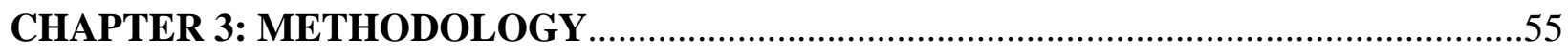

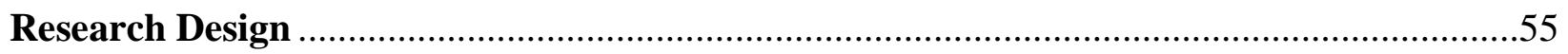

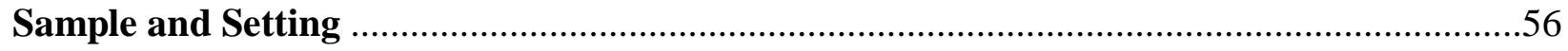

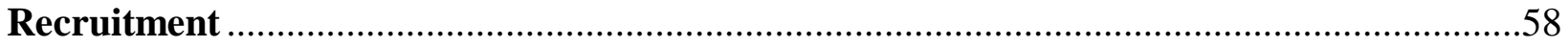

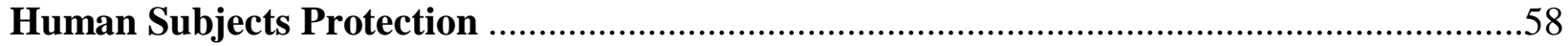


TABLE OF CONTENTS - Continued

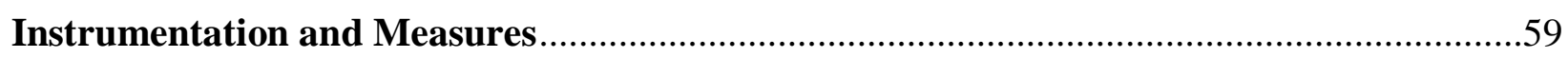

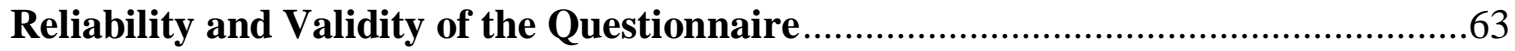

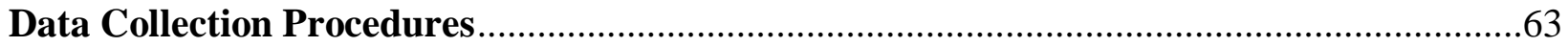

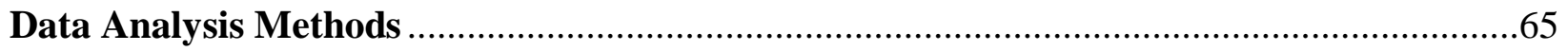

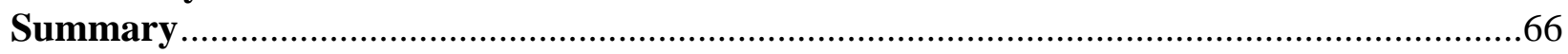

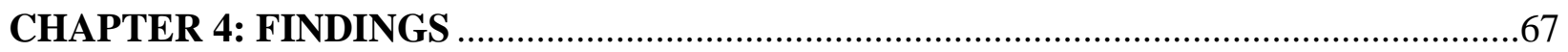

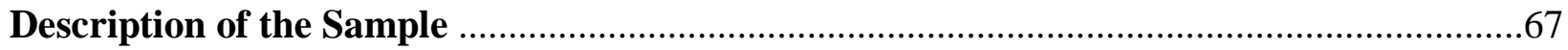

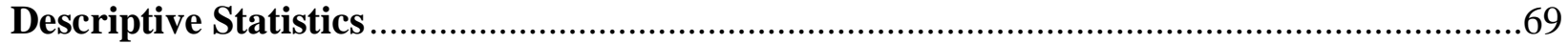

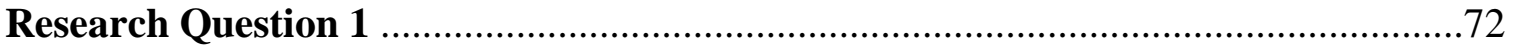

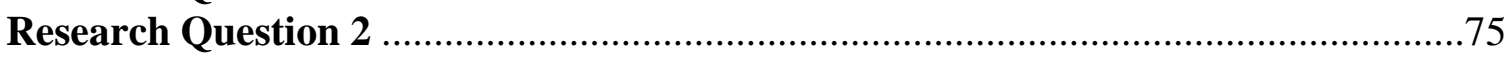

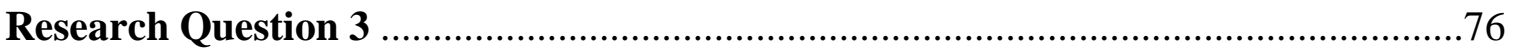

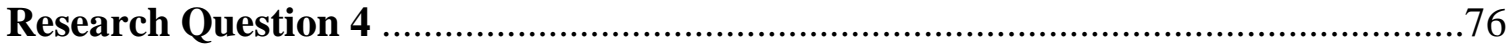

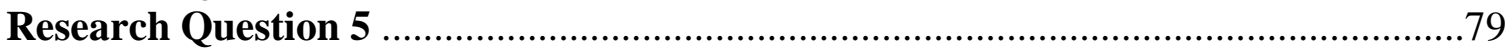

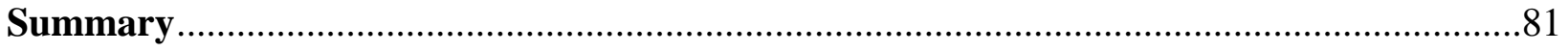

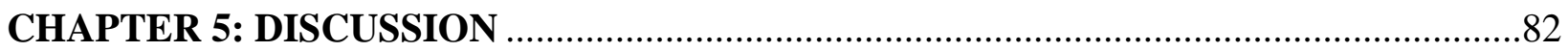

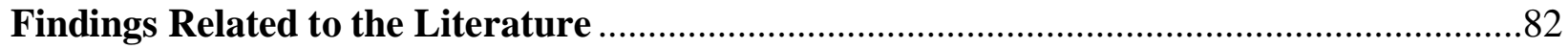

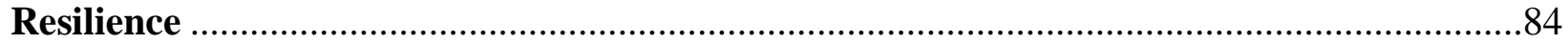

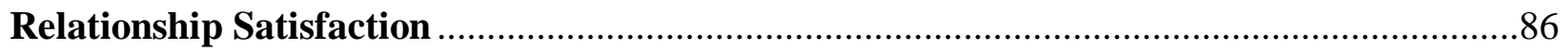

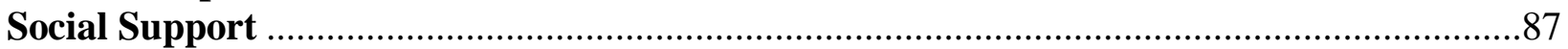

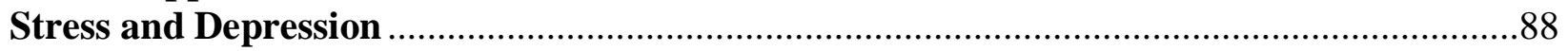

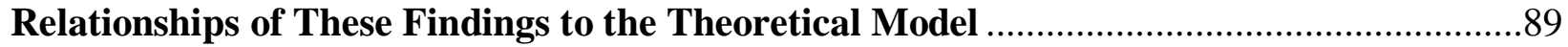

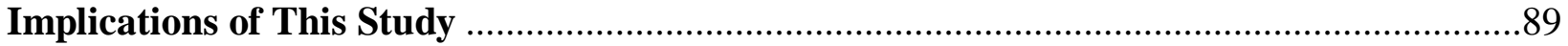

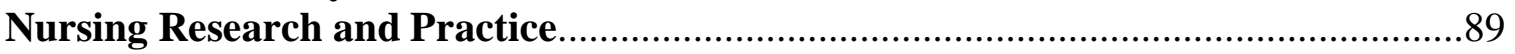

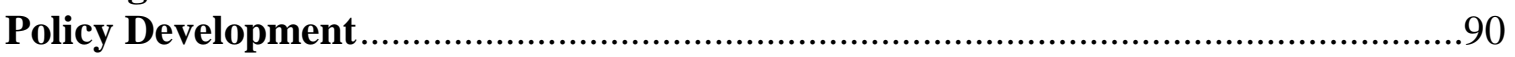

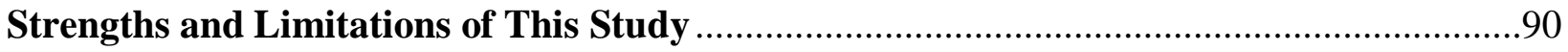

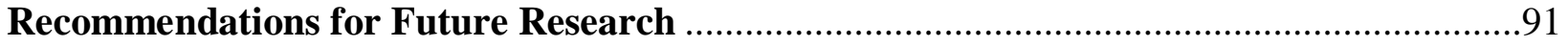

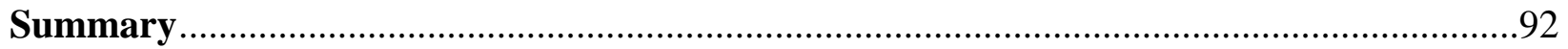

APPENDIX A: INSTITUTIONAL REVIEW BOARD APPROVAL .................................93

APPENDIX B: INSTITUTIONAL REVIEW BOARD CLOSURE REPORT ........................96

APPENDIX C: INSTITUTIONAL REVIEW BOARD AUDIT RESULT .............................98

APPENDIX D: COVER LETTER FOR MILITARY WIVES ..............................................100

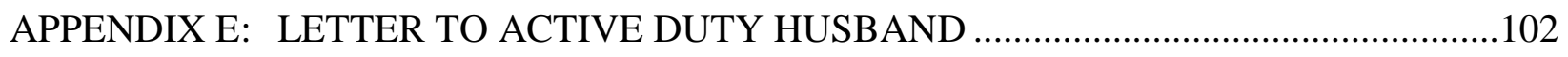

APPENDIX F: HUMAN PROTECTION APPROVAL (MILITARY) ..................................104

APPENDIX G: RESEARCH INFORMATION SHEET ...................................................106 
TABLE OF CONTENTS - Continued

APPENDIX H: PRE-SEPARATION SURVEY QUESTIONNAIRES.................................108

APPENDIX I: POST-SEPARATION SURVEY QUESTIONNAIRES ...............................114

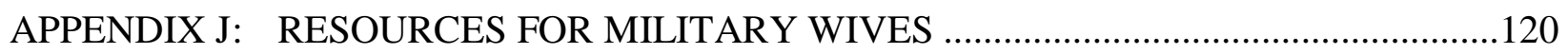

APPENDIX K: APPROVAL LETTER FOR THE USE OF INSTRUMENTS ......................122

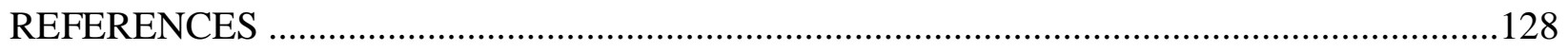




\section{LIST OF FIGURES}

FIGURE 1. Modified Theoretical Framework for the ABCX Model.........................................31

FIGURE 2. Stress vs. Social Support with Best-Fit Line. ........................................................78

FIGURE 3. Stress vs. Resiliency with Best-Fit Line. ................................................................78 


\section{LIST OF TABLES}

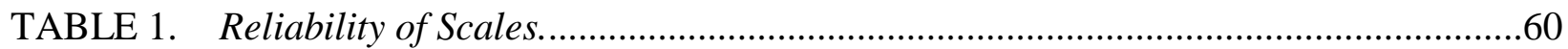

TABLE 2. Demographic Characteristics of Military Wives $(N=32)$........................................68

TABLE 3. Types and Frequencies of Communication ............................................................69

TABLE 4. Pre- and Post- Separation Scores for Depression, Social Support, Resiliency, Perceived Stress and Relationship Satisfaction.....................................................70

TABLE 5. Pre-Separation Correlations for Depression, Social Support, Resiliency, Perceived Stress and Relationship Satisfaction...................................................................71

TABLE 6. Post-Separation Correlations for Depression, Social Support, Resiliency, Perceived Stress and Relationship Satisfaction.................................................................

TABLE 7. Differences in Pre-Separation Depression by Group................................................73

TABLE 8. Differences in Post-Separation Depression by Group.............................................75

TABLE 9. Differences in Pre-and Post-Separation Resiliency. ..............................................75

TABLE 10. Differences in Pre- and Post-Relationship Satisfaction. ……………....................76

TABLE 11. Post-Separation Survey Descriptive Statistics and Inter-Correlations for Social Support, Resiliency and Perceived Stress. ...........................................................77

TABLE 12. Linear Regression: Social Support as a Predictor of Stress........................................77

TABLE 13. Linear Regression: Resiliency as a Predictor of Stress. ...........................................77

TABLE 14. Correlations of Social Support, Resiliency, Perceived Stress, Relationship Satisfaction, and Depression with Frequency of Communication.............................80

TABLE 15. Correlations of Age, Number of Separations, Length of Separation, Length of Marriage, Time Living with Husband, Social Support, Perceived Stress, and Relationship Satisfaction with Post-Separation Depression 


\begin{abstract}
The purposes of this study were to: 1) describe the effect of short-term separation on the behavioral health of military wives using a descriptive pre-test post-test design and 2) to examine predictors of depression among wives of selected active duty military personnel during shortterm separation. Specifically, the research was guided by the following questions: 1) Does postseparation depression vary based on socio-demographic characteristics? 2) Do military wives have resiliency when separated from their active duty military husbands? 3) Is short-term separation associated with a decrease in relationship satisfaction among military wives of active duty military personnel? 4) Are stress levels in military wives in response to separation associated with levels of social support or resiliency? And lastly, 5) Do socio-demographic characteristics, social support, resiliency, perceptions of stress, and/or relationship satisfaction predict depression in military wives? The data in this study was gathered using a selfadministered questionnaire using a combination of five standard instruments: Multidimensional Scale of Perceived Social Support, Beck Depression Inventory II, Connor-Davidson Resilience Scale 10, Perceived Stress Scale, and Relationship Assessment Scale. Thirty-two military wives of active-duty military personnel participated in the study. The typical military wife was in her early thirties, was white, had a college degree, was a homemaker and had a family income of greater than $\$ 100,000$. Average length of marriage was 10 years with about two separations. The results indicated that there is no change in levels of resiliency and levels of relationship satisfaction pre- and post- separation. Sociodemographic, age, number of separations, length of separations, length of marriage, time living with the husband, and social support had no significant relationship with post-separation depression. The study revealed that resiliency is a
\end{abstract}


significant predictor of stress scores, but social support was not a predictor of stress scores.

Lastly, the study showed a strong relationship between stress and depression as predicted in the literature. Due to the small sample size typical of pilot studies and lack of power, findings should be interpreted with caution. The knowledge gained from this study will add to new findings about short-term separation. 


\section{CHAPTER 1: INTRODUCTION}

Short-term rather than lengthy separations are becoming the norm in military life, and little is known about impact of these brief separations on the behavioral health of military wives, focusing specifically on depression. The purpose of this study was to provide information on the effect of short-term separation on military wives. Findings can be used to assist the military in planning preventive measures which, in the long term, can help reduce overall healthcare costs; the findings can also be used to indicate which demographic and clinical markers predict the incidence of depression so that programs of intervention can be targeted toward those who need them most.

The term short-term separation as used in this study is a separation due to training and not a separation due to operational deployment. According to the Department of Defense, separation due to training is defined from the perspective of a family member-it is a separation that consists of training, physical departure, and time away from home either in the theater of operations or within the United States (Department of Defense [DoD], 2011, p. 3). Operational deployment is the movement of troops to perform a mission in an operational or combat environment in an overseas setting. During deployment, families may be required to live apart for various lengths of time. For example, Operation Iraqi Freedom (OIF) and Operation Enduring Freedom (OEF) have been characterized by multiple deployments (Chawla \& SolinasSaunders, 2011). However, these deployments are characterized as longer term operational deployments.

Although it is hoped that separation caused by longer deployments will decrease, separation of service members from their families due to training or short-term missions will 
continue. Separation due to deployment of three months or less for humanitarian missions and training purposes will become the norm in military life and although long-term separations are well documented as a cause of behavioral health concerns for military spouses (Angrist \& Johnson, 2000; Black, 1993; Jensen, Martin, \& Watanabe, 1996; Schumm, Bell, \& Gade, 2000), the effect of short-term separations has not been assessed.

From the $\$ 50.7$ billion fiscal year (FY) 2011 Department of Defense budget, $\$ 80.81$ million was spent for the medical care of military beneficiaries with a diagnosis of depressive disorder, the thirteenth most common outpatient diagnosis for FY 2011 (TRICARE, 2012). Depression is a serious condition with quantifiable human and economic costs that affect families, including children, teens, and adults in all stages of life (Jacob et al., 2012; Leahy, 2010). In FY 2000, the economic burden associated with depression was estimated at \$104 billion in United States.

Family separation is an expected element of military life. Soldiers can be separated from their families for several reasons, such as participating in field-training exercises, attending school, or deploying on peacekeeping or combat missions. Separations can last from a few days to several months and are likely to be recurring (Burrell, Adams, Durand, \& Castro, 2006). At any given time, $8 \%$ of Army service members can be separated from their spouses (Coolbaugh $\&$ Rosenthal, 1992). This results in more than 200,000 military wives being affected by separation due to the deployment of their husbands (Easterling \& Knox, 2010). Data from various investigations on separations of military spouses and service members have shown that the separation is an involuntary distraction in family life that triggers personal hardships as people become overloaded with challenges, must handle economic difficulties, and must attempt to 
sustain the routines of family life (Riggs, 1990; Vormbrock, 1993). Medway, Davis, Cafferty, Chappell, and O'Hearn (1995) claimed that interference in social connection may further intensify the poor mental health condition of military spouses. The data used to support their findings indicated that the emotional suffering of military spouses is associated with recurrent and wartime separations, with the outcome of family disturbance.

Since FY 1995, the percentage of Army soldiers who are married has declined. Overall, 60\% of active duty soldiers reported being married in FY 1995; this dropped to 54\% in FY 2005. Most active duty soldiers were married to civilians-89\% in FY 1995 and 91\% in 2005 (Defense Manpower Data Center, 2005). Currently, approximately $49 \%$ of enlisted soldiers and $68 \%$ of officers are married. TRICARE (2012) reported to Congress that there were 727,876 active duty military wives age 65 or younger and 49,794 active duty military husbands age 65 or younger in FY 2012. As of August 2011, 2,317,761 men and women were in uniform and of these, 1,348,405 were deployed (Martinez, 2011).

Several studies of military spouses were conducted during the wars in Iraq and Afghanistan (Eaton et al., 2008; Gorman, Blow, Ames, \& Reed, 2011; Mansfield et al., 2010). Mental health services intended to support families during deployment and re-integration were found to be underutilized. Military wives were more likely to expect to receive care for their mental health difficulties and were less worried about the associated societal stigma than were the soldiers themselves. Mental health services were provided more frequently by primary care physicians than mental health care professionals.

This study will benefit military nurses by creating a change in paradigm for selectively identifying an at-risk population and could result in changes to the delivery and performance of 
preventive military nursing care for other disease entities. Although this research was initially pursued for military healthcare consumption, the results may eventually reach into practice beyond the military, where practitioners can use the findings to assist civilians (i.e., non-military persons) with depression.

\section{Statement of the Problem}

Currently, no published English-language studies have examined the effect of short-term separations on military wives of active duty military personnel in the United States Army. This study seeks to contribute to this previously neglected area of research. Without knowing the demographic and clinical factors that predict depression in military wives during short-term separations, it is not possible to accurately develop and implement programs aimed at prevention and early intervention.

\section{Purpose of the Study}

This purpose of this study was to investigate whether short-term separations, defined as those lasting less than three months, have an adverse effect on the behavioral health of military wives of selected active duty service members serving the Army Medical Command (MEDCOM). This research examined predictors of depression in military wives of active duty military personnel during short-term separation. This exploratory study with descriptive and correlational features provided empirical data about depression among wives of active duty military personnel.

\section{Research Questions}

The study was guided by the following research questions:

1) Does post-separation depression vary based on socio-demographic characteristics? 
2) Do military wives have resiliency when separated from their active duty military husbands?

3) Is short-term separation associated with a decrease in relationship satisfaction among military wives of active duty military personnel?

4) Are stress levels in military wives in response to separation associated with levels of social support or resiliency?

5) Do socio-demographic characteristics, social support, resiliency, perceptions of stress, and/or relationship satisfaction predict depression in military wives?

\section{Background of the Study}

The purpose of this section was to present an overview of what is currently known about depression, the incidence of depression in military spouses, and the consequences of untreated depression.

\section{What is Depression?}

The logical conception of depression as a medical entity started with 18th century classifiers who categorized mental disability based on the criteria applied in botany. At the time, depression was also known as melancholia (Hill, 1968). According to Olfson et al. (2002), persons with depression generally get no treatment for their symptoms and, according to the testimony of the surgeon general, advocating treatment for individuals with depression is a more substantial problem than exploiting effective treatments (Galson, 2009). The late 1980s and first half of the 1990s saw a major transformation in the delivery of mental health services resulting from the evolution of managed care and the discovery of selective serotonin reuptake inhibitor (SSRI) medications for treatment of depression (Frank, Goldman, \& McGuire, 2009). 
Depression can be described as an acute condition of a mostly negative affect that is frequently but not essentially morbid in its effects on the quality of life. For this study, depression was defined not as normal everyday ups and downs, but as presenting with depressed mood, sadness, perceived helplessness, loss of interest or pleasure, sleep disturbance, and inability to concentrate. This study measured depressive symptoms through self-report and did not use diagnosis.

Depression is one of the most serious health dilemmas in the United States; it can have devastating effects on quality of life, relationships, work, and scholastic success (Depressive and Bipolar Support Alliance, 2006). According to the World Health Organization (WHO), depression, which affects nearly 121 million people globally, is a major cause of disability. It was the fourth principal contributor to infirmity worldwide in 2000 and is expected to reach second place as the basis of disability by 2020 (World Health Organization, 2012a).

Depression is a critical health problem that annually affects more than 19 million American adults age 18 and older (Mental Health America, 2013). The Centers for Disease Control and Prevention (CDC) has projected that 1 in 10 U.S. adults will self-report depression each year (National Alliance on Mental Illness, 2009). In the most recent (2010) CDC statebased, random-digit-dialed telephone survey of the non-institutionalized U.S. civilian population (with a sample of 235,067 from 29 participating states), 9\% met the benchmark for depression, including the $3.4 \%$ who met the criteria for major depression. The occurrence of major depression intensified with age, from $2.8 \%$ in individuals age $18-24$ to $4.6 \%$ in those age $45-64$ years; the rate declined to $1.6 \%$ among those older than 65 . 
Contrary to assumptions by some providers, depression is not a typical feature of being a woman, nor is it a female limitation. Men are not exempt from experiencing depression at some point in life; however, it is well documented that the rate of depression is twice as high in women than in men. According to the National Institute of Mental Health (NIMH), in the United States alone, more than six million men experience depression each year (National Institute of Mental Health, 2013). It is alarming that the suicide rate in men is five times higher than in women because men are less likely than women to seek help from health care providers for physical and psychological problems (Morgan, 2001).

Women are radically more likely than men to report major depression $(4.0 \%$ versus $2.9 \%)$. Those who have been previously married $(6.6 \%)$ or never married $(4.1 \%)$ have higher rates of depression than those who are currently married (CDC, 2010). The CDC (2010) and National Alliance on Mental Illness (NAMI) have stated that the greater occurrence of depression in women is not totally recognized, even though possible causes involve different reactions to stressful life events, genetic disposition, and hormonal variances (National Alliance on Mental Illness, 2009).

\section{Incidence of Depression in Military Spouses}

As of 2010, there were nearly 700,000 military spouses, mostly females, and another 400,000 who were the husbands or wives of those serving in the reserves. Most wives of active duty military personnel are younger than 65 years of age (TRICARE, 2012) and have additional responsibilities in caring for children while their spouses are deployed. The number of military wives with depression related to deployment of less than 11 months has been estimated at 27.4 per 1,000 wives, and depression related to the husband's deployment of more than 11 months at 
39.3 per 1,000 wives (Mansfield et al., 2010). Researchers have studied the psychological effect of long-term separation due to deployment but no studies have been conducted on the effect of short-term separation due to deployment, training, and military schooling on the behavioral health of wives of active duty military personnel. Short-term separation will become the new norm of military life after the war in Afghanistan ends—-so this area is understudied.

\section{Consequences of Untreated Depression}

The consequences of untreated depression can be catastrophic for individuals, their families, and society as a whole. Failure to address depression may lead to substance abuse or addiction, poor eating habits, poor disease self-management, self-injury from reckless behavior, relationship problems, social withdrawal, physical illness such as stroke and cardio-vascular disease, and suicide (Suter, Suter, \& Johnston, 2008). Studies of depressive disorder have found higher mortality and morbidity of other diseases associated with depression. For example, in cancer, depression has been linked to quality-of-life (QOL) impairments (Badger, Braden, \& Mishel, 2001; Jacobsen \& Jim, 2008), decreased immune function (Spiegel, Giese-Davis, Taylor, \& Kraemer, 2006), increased healthcare use (Bambauer et al., 2006), reduced long-term survival (Giese-Davis et al., 2010), and suicide (Misono, Weiss, Fann, Redman, \& Yueh, 2008). The mortality risk for suicide in depressed patients is more than 20 times greater than in the general population (Lepine \& Briley, 2011). According to the WHO (2012c), almost one million lives are lost yearly due to suicide, which translates to 3,000 suicide deaths each day. For every single successful suicide, 20 or more people may try to end their lives.

Depression is a devastating psychological illness that has financial and social consequences. In 2004, the CDC assessed that $25 \%$ of adults in the United States had a 
psychological disorder, and the estimated cost of treatment was $\$ 300$ billion in 2002 (Centers for Disease Control and Prevention, 2011). Stoudemire, Frank, Kamlet, and Blazer (1986) directed the initial study on the financial burden of depression in the late 1980s and at that time the cost of care related to depression was $\$ 42$ billion. The financial charge for depression based on year 2000 estimates — the last available data—was $\$ 104$ billion, of which $\$ 33$ billion (31\%) was the cost of medical care, $\$ 6$ billion (7\%) was expenses associated with death due to suicide, and $\$ 65$ billion (62\%) was the cost of lost productivity (Goetzel, Hawkins, Ozminkowski, \& Wang, 2003).

Much of the cost of depression is assumed by employers due to workplace absenteeism — workers are too sick to be fully productive (Jacob et al., 2012; Lepine \& Briley, 2011). According to Greenberg and Birnbaum (2005), from the 1990s through the 2000s, the rate of depression among workers remained constant, but there was a notable rise of more than $50 \%$ in patients requesting therapy. Jacob et al. (2012) discounted the benefit of this surge in treatmentseeking activities because of the deficiencies in the quality of care available to many people. This treatment discrepancy consisted of negligible treatment submission, failed patient follow-up, and futile techniques for monitoring and tracking symptoms. Federal and state-subsidized programs, including Medicare, Medicaid, and mental health agencies, have been seriously burdened by the cost of behavioral health maladies.

Depression can also generate differing economic and associated concerns in families (Depressive and Bipolar Support Alliance, 2006). Badger (1996) conducted a grounded theory study about the effects of a family member's depression on the family. The study found that families living with a depressed member underwent a transformation in which the family 
members and family functioning changed. Family members believed that the individual affected by depression became a different person, like a stranger. The family used various strategies to treat the depression within the family and finally sought outside help. In the process, family members themselves changed and family functioning was forever altered. This is testament that family members are directly affected by depression.

In 2009, the Institute of Medicine (IOM) and the National Research Council (NRC) reported that depression affects millions of U.S. adults over their lifespan, many of whom are parents with children. In any given year, an estimated 7.5 million adults with depression have a child under the age of 18 living with them. A growing body of research has shown that parental depression can influence how people take care of their children, affecting children's growth and development, educational performance, and social well-being (Institute of Medicine - National Research Council, 2009). If not treated promptly and adequately, both parental and child depression can lead to suicide, which can result in economic burdens and a strain on the social and health resources of the United States (Williams, O’Connor, Edder, \& Whitlock, 2009).

\section{Significance to Nursing and Healthcare}

Military wives are a vulnerable population that faces unique challenges related to the military way of life (Blank, Adams, Kittelson, Connors, \& Padden, 2012). Work-related separation of families is becoming more common in our society. For civilians, the rate of business or work-related separation is difficult to determine because statistics are not readily available. On the other hand, separation is a norm in military life. However, separation due to deployment can cause family members, especially spouses, to confront an array of emotional and 
social problems, including increased anxiety, depression, and family conflict (Black, 1993; Blount, Curry, \& Lubin, 1992; Isay, 1968; Kelley, 1994).

Deployment disrupts normal family routines and requires changes in roles and responsibilities. Military wives confront the uncertainty of the whereabouts and well-being of the deployed husband. They also endure psychologically in the absence of their husbands, especially when considering the added stresses that combat deployment can produce during a separation. Separation places additional demands on family members in terms of managing the household, with the military spouse taking on the role of single parent and solo care provider for children. The roles of military wives create challenges not faced by civilian wives. They often fill roles unique to military families, such as being supportive of a husband whose life belongs to the military and who may constantly be called on missions to deal with a crisis, attend training missions, or participate in other activities.

In the current economic climate, costs, expenditures, and the need for fiscal prudence are top priorities, making the $\$ 80.81$ million needed to treat depression in military beneficiaries a target for reduction strategies. While much of the cost associated with the separation-depression phenomenon is likely due to long-term deployment, no known studies have been conducted regarding the effect of short-term separations, which are becoming increasingly common.

As important as it is to understand the effect of separation on the behavioral health of military spouses, it is also critical to use this knowledge to develop programs of prevention and intervention. Basing these programs on identifying who is at greatest risk allows the military to be a wise steward of the financial resources allocated by the government. Similarly, the WHO (2002) has called for the development of behavioral health interventions that are evidence-based; 
the increased awareness that comes from recognizing the etiology and epidemiology of these disorders requires "governments and nongovernmental organizations to develop and implement effective preventive measures" (WHO, 2002, p. 29) to preserve resources, demonstrating a use for the findings of the study in the civilian sector.

The results added new information to the literature that can serve as background for developing programs for prevention and early intervention. In addition, the data may be used to assist in fiscal planning for programs for preventive medicine and clinical care needs.

\section{Theoretical Perspectives and Worldview}

The core paradigms of nursing research have undergone radical transitions over the past decades due to the integration of models from other disciplines. Recognizing a variety of worldviews helps organize the process of research inquiry. Worldviews have become the new foundation and source of information for 21 st century nurses.

This research embraced a mechanistic worldview. The metaphor for the mechanistic worldview is the machine. According to this premise, humans are reactive in nature and it is assumed that the whole is at least equal to the sum of its parts (Reed \& Crawford-Shearer, 2008). The mechanistic worldview maintains that through the study of individual components, the individual as a whole can be understood. This worldview influenced the conceptualization of this research in the following ways. First, the individual can be conceptualized and understood only by considering the factors that make human beings physical, social, and economic in nature; each part influences all others. The parts make up the whole but are still separate. Studying an emotional response is accomplished by reducing it to its simplest elements: the behavioral element and the social impact. Second, the individual is described as a passive-reactive entity, 
which means that development does not occur solely within the individual; instead, it is a response to outside stimuli. Third, change is quantitative, and changes in behavior are viewed as differences that can be operationally defined and measured (Hayes, Hayes, \& Reese, 1988).

One theoretical perspective applied to this research was Hill's (1949) family stress theory. As a social scientist working for the U.S. Army, Hill was charged with assessing the impact of war casualties on American families during World War II. This theory was also developed to explain families' responses to war-time separation and reunion (Friedman, Bowden, \& Jones, 2003). It explains the strain in family functioning that occurs during times of deployment and posits that acute stressors in individuals' lives lead to whole-family crises (Molaison, 1990). The theory of family stress, also known as the ABCX model, describes the impediments to families coping with stress. The model hypothesizes that stressors, the family's level of available resources, and the family's perception of the stressors all affect family functioning (McCubbin \& McCubbin, 1987).

Family stress theory is a clear, parsimonious model explaining the dynamics that produce crisis in some families and insulate others. Hill advanced the ABCX framework in which he acknowledged an important set of variables (factors A, B, C, and X) and their links to family difficulty. According to Hill (1965), as cited in Friedman et al. (2003), “A (the event and related hardships) interacting with $\mathrm{B}$ (the family crisis meeting resources) interacting with $\mathrm{C}$ (the definition that the family makes of the event) produces X (the crisis)" (p. 468).

\section{Family Stressors (A)}

The first component of the $\mathrm{ABCX}$ model (A) represents the stressors confronting the family. Hill (1949) defined stressors as "life events or occurrences of sufficient magnitude to 
bring about change in the family system" (McCubbin et al., 1980, p. 858), or circumstances for which the family has no previous foundation. Hill further defined stressors in relation to hardships, which he operationalized as the number of nonconformities in normal family functioning made vital by the stressor's existence. Patterson and McCubbin (1983) suggested that family stress can become challenging if it is communicated as unfriendly or disapproving and family members show disappointment or demonstrate symptoms of dissatisfaction.

According to Peebles-Kleiger and Kleiger (1994), scholars have argued that wartime deployments are distressing rather than normative stressors. Building on the ABCX model, causes of stress can be external or internal (Patterson, 1988). Examples of external sources of stress include new parenthood, financial problems, job loss, separation from loved ones, new role expectations during the husband's deployment, divorce, relocation, retirement, and bereavement (Segal \& Harris, 1993).

Other diseases causing increased stress may be present as well. Research has shown that anxiety disorders, posttraumatic stress disorder (PTSD), obsessive-compulsive disorder (OCD), panic disorder, or social phobia often co-exist with depression (Regier, Rae, Narrow, Kaebler, \& Schatzberg, 1998; Devane, Chiao, Franklin, \& Kruep, 2005). Other diagnoses that significantly co-exist with depression are alcohol and substance abuse or dependence (Conway, Compton, Stinsons, \& Grant, 2006) or medical illness such as heart disease, stroke, cancer, HIV/AIDS, diabetes, and Parkinson's disease (Cassano \& Fava, 2002). Although comorbidities of depression-related disorders may intensify the effect of the separation on the military spouse, knowing that this is the case is equally important as it helps identify which wives would benefit most from intervention. 
Other factors contributing to depression are (a) stressful life events (i.e., significant loss, death of a close family member or friend, career crisis, divorce, social isolation, and early deprivation), (b) chronic illness and physical disability, (c) family history, (d) psychological risk factors including perceived low social support, less optimism or resilience, and low self-esteem, and (e) social risk factors including poorer social functioning, recent losses and stressful life events, history of trauma or abuse, and/or substance abuse.

In this study, the stressor event (A) will be the short-term separation (defined and measured as 1 to 12 weeks) that is necessitated by the husband's education or training requirements (see modified theoretical framework of the ABCX model in Figure 1). Separation can be one of the hardest experiences in military life, but the truth is that everyone in the military will experience some kind of separation at some point. Separation caused by deployment or training, because of its issuance by the government, is out of the hands of both the service member and his or her spouse and family, and "perceived lack of control" itself causes stress (Leyva, 2003, p. 177).

\section{Coping Resources (B)}

The B in this theory refers to coping resources. Hill (1949), as cited in Walker (1985), suggested that resources are mechanisms that are available for use in coping with stressful events. According to McCubbin and Patterson (1983b), factor B can be defined as "the family's ability to prevent an event of change in the family social system from creating some crises or disruption in the system" (p. 89). Resources for the ABCX model can be either internal or external. Internal resources include healthy habits, self-reliance, adequate amounts of sleep, resiliency, optimism, and financial security. In this study, the resiliency characteristics of 
military wives was measured. Saltzman et al. (2011) stated that the study of military families carries considerable promise for the development of paradigms of the process of resilience. There is a crucial need to develop and evaluate resilience-related programs for families undergoing short-term separation, but before this can happen, baseline data are needed to support the presence of resiliency in military wives.

External resources for the military spouse in this context can be achieved from nonmilitary resources such as having resilient children, a positive peer system, satisfying work, preoccupation, and busyness. Military resources can be categorized as formal or informal. Formal resources are more structured, such as the Family Readiness Group (FRG) and Army One Source (AOS), while informal resources include the use of communication systems like SKYPE, telephones, peer groups, web communication such as blogs, and spontaneous Internet support gatherings. Bandura (1982) and Silver and Wortman (1980) stated that resources can be either individual or familial. Individual resources include personal abilities and traits. Cohesion and adaptability of the family as a functioning unit also provide valuable assets when facing stressors as a group (Walker, 1985).

For this study, the available resources (B) included demographic variables such as income and employment status, as well as military spouses' resiliency and available social support networks. The following sections discuss resiliency and social support in relation to family, and more specifically military wives.

Resilience, according to Luthar (2006), is a dynamic process surrounding positive adaptation, and not merely the absence of pathology or dysfunction, within a context of significant adversity. Earlier studies of resilience were focused on individual traits such as 
"hardiness" and, more recently, on resilient adaptation in diverse settings with an emphasis on the resilience processes over time. Military families carry considerable promise in the development of resiliency research due to separation caused by deployment. This is in response to families' urgent need for increased resilience and programs to address the problems brought about by separation. According to Saltzman et al. (2011), understanding the resilience processes within military families is of special importance at the current time given the ongoing stress of deployment.

In addition to resiliency, the ABCX model was modified to also include the use of social support as a resource for this study. Since the mid-1970s, there has been increased concern about the role of social support as a coping resource and research has validated that the sufficiency of social support is clearly linked to the gravity of psychological symptoms and performs as a defense between stressful life occurrences and symptoms (Zimet, Dahlem, Zimet, \& Farley, 1988, p. 30). More recent studies have revealed that social upkeep is crucial in preserving physical and psychological well-being. The damaging results of poor social care and the protective outcomes of good social support in mental debility have been properly recorded (Ozbay et al., 2007). Social support has been explained as "support accessible to an individual through social ties to other individuals, groups and the larger community" (Lin, Simeone, Ensel, \& Kuo, 1979, p. 108). The National Cancer Institute has defined it as "a network of family, friends, neighbors, and community members that is available in times of need to give psychological, physical, and financial help" (National Cancer Institute (NCI), 2013, p. 1). The theoretical model of social support includes two dimensions: structural (the linkage between the size and incidence of social relations) and functional, which is emotional (acceptance of love and 
empathy) and instrumental (useful aid such as gifts of money or support with child care).

Researchers have determined that the functional factor is a superior predictor of good health than the structural dimension, even though both are significant (Ozbay et al., 2007).

\section{Perceptions of Stressors (C)}

McCubbin and Patterson (1983a) and Hill (1968) also described perception of stressors as being determined by how the family understands the crisis experience, including the full set of circumstances that heralded the crisis. McCubbin and Patterson (1983c) acknowledged that objective cultural meanings of the severity of life events and changes are signified by the collective conclusion of the social system. His personal definition of the stressor related to hardship and how the family is affected by it.

In this study, perception of stress (C) was measured using the Perceived Stress Scale (PSS), which asks military wives to indicate the frequency of a situation being considered stressful (Cohen et al., 1983). Stress is characterized as a state in which the ecological and core demands exceed the adaptive resources of a person or social system (Monat \& Lazarus, 1991). The perception of stress and how it alters one's health differs theoretically from the extent of stress that a person faces. An individual can experience very minor stress but consider it to have a great bearing on his or her health. Research has shown that the perception of stress changes one's health and may influence a person's potential health outcomes (Keller et al., 2012, p. 677). Crisis or Non-Crisis (X)

Crisis is described as the family's failure to endure due to the persistent challenge of their circumstances (Smith \& Liehr, 2008). The force of family stressors, resource depletion, and discernment generates a family crisis (Lee, 2009), usually believed to represent an incredible 
stress reaction in situations during which individual or family resources are depleted (Boss, 1988). The $\mathrm{X}$ factor has been posited as a constantly changing variable suggesting the amount of unruliness, insufficiency, or level of powerlessness in the family social disparity (McCubbin \& Patterson, 1983a). Stress may never reach a crisis level if the individual or family is capable of using existing resources effectively and articulates the condition so as to resist the complete change and sustain the family strength (McCubbin \& Patterson, 1983c).

As illustrated in Figure 1, in this study, the crisis (X) was the depression experienced as a result of interactions between A (stressful event defined as short-term separation due to training) + B (existing resources including the resiliency, marital satisfaction, and social support available to military wives) $+\mathrm{C}$ (perceptions of stress) $=\mathrm{X}$. This study attempted to show that the interaction of $\mathrm{A}, \mathrm{B}$, and $\mathrm{C}$ can have a significant impact on depression in military wives.

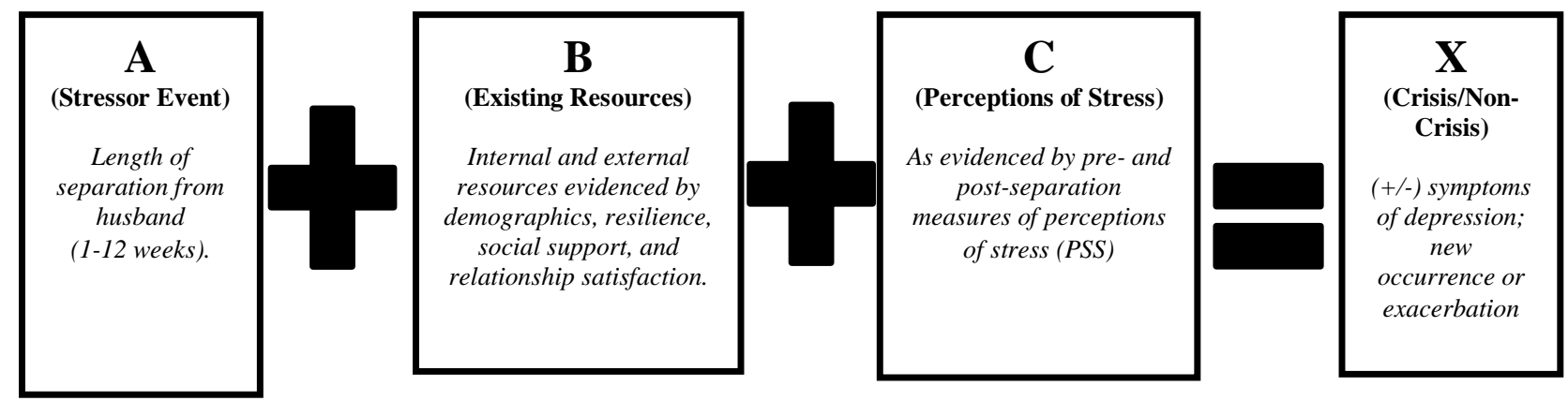

FIGURE 1. Modified Theoretical Framework for the ABCX Model.

\section{Implementation of the $\mathrm{ABCX}$ Theory}

Hill's ABCX model (Smith \& Liehr, 2008) clearly adopted two metaparadigms (person and environment). In this theory, Hill regarded families as persons, family members as human significant others, and physical surroundings, which include social, political, and economic conditions, as environment (Fawcett, 2005). According to Whitchurch and Constantine (2009), 
the family stress theory recognizes the family as a social system, allowing the integration of family members within its society, along with the organization and the world. Hill did not effectively address health in the original theory, but the extension of his theory into the double ABCX model clearly dealt with health, such as chronic illness in children, cancer, and elder care (Smith \& Liehr, 2008).

Although the ABCX theory is modeled for use in a family setting, for the purposes of this study, it was applied to individuals, specifically wives of active duty military personnel. The theory was used as a framework to guide the study (see Figure 1).

This theory is beneficial in assessing, planning, and implementing practice interventions as it centers on the particular facets of the physical and behavioral illness trajectories that families may experience (Smith \& Liehr, 2008). It also helps nurses in discerning the course and phases of a disease, which allows them to offer individual and family coping approaches based on the concepts of stressors, existing resources, and perception of crisis. The ABCX theory was integrated into the framework of the study by identifying specific risk and protective factors. Ultimately, an intervention leading to improved adaptation for spouses during short-term separation may be developed to prevent or mitigate the occurrence of depression and related disorders.

\section{Summary}

This chapter has presented an overview of the effect of military separation due to deployment and training and its relationship to the occurrence of emotional problems, particularly depression, in military wives during the time of separation. It also revealed that the effect of short-term separation on the behavioral health of military wives is understudied and 
outlined a format of research designed to determine which demographic and clinical markers best predict mood disorders in military wives. Finally, the significance of this research to nursing practice as well as the theoretical basis for the study was explained. 


\section{CHAPTER 2: REVIEW OF THE LITERATURE}

This chapter presents the literature related to depression, military life, facts about military wives, and the effects of separation due to deployment on military spouses. Research into the effects of long-term separation predominates in the literature. This is because lengthy deployments in the Gulf Wars generated a great deal of contemporary research. As of this writing, only one known study has investigated the effects of short-term separations. However, there may be many similarities in the experiences of couples who must separate for a year or more and those of couples forced to be apart for shorter periods of time. Therefore, this review presents the literature related to separations due to long-term deployments and applies what may be relevant to shorter term deployments.

\section{Who Are Military Wives?}

Military families stand behind their service members; they deal with short and long separations due to deployment, training, and education. Across the Department of Defense (DOD), in both the active duty and selected reserve populations, there are 2,259,359 military personnel and 3,130,808 family members, including spouses, children, and adult dependents. Of the military personnel, $39.9 \%$ are single with no children, $37 \%$ are married with children, $16.2 \%$ are married without children, and 6.9\% are single with children (Department of Defense, 2012).

In 2011, a majority (69.6\%) of officers and more than half (54\%) of enlisted personnel reported themselves as married (Department of Defense, 2012). The term military wife is frequently used to refer to any adult in a committed relationship with a service member; however, in this study, the term refers specifically to a female who is legally married to a male service member of the United States Army. There are 1.1 million military spouses and $92 \%$ is 
women, with $74 \%$ being 18-34 years of age. Because nearly half of active duty service members are younger than 26 , this means that military spouses as a demographic are predominantly young (Department of Defense, 2007; Lester et al., 2010). According to the 2000 Census figures, military wives are less likely to be employed than civilian wives and earn less than civilian wives (Lim, Golinelli, \& Cho, 2007). According to the Department of Defense (2007), 41\% to $46 \%$ of the spouses of both active duty officers and enlisted service members is employed in the civilian sector and $7 \%$ to $10 \%$ is actively seeking work. Military spouses are more likely to experience frequent long-distance relocations and are more likely to have young children at home. Although the idea that military spouses live in rural settings that limit their employment options and wages is widespread, in reality they are more likely to live in cosmopolitan areas. Moreover, they are more likely to have graduated from high school and to have some college education than their civilian counterparts (National Defense Research Institute, RAND, 2005).

When the United States entered the war on terrorism following the attacks of September 11, 2001, an estimated $54.7 \%$ of service members was married. This number excluded the many families formed by couples who cohabitate as life partners without a marriage license, the half of all parents who raise children without being married, and those who parent together after divorce. It also excluded military personnel in the lesbian-gay-bisexual-transgender (LGBT) community, whose family connections were not recognized by the military until 2012. Were all these groups considered, the percentage of service members with a significant other whose life is affected by their service would be much higher. Although this research has classified a military wife by the most easily identifiable means, this choice was made with the understanding of how 
much more far-reaching the impact of the findings could be if applied to the full range of females who are significant others to military personnel.

\section{Unique Stressors of Military Wives and Military Life}

The unique stressors that military wives encounter make them a special population. Understanding military wives as a demographically vulnerable population is crucial in understanding their experiences because it contributes to an understanding of why they are susceptible to behavioral health challenges. Military wives face multiple stressors: exposure to a new culture, psychological issues, ethnicity, economic challenges, unstable income, social support, and access to healthcare.

The first stressor military wives face comes from their introduction to a new culture: military life. Culture shock is an actuality for all military spouses, with the possible exception of those raised in military families. The military has an exclusive organizational culture which is frequently expressed through unwritten tenets, policies, views, perceptions, and established processes. The culture is based on tradition, goals, composition, and military history. Military culture demands leadership and loyalty and suggests an extremely systematized and authoritarian way of life (Mewes, 2011). The hyper-masculine military culture relegates and devalues spouses (Muriel McQueen Fergusson Centre for Family Violence Research at the University of New Brunswick and the Resolve Violence and Abuse Research Centre at the University of Manitoba, 2000). Civilians who become military wives must be ready to prevail over difficulties that accompany military life while concurrently adapting to military culture. Adjusting to military culture does not happen instantly, but slowly and gradually. Military wives must be flexible, and they need to be prepared to triumph as rapidly as possible over obstacles their family encounters. 
Second, military wives' psychological issues and those of their spouses intensify during times of deployment separation. Evidence has suggested that military wives are at risk for depression and anxiety during separation from their husbands, regardless of whether the separation is caused by deployment (Eaton, Hoge, Messer, Whitt, \& McGurk, 2008; Steel-Fisher, Zaslavsky, \& Blendon, 2008; Warner, Appenzeller, Warner, \& Greiger, 2009). However, when their husbands are sent to fight far from home, additional stressors are experienced. Wives who worry about the security and well-being of their deployed husbands feel a heightened sense of anxiety and this is compounded by their increased responsibility for affairs at home and the loneliness they experience throughout the spouse's deployment.

Military wives are more frequently ethnic minorities than their civilian counterparts. Harrell, Lim, Castaneda, and Golinelli (2004), in a report commissioned by the RAND Corporation and submitted to the Office of the Secretary of Defense, noted this demographic disparity, which is especially true for those married to service members in the Army and the Marine Corps. In fact, many Army and Marine Corps wives (30\%) are members of a minority group. Among non-Anglo wives, those with African and Asian ancestry are overrepresented in all the services, while Latinas are underrepresented. As members of minority groups, these wives may experience bias in the workforce and are likely to be financially challenged due to lower salaries than their civilian colleagues (Browne, 1999; Higginbotham \& Romero, 1997).

Military wives maybe economically deprived for many reasons. They are less likely to be employed full time because of recurrent transfers. Although in-state relocations have an insignificant effect on employment, moving out of state or overseas has a substantial, deleterious effect on employment (Hosek, Asch, Fair, Martin, \& Mattock, 2002). Mobility causes 
interruption in employment and prevents the accumulation of tenure. In contrast, residence location, most commonly on or near military bases or in non-metropolitan areas, has a steady and positive effect on unemployment, though this is not sufficient to overcome the disruption caused by repetitive relocation. Civilian wives also earn about twice as much as military wives; in 1990, the annual income gap between military and civilian wives ranged from $\$ 5,500$ to $\$ 7,400$ (Higginbotham \& Romero, 1997).

A fifth stressor is that although active duty military families have a very stable income, the salary of many enlisted personnel is low. Furthermore, financial stability is more complex for families of activated reservists or guard members. Deployment of these servicemen and women represents a significant monetary shortfall for their families as they no longer receive their civilian pay during separation from work (Chartrand \& Siegel, 2007). Military salaries differ broadly, but the starting monthly pay can be as low as $\$ 1,347$ (Office of the Deputy Under Secretary of Defense, 2008).

Military wives have inadequate social support in relation to the degree of stress they experience. Most military wives have moved or separated from their closest family members, relatives, and friends one or more times. The military recognizes this fact of life and, according to Huebner and Mancini (2005), military support systems designed as surrogate family environments are accessible to active duty families. However, authorities acknowledge that many reserve and guard families have no way to access the available support (Eaton et al., 2008).

Finally, military wives' access to healthcare can be tenuous. Wilson (2009) reasoned that spouses of reservists and guard members must navigate an especially tortuous road when seeking military healthcare because they are geographically dispersed from military posts, where most 
military healthcare facilities are located. In contrast, active duty service members and their spouses have excellent access to healthcare, although making an appointment to see a provider, especially in the specialties, is difficult at times.

\section{Military Life}

More than a decade after September 11, 2001, when the United States was attacked by terrorists, the resultant "Global War on Terrorism has sent over 1.8 million American military service members into Iraq and Afghanistan to fight the war on terrorism" (Verdeli et al., 2011, p. 488). The experience of day-to-day life in the military varies according to the service branch, career choice, and location, but service members have several experiences in common.

Viewed from the outside, the life of a military wife may seem to be full of difficulties and risks. Being married to a military service member is often seen as a noble but difficult undertaking due to frequent separations for deployment, training, and education. Certainly some aspects of married life are the same regardless of military or civilian status. Couples must devote time to getting to know and work with another person, while simultaneously raising children, working through their career trajectories, caring for aging parents, and adapting to the changes brought on over the course of a lifetime together, regardless of whether one of them wears a uniform. However, along with these normal experiences of marriage, military wives have to overcome the hindrances of learning and adjusting to military culture, and new military spouses can easily be devastated by the change in status, living arrangements, and demands of the spouse's job. Military life presents many challenges and stressors, but opportunities exist as well. The lifestyle commonly involves temporary or permanent relocations, worry about a spouse's safety during times of deployment, a spouse frequently changing career trajectories, and the 
wife's own career interruptions. Even though these elements are stressful, they can also be stimuli for personal growth and empowerment when dealt with in ways that are healthy and productive.

Being a part of the military as a couple does not mean giving up a social life. In fact, it's quite the opposite. Military service members and their families can maintain active social lives by utilizing recreational facilities on base, attending entertainment events, and participating in sports leagues. These are organized through the Morale, Welfare, and Recreation (MWR) Center located on every base; these centers provide programs and services for individual soldiers and families as a whole. Off base, the military's discounted travel opportunities mean that couples may have more opportunities for travel than their civilian counterparts of the same age.

One unique aspect of the military family is the experience of mandatory periods of separation through deployment, an inherent part of military life. Military families have always experienced separations, short or long, and recently many have endured multiple deployments to areas of the world unfamiliar to most Americans, a factor significantly adding to stress.

\section{Depression in Women}

Depression is the leading cause of disease-related disability among women throughout the world (Kessler, 2003). It is diagnosed more commonly in women than men, and the female/male ratio based on the frequency of assigned diagnosis-related group (DRG) codes is roughly 2:1 (Blehar \& Keita, 2003; Kessler, 2003). Data from research conducted by the Centers for Disease Control and Prevention (CDC; 2010) during 2006-2008 with 235,067 respondents, using the Behavioral Risk Factor Surveillance System (BRFSS), found that women were significantly more likely to have incidents of depression than men. The number of women 
diagnosed with major depressive disorder (MDD) was 145,225 (4.0\%), while for men it was $89,842(2.7 \%)$, which indicates that depression is more prevalent in women than in men.

One study conducted during a separation due to war deployment estimated that the number of military wives with depression related to their husband's 1- to 11-month deployment was 27.4 per 1,000 wives and 39.3 per 1,000 wives for deployment of more than 11 months (Mansfield et al., 2010). Unfortunately, the study did not identify a specific duration of separation, but rather a range from 1 to 11 months and then 11 months or more, which could have biased the findings. Pincus, House, Christenson, and Adler (2004) argued that different emotional stages occur during the deployment cycle (i.e., the period of separation) and understanding the emotional challenges that occur during each period can assist the family in coping positively with separation and deployment.

Much of the disparity in depression between the genders may stem from the greater frequency of contact women have with the healthcare system. In addition, women demonstrate greater cultural comfort in expressing emotional concerns. However, despite these alternate explanations for the discrepancy between genders, women are also vulnerable to depression due to physiological changes from endocrine and hormonal issues. Forms of depression related primarily to women's reproductive concerns include premenstrual dysphoric disorder (PMDD), perinatal or postpartum depression, postpartum psychosis, and menopause-related depression (Noble, 2005).

According to Kessler et al. (2003), depression affects both men and women, but more women than men are likely to be diagnosed with depression in any given year. The National Institute of Mental Health (NIMH; 2013) has stated that efforts to explain this difference are 
ongoing, with research focusing more on women's genetic, biological, chemical, hormonal, environmental, psychological, and social factors, all of which intersect to contribute to depression that is unique to women.

\section{Depression as It Applies in This Study}

Depression is a complex and multifactor physical and behavioral health issue in which etiology, signs, and symptoms vary among individuals. In this study, it is the occurrence and intensity of depressive symptoms, not the diagnosis, which will be studied. Many people experience depressive symptoms without meeting the diagnostic threshold for any one type of depressive disorder and may or may not experience an increased frequency or intensity of symptoms during exposure to a given stressor.

Participants in this study were asked to report their emotional experiences and the behaviors that accompany them, using a 21-item Beck Depression Inventory Scale-II (BDI-II) (Beck, Steer, \& Brown, 1996; Sharp \& Lipsky, 2002), which is designed to detect small increments of emotional change. This allowed the researcher to determine whether a pattern existed between short-term separation and the onset, exacerbation, or mitigation of depressive symptoms. Whether or not a woman who participated in this study began with an underlying depressive disorder or experienced these symptoms only with the level of stress brought on by a short-term separation, it was the change in her emotional and behavioral experience that was of interest.

\section{Theories of Depression}

The etiology of depression is complex; the origin can be genetic, physiological, or hormonal and it can be triggered by stressful conditions, as well as by psychological and social 
factors (Salgado-Delgado, Osorio, Saderi, \& Escobar, 2011). Many theories of depression have influenced therapy and how depression is managed as a disease and as a component of other somatic disorders. Theories are frequently based on the bio-psychosocial model, with treatment that moderates the physical effects of depression through food, sleep, exercise, and medication (Schneider, Coutts, Gruman, \& Coutts, 2005).

Depression can be caused by a disturbance in the balance between neurotransmitter levels (Nutt, 2008), an abnormal pattern of brain-pathway stimulation that allows the brain to ruminate about a difficult, painful, sad, or disappointing experience long after the actual event is concluded, and reactions that occur to the behavior of a person experiencing depression. This combines elements of the biological and the psychosocial theories of depression in a way that reflects both the physical reality of the disease as a pathological reaction different from sadness and, at the same time, acknowledges the interactivity between human beings and those they live and work with each day. Depression decreases human efficacy and this theoretical model respects the idea that the functional decline that occurs and its impact on others can be more deleterious to the person experiencing depression than the emotional or physical symptoms themselves.

The bio-psycho-social perspective of depression (Campbell, Clauw, \& Keefe, 2003) postulates that separation due to short-term deployment increases vulnerability to stress in the absence of resilience and a good social support network. Having a resilient personality can assist in handling stress and be a good coping tool for managing the symptoms of depression, while having a good social support network can also reduce the negative effects of stress. Having strong social support enables peoples to handle stress more effectively. 
Theories related to depression discussed in these sections include interpersonal psychotherapy theory, psychodynamic theory, the stress-vulnerability model, and cognitive behavioral theory of depression. In addition, the biological theories of depression that have been explored include the monoamine/5-HT hypothesis and a theory based on understanding how neurotransmitters, chemicals responsible for the transmission of electrochemical energy between the neurons, are affected by circadian rhythms.

\section{Psychosocial Theories}

Interpersonal psychotherapy theory (IPT) was founded on two major principles. First, depression is a medical illness and a treatable condition. Second, there is a connection between the patient's mood and disturbing life occurrences that either initiate or follow the onset of depression. Research has validated that depression regularly follows a disturbing change in one's interpersonal environment such as the death of a loved one, struggle with a significant other, and some life cataclysm (e.g., geographic or career move). The focus of IPT is on interpersonal conflicts, life transitions, grief, loss, and social isolation. For example, relationship-focused interventions such as IPT, or couples or family therapy, can effectively strengthen family functioning amid illness-related changes, reduce the risk for psychiatric morbidity, and enhance the quality of life of both patients with cancer and their families. In this theory, the bottom line is that depression is believed to be related to what is happening in the person's life (Markowitz \& Weismann, 2004). IPT has been well documented to be effective in populations such as depressed primary care patients (Cuijpers et al., 2011).

Psychodynamic theory, initially proposed by Freud (late 1800s and early 1900s), suggests that depression is a result of anger, which he believed came from imbalanced cognition and 
abnormal behavior in childhood. Freud thought that the conscious and unconscious parts of the brain live in opposition to each other and create a conflict that can result in repression of emotions, a state in which an individual is unaware of certain troubling motives or desires that influence him or her in a negative way (Nemade, Reiss, \& Dombeck, 2013). An example of this is seen in children who grow up with inconsistent parents who behave in a loving way in public and an abusive manner in private. The volatility and unpredictability lead to insecurity in the children. Most of these children become angry and resentful over time, but due to their instinctual sense that parents are essential to survival the child's anger is repressed. Those who subscribe to Freud's theory believe that depression is caused by anger converted into self-hatred. According to Nemade et al. (2013), this theory suggests that a person must successfully resolve early developmental conflicts by developing trust, affection, and successful interpersonal relationships to overcome repression and eventually develop the ability to prevent episodes of depression or at least mitigate the effect of depression on everyday life.

The stress-vulnerability model (Zubin \& Spring, 1977) proposes that depression occurs in individuals with a family history and genetic predisposition to the disorder. Current research shows that stress vulnerability, as exemplified by the presence of negative life events, can be an etiological specific risk for depression and that negative life events such as separation and financial problems can be non-specific risk factors for the occurrence of depression (Hankin et al., 2004).

This model also suggests that being vulnerable is not sufficient to manifest depression, but that this deleterious cascade of emotional responses must be triggered by environmental processes. The proximate environmental factor can be biological, such as an infection or the use 
of drugs or alcohol, or psychosocial, such as a stressful living situation, upcoming school exams, or separation from loved ones due to travel. As previously noted, the ABCX model is a stressvulnerability theory suggesting that the separation of military wives from their husbands creates a significant stressor due to the changes in family structure and added responsibilities.

Another psychosocial approach is cognitive behavioral theory (CBT). This practice-based model integrates the theoretical perspectives and therapeutic techniques of both cognitive and behavioral theory and therapy. It is centered on helping clients develop skills to monitor and change their own thoughts, emotions, and behaviors. CBT is a comprehensive term that comprises a range of distinct therapy models (Herbert \& Forman, 2011). It has been the most widely used type of counseling with patients with depressive symptoms over the past several decades (Badger \& Lazenby, in press).

\section{Biological Theories}

The monoamine hypothesis suggests that depression is the result of a lower than adequate activity of monoamines, especially 5-hydroxytryptamine receptors (5-HT receptors). Substantial evidence exists that depressed levels of 5-HT, as measured by its metabolites, have a positive correlation with depression and researchers have demonstrated that patients with low levels of one or more 5-HT metabolites are more likely to commit suicide than people without this chemical challenge. This predicts that depression is due to decreased levels of serotonin, norepinephrine, and/or dopamine in the central nervous system (Delgado, 2000; Stahl, 1997).

The theory of circadian rhythm disruption proposes that abnormal sleeping and waking patterns may play a causative role in depression. In 1965, Aschoff, a physician and physiologist, expanded on Kleitman's (1957) human isolation experiments. Subjects positioned in an 
underground bunker were permitted to turn lights on or off according to their own internal rhythms. Aschoff tracked their sleep-wake cycles, body temperature, urine output, and other physiological and behavioral variables. He determined that humans — like the plants studied by de Mairan - have endogenous circadian cycles. This work brought the theory of circadian rhythm disruption to light, suggesting that some type of depressogenic substance is being released during sleep and deactivated during periods of wakefulness (Vitaterna, Takahashi, \& Turek, 2013). Individuals with a diagnosis of unilateral or bipolar depressive disorder often say that their symptoms peak in the morning and decrease as the day goes on, which is consistent with the idea that this substance is being depleted as the day progresses. The two factors leading to circadian rhythm disruption are an increase in nocturnal activity that is accompanied by a decrease in sleeping time and extended exposure to artificial light at night (Salgado-Delgado et al., 2011). According to Caldwell (2010), depression is linked to a molecular disturbance in the body's 24-hour clock. Scientists have examined the genes that control the circadian rhythm in people with and without depression. Individuals with a history of depression have a higher level of this "clock gene" that plays a role in regulating the circadian rhythm; thus, their threshold for depression caused by circadian disruption is lower.

No one theory explains all forms or all cases of a single form of this complex and diverse set of disorders. Individual theories must be merged to achieve a comprehensive understanding of depression. However, understanding the etiologies of depression more thoroughly may aid in prevention of psychopathology and allow development of therapeutic approaches to better manage the disorder. 
The underlying theory chosen for this research was Hill's (1949) theory of family stress and adaptation, which employs a stress-vulnerability approach. By determining factors that are protective against depressive symptoms and those that predict a higher risk, it is possible to target interventions to those most in need. The interaction between (A) the stressor, (B) resources including resiliency and social support, and (C) perceptions of stress determines $\mathrm{X}$, the crisis (depression).

\section{Separation Related to Deployment and Military Wives' Mental Health}

A growing field of research has confirmed the effect of deployment on military wives’ emotional and psychological status, but considerably less attention has been focused specifically on this population rather than those who are deployed.

"It's never easy to cope with the absence of a loved one, especially a husband or wife. This goes double for wives whose husbands are engaged in military service. Long stretches of time alone, uncertainty about future moves or deployments, and the responsibilities of raising a family can weigh heavily on [the] military wife" (Blankinship, 2013, "How to Cope").

Blount, Curry, and Lubin (1992) and Hunter (1982) identified different types of military separations and each has a random set of outcomes for families. Unforeseen and extended deployments are apt to generate more problems than shorter times apart and separation during wartime causes more problems than peacetime deployment.

The military family is said to carry the problem of deployment (Department of the Army, 2009). The veracity of this is substantiated by the added roles and responsibilities that fall on the shoulders of the non-deployed spouse during lengthy episodes of separation (Eaton et al., 2008). Military deployments create stress for spouses from many sources, commencing with the sense 
of disorder related to the expected and then forthcoming departure of the service member. For many, this is compounded by the additional and increased parenting and domiciliary management roles and, at the same time, by both spouses (partners or co-parents) being denied the comfort, support, and joy they normally have in the context of their friendship and marital relationship. During the reintegration of the deployed spouse or partner, the couple must go through an additional time of stress, a period of reintegration and readjustment to their roles, a factor that few outside the military can appreciate as being difficult (Long, 1986).

Family separation is typical of military life. Coolbaugh and Rosenthal (1992) estimated that $90 \%$ of all the service members living with their wives can predict being separated from the family home a minimum of one day in each six-month period, $58 \%$ for two or more weeks, and approximately $37 \%$ for one month or longer. They also stated that at any given time, $8 \%$ of Army service members can be separated from their spouses on a short-term basis due to shortterm deployments, humanitarian missions, training, and military schooling. Statistics from research on the separation of military spouses and service members have shown that the separation becomes an involuntary disturbance in family life that produces personal distress as individuals become overwhelmed with multiple demands, confront financial difficulties, and try to sustain the normality of family life (Riggs, 1990; Vormbrock, 1993). Medway, Davis, Cafferty, Chappell, and O'Hearn (1995) stated that interference in social attachment has the capacity to intensify the mental health status of military spouses and studies have shown that emotional distress in military spouses is correlated to both intermittent and wartime separations.

Scholars have found that numerous behavioral health challenges result from military separations. Their work has demonstrated that military families, including spouses (partners) and 
children, commonly display increased signs and symptoms of depression and anxiety during separations (Ursano, Holloway, Jones, Rodriguez, \& Belenky, 1989; Black, 1993; McNulty, 2003; Knapp \& Newman, 1993; Kelley, 1994). Previous research has shown that the spouse of a deployed service member may also experience new or intensified stressors due to the shift in family dynamics and roles. These spouses experience loneliness, role overload, financial concerns, and the loss of role clarity within the family. In addition, increased parenting demands arise during the deployment. Children's sense of loss, fear, and abandonment when their father is deployed can make parenting more challenging, especially from a distance, and this disruption in family functioning may also occur when the service member returns and attempts to reassume an on-site parental role (Drummet, Coleman, \& Cable, 2003).

In a review of 6,585,224 electronic medical records for all outpatient medical visits of 250,626 wives of active duty U.S. Army soldiers from January 1, 2003, through December 31, 2006, Mansfield (Mansfield et al., 2010) and found that Operation Iraqi Freedom (OIF) and Operation Enduring Freedom (OEF) deployments were associated with increased diagnoses of depression and other mental illnesses. The study specifically compared the adjusted risk difference among wives whose husbands were deployed from 1 to 11 months, more than 11 months, or not deployed at all. The study showed that military wives with husbands deployed from 1 to 11 months or more than 11 months had an $18 \%$ to $24 \%$ higher incidence of diagnosis of depression than those for whom there was no deployment. Steel-Fisher, Zaslavsky, and Blendon (2008) studied health and well-being in military spouses during their partners' deployment and compared military spouses with partners who had extensions of deployment and those whose partner returned home early. In the study, 798 participants were spouses of active 
duty soldiers. Of those, 355 military spouses had their husbands' deployment tours extended for an unknown period of time. Those spouses fared worse in all the measures, including mental well-being, especially regarding depression.

The emotional impact of deployment on 940 military wives whose husbands were deployed in Iraq or Afghanistan was conducted (Eaton et al. ,2008). The results of the study revealed that more than $20 \%$ of the sample reported stress or emotional difficulties that negatively affected their quality of life. In addition, almost $20 \%$ of the spouses met the screening criteria for major depression and anxiety disorders. Similarly, Warner, Appenzeller, and Grieger (2009) found that $43 \%$ of spouses preparing for deployment separation met the criteria for moderate to severe depression, which would have affected the emotional upheaval experienced by the soldier just prior to deployment into very dangerous duty.

Another study of 163 partners of active duty Marine and Army personnel found substantially higher levels of depression and anxiety, as measured by the Brief Symptom Inventory, than community norms (Lester et al., 2010). Note, however, that military families have access to medical care with behavioral health parity, something many civilians do not yet enjoy. This increased access to services may increase diagnoses without an actual increase in the occurrence of behavioral health challenges.

Finley (2004) conducted a qualitative study of male married Coast Guard personnel and wives regarding their experiences of short-term shipboard deployment separation (two months at sea, two months at home port). She interviewed 19 male married Coast Guard personnel and 10 Coast Guard wives about their experiences regarding short-term separations. The study found that generally both the husband and the Coast Guard wives maintained a positive attitude toward 
the deployment lifestyle, and the wives developed more independence and self-esteem as a result of deployment separations. The findings suggested that deployments disrupt daily life routines, but resulted in less loneliness and less opportunity to build up daily stressors.

The research examined in this literature review has shown that the existing research is incomplete and suggests a need for further study. Several researchers have explored the effects of deployment on military wives (Eaton et al., 2008; Mansfield et al., 2010; Steel-Fisher et al., 2008; Warner et al., 2009), studying the effects of long-term separation due to deployment, but only one known study has focused on short-term separation (16 weeks' duration). The data were not collected based on the duration of deployment-separation but only on the categories of deployment or non-deployment, which makes causal associations difficult to generalize. All these studies correlated the effects of separation to a broad range of emotional and psychological problems (e.g., post-traumatic stress disorder, anxiety, depression, mood disorder, stress level), not to one specific diagnosis such as depression. Another conflicting area of study is the effect of deployment separation on marital satisfaction.

In 2008, McLeland et al. found that deployment negatively affects marital satisfaction, but this was contradicted by research conducted by Allen and colleagues (Allen et al., 2010), who found that levels of marital satisfaction are not affected by deployment alone. This study attempted to determine whether marital satisfaction is affected by short-term separation.

This research included the consideration of military wives' socio-demographic, perceived stress, social support, and resiliency variables, as well as the level of relationship satisfaction, which has been understudied. The risk factors included in the socio-demographic status interplay with stress, social support, and how couples communicate during short-term deployment is an 
interesting avenue of study. Clearly, there is a need for more work. Research describing the effects of short-term separation due to training on military wives is a worthwhile endeavor.

\section{Understanding the Impact of Short-Term Separation Results in a New Generation of}

\section{Learning About Military Wives and Depression}

The consequences of separation on families have continually been investigated within the context of changes in family composition (e.g., through divorce or death). More recent studies have observed that military-induced separations alone create stress for military families, specifically military spouses, due to expectations of the service member's exodus, a change in roles at home, disengaged relationships, and loss of emotional support (Kelley, 1994).

This study added to the literature by exploring the occurrence of depressive symptoms in wives of active duty military personnel during short-term episodes of separation. In addition, identifying those factors which are predictive, as well as those that put the military wives at risk for depressive symptoms, may lead to improved use of resources by targeting preventive programs to spouses at high risk of depressive symptoms during short-term military separations.

As the basis for a conceptual framework, the study illuminated the impact of short-term separation on military wives. The theory of family stress and adaptation, otherwise known as Hill's ABCX model, was modified to be more linear and deterministic to fit this study. As previously mentioned, the study described the pre-separation and post-separation differences in short-term separations on military wives of active duty military personnel, emphasizing whether socio-demographics and factors such stress, resiliency, and relationship satisfaction can result in depression in military wives during short-term separations. 


\section{Summary}

The potential impact of short-term separation due to training on the behavioral health of military wives is an important but understudied area of military life. Healthcare policy makers will be in a better position to make decisions that can improve the quality of life throughout the military service community when knowledge about the effects of short-term separation is increased. The war in Afghanistan is winding down, with a final withdrawal of most forces scheduled for December 2014, but separation of service members from their families due to training will continue as the military aims for a ready force, ready to deploy. In the next chapter, the design and methods of the study are discussed. 


\section{CHAPTER 3: METHODOLOGY}

This chapter defines the methodology used in the study. The research design, context of the study, data collection procedures, sampling methods and recruitment of subjects, measures, data analysis, and human subject protection are described. The purpose of this study was to determine whether short-term separation has an adverse effect on the behavioral health of military wives.

The study was guided by the following research questions:

1) Does post-separation depression vary based on socio-demographic characteristics?

2) Do military wives have resiliency when separated from their active duty military husbands?

3) Is short-term separation associated with a decrease in relationship satisfaction among military wives of active duty military personnel?

4) Are stress levels in military wives in response to separation associated with levels of social support or resiliency?

5) Do socio-demographic characteristics, social support, resiliency, perceptions of stress, and/or relationship satisfaction predict depression in military wives?

\section{Research Design}

This study used a descriptive pre-test post-test design to investigate whether short-term separations, defined as those lasting less than three months, have an adverse effect on the behavioral health of military wives of selected active duty service members serving the Army Medical Command (MEDCOM). First, a pre-separation survey about socio-demographic status, perceived stress, social support, resilience, general relationship satisfaction, and depression was 
collected from military wives before separation. Prior to the husband's return home, a postseparation survey was collected related to perceived stress, social support, resilience, general relationship satisfaction, and depression (excluding socio-demographic factors) to determine whether there had been a change since the separation.

\section{Sample and Setting}

The study was conducted at the Leadership Training Center at Fort Sam Houston, Texas, where approximately 278 male married active duty soldiers attend leadership training each year. An a priori power analysis was conducted using SPSS Sample Power software. Based on the estimated population parameters, a minimum of 54 subjects was considered adequate to provide an $80 \%$ accurate ability to detect differences, with a medium to large effect size $(0.65)$ in the preand posttest results that was examined via the paired sample t-test. A minimum of 35 participants was required for the bivariate correlation $(1-\beta=.95)$ and 65 cases were needed for the linear regression analysis $(1-\beta=.95)$.

According to Fincham (2008), surveys sent via e-mail have a response rate of only $25 \%$ to $30 \%$ without a follow-up e-mail and reinforcement. Therefore, $60 \%$ of the sample in this study was expected not to respond. The power analysis above provided the minimum sample size needed for each test to obtain the minimum .80 power desired in a study. A sample of 285 met the requirements with an anticipated return rate of 30\%. Yun and Trumbo (2000) found that surveys using multiple contact methods (e.g., e-mail, mailed options) yielded response rates as high as $70 \%$. Also, the response rates to both web and mailed survey instruments increased if the surveys were preceded by mailed contact to non-respondents combined with personalization and provision of incentives (Converse et al., 2008; Kaplowitz et al., 2004). 
Since no research was available regarding the response rate of military families to surveys, it was anticipated that the military culture of "following orders or obeying orders" learned from their active duty husbands' behavior would transfer to military wives and motivate them to answer the survey. Thus, it was assumed that the response rate would be higher among these military wives. This assumption was false as the response rate was 39.5 , only slightly higher than documented in the literature.

A single military base (Fort Sam Houston), which houses the Army Medical Command (MEDCOM), was selected. The military officers attending the Captains Career Course are separated from their spouses for a 4- to 12-week period.

The inclusion criteria for the participants in the study were:

1. A female married to a U.S. Army officer

2. Willing to participate

3. English speaking

4. Wife of military officer who is scheduled to attend the Captains Career Course The exclusion criteria were:

1. Spouse not currently an enlisted or commissioned member of the U.S. military.

2. Wife of military officer belonging to the U.S. Army Reserve or National Guard.

3. Self-reported diagnosis of depression. A participant having an actual diagnosis of depression would have contaminated the results of the study.

4. Currently taking anti-depressants.

5. Self-report as pregnant at the time of recruitment. According to a joint report of the American Psychiatric Association (APA) and the American College of 
Obstetricians and Gynecologists (ACOG), between $14 \%$ and $23 \%$ of women have symptoms of depression in pregnancy (Yonkers et al., 2009). Including pregnant women in the study would have added an additional confounding factor of a risk associated with the pregnancy.

6. Engaged in private therapy, counseling with a behavioral health or professional life-health coach, or in another form of preventive or therapeutic outlet.

7. Wife who accompanied her husband to the Captains Career Course.

\section{Recruitment}

The sampling frame consisted of those wives identified by their husbands' enrollment or future attendance at the Captains Career Course training conducted at the Army Medical Department (AMEDD) Center and School at Fort Sam Houston, Texas. After receiving approval from the 32nd Brigade Commander, Dean of the AMEDD Center and School, and the Brooke Army Medical Center (BAMC) Institutional Review Board (IRB), a list of future students for the Captains Career Course was acquired. The participants were identified and contacted via the U.S. Postal Service using regular mail to solicit their participation in the study.

\section{Human Subjects Protection}

Participants were given informed consent. Confidentiality was discussed in writing and stressed throughout the process. The consent process was designed to allow a participant to ask questions by contacting the researcher by phone and to withdraw if desired without negative consequences to her husband's status in the Captains Career Course class.

Every attempt was made to protect the participants from any psychological and unforeseen risks. Approval from BAMC-IRB was obtained and a deferral IRB oversight from the 
University of Arizona was also approved. The participants are not identified in any reports or publications that will result from this study. Only the researcher, the IRB, and the dissertation committee had access to the information provided by the participants. The completed surveys were secured in a locked, fireproof box in the researcher's home office until the study ended. The BAMC-IRB protocol for securing data was also used for this research. All other confidential material was kept in a secure filing cabinet at the researcher's office.

\section{Instrumentation and Measures}

The data collection instrument used in this study was created by the researcher. It incorporated items from preexisting questionnaires with the full permission of the instrument creator.

Data were collected about the socio-demographic characteristics of the participants. Information included age, length of separation, ethnicity, education, length of marriage, employment status, period of time living with husband, household income, number of children, primary language, as well as frequency of contact and how the couple communicated while the active duty husband was in training.

Perceived stress was measured using Cohen and Williamson's (1988) Perceived Stress Scale (PSS). The PSS measures the degree to which situations in one's life are appraised as stressful. Each item is scored on a 5-point rank-ordered scale, ranging from $1=$ never to $5=$ very often. Instead of using total scores, composite (mean) scores were used in the inferential analyses. Cohen and Williamson examined the construct validity of the PSS and found that the scores were moderately related to responses on other measures of appraised stress (i.e., Job Responsibilities Scale, Life Event Scales). They reported a measure of internal consistency 
(Cronbach's alpha) of .78. The PSS provides better predictions for psychological symptoms, physical symptoms, and utilization of health services than other similar instruments. In this study, 10 items Perceived Stress Scale was found to be highly reliable; pre-separation Cronbach's $\alpha=.85$ and post-separation Cronbach's $\alpha=.84$ (Table 1).

TABLE 1. Reliability of Scales.

\begin{tabular}{lccc}
\hline \multicolumn{1}{c}{ Scale } & N (items) & $\begin{array}{c}\text { Pre-Separation } \\
\text { Cronbach's } \boldsymbol{\alpha}\end{array}$ & $\begin{array}{c}\text { Post-Separation } \\
\text { Cronbach's } \boldsymbol{\alpha}\end{array}$ \\
\hline Perceived Stress Scale & 10 & 0.845 & 0.842 \\
Multidimensional Scale of Perceived Social Support & 12 & 0.917 & 0.945 \\
Connor-Davidson Resiliency Scale 10 & 10 & 0.917 & 0.911 \\
Beck Depression Inventory II & 21 & 0.847 & 0.887 \\
Relationship Assessment Scale & 7 & 0.914 & 0.927 \\
\hline
\end{tabular}

Social support was measured using the Multidimensional Scale of Perceived Social Support (Canty-Mitchell \& Zimet, 2000). The Multidimensional Scale of Perceived Social Support (MSPSS) was used to examine participants' social support networks. The MSPSS consists of 12 items that measure social support systems, including family, friends, and significant others. Items are typically rated on a 7-point Likert scale ranging from very strongly disagree (1) to very strongly agree (7). Cronbach's internal consistency for the MSPSS ranged from .85 to .91 and had a test-retest reliability ranging from .72 to .85 (Zimet, Dahlem, Zimet, \& Farley, 1988). Validity was established through the negative association of scores on the MSPSS with scores on measures of depression (Zimet et al., 1990). To ensure consistency with the other scales used in this study, the scale was modified to a 5-point Likert-type scale ranging from $1=$ strongly disagree to $5=$ strongly agree with a neutral midpoint. In this study, the 12 items 
Multidimensional Scale of Perceived Social Support was found to be highly reliable; preseparation Cronbach's $\alpha=.92$ and post-separation Cronbach's $\alpha=.95$ (Table 1).

Resilience was measured using the CD-RISC or Connor-Davidson Resilience Scale (Vaishnavi, Connor, \& Davidson, 2007). The 10-item CD-RISC uses a 5-point Likert-type scale ranging from $1=$ strongly disagree to $5=$ strongly agree with a neutral midpoint. Rather than using the total scores in the CD-RISC, the researcher computed a composite score for each respondent that served as the measure of resiliency in this study.

In a study of 577 participants, Cronbach's alpha was .89 and the item total correlations ranged from 0.30 to 0.70 (Conner \& Davidson, 2003). An assessment of the test-retest reliability found little to no clinical change from time 1 to time 2. It also demonstrated a high level of agreement, with an intraclass correlation coefficient of .87. Netuveli et al. (2008) found that women were more resilient than men and the difference was stronger among older women. In this study, the 10 items Connor-Davidson Resilience Scale was found to be highly reliable; preseparation Cronbach's $\alpha=.92$ and post-separation Cronbach's $\alpha=.91$ (Table 1).

Symptoms of depression were collected using the 21-item Beck Depression Inventory (BDI) Scale-II (Beck, Steer, \& Brown, 1996; Sharp \& Lipsky, 2002). The BDI-II is a scored instrument with item values ranging from 0 to 3 . A higher score indicates more severe depression symptoms, with a total possible score of 63 . The test-retest reliability of the BDI-II is higher than the earlier version (BDI-I) and has been reported at .92 for outpatients (Beck, Steer, Ball, \& Ranieri, 1996) and .93 for college students (Storch, Roberti, \& Roth, 2004). The content validity of the BDI-II was improved by adding and rewording items to conform to the standards of the Diagnostic and Statistical Manual of Mental Disorders, Fourth Edition (DSM-IV). Factorial 
validity was established by the inter-correlations of the 21 items calculated from the sample responses. In terms of construct validity, the instrument was assessed by administering both the BDI-I and BDI-II to a sample of 191 outpatients. A correlation of $.93(\mathrm{p}<.001)$ was found, with a mean score 2.96 points higher than the BDI-I. Fourteen studies reported correlations between the BDI and clinical ratings; coefficients for psychiatric patients ranged from .55 to .96 , with a mean of .72. The BDI is the mostly widely used instrument to measure depression and has been used for more than 35 years (McDowell, 2006). In this study, the 21 Beck Depression Inventory II was found to be highly reliable; pre-separation Cronbach's $\alpha=.85$ and post-separation Cronbach's $\alpha=.89$ (Table 1).

Relationship satisfaction was measured using a modified Relationship Assessment Scale (RAS; Hendrick, 1988). The RAS is a 7-item survey designed to measure general relationship satisfaction using a 5-point rating scale, and it has good internal consistency, with Cronbach's alpha of .86. It has concurrent validity with significant correlations on similar measures, such as the Dyadic Assessment Scale, Couples Satisfaction Index Survey, and Marital Adjustment Test. Hendrick found that RAS had significant predictive capability in identifying couples that stayed together or broke up. The test was used, tested, and translated to different languages and maintained its high test-retest reliability and measurement properties across different ethnicity and age-diverse couples. In this study, the 7 items relationship Assessment Scale was found to be highly reliable; pre-separation Cronbach's $\alpha=.92$ and post-separation Cronbach's $\alpha=.93$ (Table 1). 


\section{Reliability and Validity of the Questionnaire}

The internal consistencies of the measures were examined using Cronbach's alpha and are reported in Table 1. Due to the exploratory nature of the study, principal components analysis was used to detect the underlying dimensions of the survey to ensure the validity of the items used to measure perceived stress, social support, relationship satisfaction, depression, and resiliency. All analyses featured 32 cases, except for the depression scales, for which 31 valid cases were available.

\section{Data Collection Procedures}

Upon receiving the list of incoming students for the Captains Career Course, the researcher sent a letter via postal mail addressed to the active duty soldier who would be attending the Captains Career Course. Two cover letters were sent, one to the husband and one to the wife. The husband's letter asked him to give the materials to his wife and the wife's letter requested her participation. In each letter, participants were assured that their participation was voluntary and that their husbands' status or course standing would not be affected regardless of whether they chose to participate. The mail packet was mailed to the participants using the address of their active duty husband and contained the Research Information Sheet, Survey Questionnaire, a self-addressed stamped envelope, and a list "Resources for Military Families in Need of Assistance."

The questionnaire was mailed at least two weeks before the soldier's report date for the Captains Career Course. The return of a completed survey was considered implied consent to participate in the study, as approved by the BAMC-IRB. The Research Information Sheet explained the details of the study, and the participants were allowed to contact the researcher if 
they needed further explanation. A waiver for obtaining a signed consent form was approved because the research presented no more than minimal risk of harm to participants and involved no procedures for which written consent is normally required outside of the research context. The investigator provided all participants with a written statement - the Research Information Sheet -about the study.

To match the questionnaires, a list of names with subject ID numbers was generated to identify where to send the post-separation survey. Participants were asked to complete the preseparation survey and return them in the self-addressed stamped envelope. The researcher's name and address were used as both the return and sending address to protect confidentiality of the participants. A unique identification number was assigned to match the pre- and postseparation surveys and no names were used on the surveys. A list of participant names and ID numbers was kept separated from all other materials and destroyed upon completion of the study.

About two weeks after mailing the pre-separation survey, a postcard was sent to participants to remind them to complete and return the survey. After this one reminder, no other reminder was sent. Once the researcher received the completed survey using the self-addressed stamped envelope, a $\$ 10$ Starbucks gift card was mailed to the participant. The follow-up survey questionnaire was mailed two weeks prior to completion of the soldiers' training, allowing the participants time to mail the completed survey back to the researcher prior to their husbands' return home. Once the researcher received the completed survey using the self-addressed stamped envelope, a second $\$ 10$ Starbucks gift card was sent via postal mail to the participant. The researcher was available at all times via e-mail or phone if participants had questions about the survey. 


\section{Data Analysis Methods}

Descriptive statistics were used to summarize the socio-demographic characteristics of the sample. The means and standard deviations were reported for each scale to address the relevant descriptive research questions. Inferential procedures were used to compare the pre- and post-separation results, examine the relationships among the variables, and test the utility of the variables in predicting depression in military wives.

A one way analysis of variance was conducted to compare the military wives' pre- and post-separation depression levels between each of the following factors: race, education, income, and the number of children. Chi square was also ran to have a more conservative test due to uneven cell sizes in some of the groups, the results yield no differences from the ANOVA analyses, in that all analyses were still not significant.

A paired sample t-test was used to compare pre- and post- separation resiliency and relationship satisfaction levels. Pearson product moment correlations were used with continuous level measures and biserial correlations were used with the continuous and ordinal-level variables.

Linear regression analysis was used to further examine the relationship among the predictor variables: demographics (age, number of separations, length of separations, length of marriage, and time living with husband), resilience, social support, perceived stress, and relationship satisfaction. Those with statistical significance were used to determine their predictive attributes. The regression equation indicated the relative value of each significant predictor variable $(\mathrm{X})$ in predicting the outcome or criterion variable $(\mathrm{Y})$. Stepwise data entry was used to isolate the individual predictors and compute the effect size of each of the variables. 


\section{Summary}

This chapter described the methods and procedures employed to provide insights into the possible effects of short-term separation on military wives of active duty service members. The research design, sample and setting, recruitment, human subject protection, measures, data collection procedures, and data analysis method were presented. 


\section{CHAPTER 4: FINDINGS}

This chapter presents the findings of this study. The purpose of the study was to examine the effects of short-term separation on the behavioral health of military wives. The research questions are: 1) Does post-separation depression vary based on socio-demographic characteristics? 2) Do military wives have resiliency when separated from their active duty military husbands? 3) Is short-term separation associated with a decrease in relationship satisfaction among military wives of active duty military personnel? 4) Are stress levels in military wives in response to separation associated with levels of social support or resiliency? 5) Do socio-demographic characteristics, social support, resiliency, perceptions of stress, or relationship satisfaction predict depression in military wives?

A total of 81 surveys were mailed out to military wives. Thirty-four military wives completed the pre- and post- surveys for the first iteration of data collection, but only 32 surveys were used in this analysis. Two surveys were excluded because the pre- and post- surveys were postmarked and mailed at the same time, so the assumption was that the pre-survey had not been completed before the separation. The survey response rate was 39.5 percent which is higher than the normal return rate for surveys at 33.3 percent (Watt, Simpson, McKillop, \& Nunn, 2002).

\section{Description of the Sample}

Thirty two military wives participated in this study (Table 2). The mean age was 33.78 $(S D=6.39)$. Most respondents were Caucasians $(75 \%)$. The majority had a four-year college degree (53\%), with a combined annual income of more than $\$ 100,000(43 \%)$. English was the primary language (91\%) spoken. Most participants had 2-3 children living with them at home. More than half of the military wives were homemakers (56.3\%). 
TABLE 2. Demographic Characteristics of Military Wives $(N=32)$.

\begin{tabular}{lccc}
\hline Characteristic & Range & Mean & SD \\
\hline Age & $22-48$ & 33.78 & 6.39 \\
Number of separations & $0-10$ & 1.75 & 1.83 \\
Length of separation (in months) & $1-15$ & 8.06 & 4.05 \\
Length of marriage (in years) & $1-23$ & 10.00 & 6.54 \\
Time living with husband (in years) & $2-23$ & 10.67 & 6.13
\end{tabular}

\begin{tabular}{lcc}
\hline Race/Ethnicity & Frequency & Percent \\
\hline White & 24 & 75.0 \\
Asian-Pacific Islander & 3 & 9.4 \\
Hispanic or Latino & 2 & 6.3 \\
Black or African American & 3 & 9.4 \\
\hline Education & & \\
\hline High school diploma & 1 & 3.1 \\
Some college & 2 & 6.3 \\
Associate degree & 5 & 15.6 \\
4-year college degree & 17 & 53.1 \\
Master's degree & 6 & 18.8 \\
Doctoral degree & 1 & 3.1 \\
\hline Employment & & \\
\hline Full-time & 12 & 37.5 \\
Part-time & 1 & 3.1 \\
Homemaker & 18 & 56.3 \\
Student & 1 & 3.1 \\
\hline Combined Annual Income & & \\
\hline \$50,000-74,999 & \multicolumn{2}{c}{} \\
\$75,000-99,999 & 7 & 21.9 \\
Missing & 9 & 28.1 \\
\hline Number of Children & 14 & 43.8 \\
\hline 0 (none) & 2 & 6.3 \\
2 & & \\
3 & & \\
4 or more & \multicolumn{2}{c}{} \\
\hline Primary (Native) Language & 9 & 12.5 \\
\hline English & 8 & 28.1 \\
Spanish & 6 & 25.0 \\
\hline
\end{tabular}


Military wives were asked how many days per week they communicated with their husbands. In excess of 70\% (Table 3) reported communicating with their husbands every day of the week. Most military wives reported using multiple modes of communication; however, the frequency and duration of each mode of communication was not reported.

TABLE 3. Types and Frequencies of Communication.

\begin{tabular}{ccc}
\hline Communication Frequency & Frequency & Percent \\
\hline 0 & 0 & 0.0 \\
1 & 0 & 0.0 \\
2 & 1 & 3.1 \\
3 & 1 & 3.1 \\
4 & 2 & 6.2 \\
5 & 3 & 9.4 \\
6 & 2 & 6.3 \\
7 & 23 & 72.7 \\
\hline Communication Type & & \\
\hline Email & & 71.9 \\
Phone & 23 & 96.9 \\
Skype & 32 & 71.9 \\
Text & 23 & 93.8 \\
Letter & 30 & 3.1 \\
\hline
\end{tabular}

\section{Descriptive Statistics}

The mean scores and standard deviations of depression, social support, resiliency, perceived stress, and relationship satisfaction are reported in Table 4. The mean scores for preand post-separation depression were $7.52(S D=6.12)$ and $7.74(S D=6.48)$. The mean score for post-separation depression was slightly higher compared to the pre-separation depression score, although it was not significantly different. The pre-separation and post-separation mean scores for social support were $5.52(\mathrm{SD}=0.96) ; 5.36(\mathrm{SD}=1.091)$, for resiliency $3.93(\mathrm{SD}=0.67), 3.91$ ( $\mathrm{SD}=0.64)$; for stress $2.72(\mathrm{SD}=0.67), 2.72(\mathrm{SD}=0.66)$; and for relationship satisfaction were 4.27 ( $\mathrm{SD}=0.81), 4.22(\mathrm{SD}=3.11)$, respectively. There were no significant differences in the pre- 
separation and post-separation mean scores for social support, resiliency, perceived stress or relationship satisfaction.

TABLE 4. Pre- and Post-Separation Scores for Depression, Social Support, Resiliency, Perceived Stress and Relationship Satisfaction.

\begin{tabular}{lcccc}
\hline \multirow{1}{*}{ Variable } & \multicolumn{2}{c}{ Pre-Separation } & \multicolumn{2}{c}{ Post-Separation } \\
\cline { 2 - 5 } & M & SD & M & SD \\
\hline Depression & 7.52 & 6.120 & 7.74 & 6.481 \\
Social Support & 5.52 & 0.960 & 5.36 & 1.091 \\
Resiliency & 3.93 & 0.670 & 3.91 & 0.644 \\
Perceived Stress & 2.72 & 0.670 & 2.72 & 0.667 \\
Relationship Satisfaction & 4.27 & 0.814 & 4.22 & 3.110 \\
\hline
\end{tabular}

Table 5 presents the correlational matrix for the five measures at pre- separation. Preseparation depression scores were significantly positively correlated with perception of stress $(r=.74, p<.001)$ and significantly negatively correlated with social support $(r=-.42, p=.016)$, resiliency $(r=-.61, p<.001)$, and relationship satisfaction $(r=-.53, p=.006)$. All correlations were in the predicted direction as discussed in the literature. The correlation also indicates that social support and relationship satisfaction were positively correlated $(r=.39, p=.027)$, and stress was negatively correlated with relationship satisfaction $(\mathrm{r}=-.62, p=.005)$ and resiliency $(\mathrm{r}=-.49$, $p=.005$ ). Again, these correlations were in the predicted direction as discussed in the literature. This indicates that those wives who had more resiliency and greater social support and relationship satisfaction had less depression. Those wives who had more stress were more likely to have higher depressions scores.

In sum, those wives who had higher depression experienced higher perceived stress and had decreased social support, resilience and relationship satisfaction. 
TABLE 5. Pre-Separation Correlations for Depression, Social Support, Resiliency, Perceived Stress and Relationship Satisfaction.

\begin{tabular}{lccccc}
\hline & Depression & $\begin{array}{c}\text { Social } \\
\text { Support }\end{array}$ & Resiliency & $\begin{array}{c}\text { Stress } \\
\text { Perceptions }\end{array}$ & $\begin{array}{c}\text { Relationship } \\
\text { Satisfaction }\end{array}$ \\
\hline Depression & 1.00 & $-0.416^{*}$ & $-0.608^{* *}$ & $0.743^{* *}$ & $-0.534^{* *}$ \\
Social Support & & 1.00 & 0.320 & -0.216 & $0.390^{*}$ \\
Resiliency & & & 1.00 & $-0.487^{* *}$ & 0.322 \\
Perceived Stress & & & & 1.00 & $-0.614^{* *}$ \\
Relationship & & & & & 1.00 \\
Satisfaction & & & & & \\
\hline
\end{tabular}

${ }^{*} \mathrm{p}<.05,{ }^{* *} \mathrm{p}<0.01$

Table 6 shows the post-separation depressions scores were significantly positively correlated with perception of stress $(r=.76, p<.001)$ and significantly negatively correlated with resiliency $(r=.63, p=<.001)$ and relationship satisfaction $(r=.48, p=.005)$. The relationships among the variables operated similarly post-separation as pre-separation, except for social support. Again, those wives who had more resiliency had less depression. In addition, those wives who had less relationship satisfaction and more stress post-separation were more likely to have higher depressions scores. The correlation between depression scores and social support $(r=.30)$ not significant.

TABLE 6. Post-Separation Correlations of Depression, Social Support, Resiliency, Perceived Stress and Relationship Satisfaction.

\begin{tabular}{lccccc}
\hline & Depression & $\begin{array}{c}\text { Social } \\
\text { Support }\end{array}$ & Resiliency & $\begin{array}{c}\text { Stress } \\
\text { Perceptions }\end{array}$ & $\begin{array}{c}\text { Relationship } \\
\text { Satisfaction }\end{array}$ \\
\hline Depression & \multirow{2}{*}{1.00} & -0.297 & $-0.631^{* *}$ & $0.763^{*}$ & $-0.483^{* *}$ \\
Social Support & & 1.00 & 0.318 & -0.241 & 0.282 \\
Resiliency & & & & $-0.566^{* *}$ & 0.346 \\
Perceived Stress & & & & 1.00 & $-0.405^{*}$ \\
Relationship & & & & & 1.00 \\
Satisfaction & & & & & \\
\hline
\end{tabular}

$* \mathrm{p}<.05, * * \mathrm{p}<0.01$ 


\section{Research Question 1}

The first research question (RQ1): Does post-separation depression vary based on demographic characteristics? One way analysis of variance (ANOVA) was used to separately compare post-separation depression levels between each of the following factors: race, education, income, and the number of children. Table 7 (Differences in Pre-Separation Depression) and Table 8 (Differences in Post-Separation Depression) show an analysis of variance summary table. Chi square was also ran to have a more conservative test due to uneven cell sizes, the results yielded no differences to the ANOVA results.

Table 7 shows pre-separation depression and the grouping variables: race (white military wives, non-white military wives), education (military wives with no four-year degree, military wives with four-year degree, and military wives with post-graduate degree), income (military wives with combined annual income of $\$ 50,000-\$ 74,000$, military wives with combined annual income of $\$ 75,000-\$ 99,000$, and military wives with combined annual income of over $\$ 100,000)$, and, lastly, number of children (military wives with no children, military wives with 1 child, military wives with two children, military wives with three children, and military wives with four children or more). Each category was dummy coded to enable use of a one-way ANOVA with pre- and post-separation depression levels as dependent variables, and race, education, income, and number of children as the independent variables. 
TABLE 7. Differences in Pre-Separation Depression by Group.

\begin{tabular}{|c|c|c|c|c|c|}
\hline \multicolumn{6}{|c|}{ Depression } \\
\hline & $\mathbf{N}$ & Mean & $S D$ & $\mathbf{F}$ & p \\
\hline \multicolumn{6}{|l|}{ Race } \\
\hline Non-White & 8 & 6.375 & 4.241 & 0.168 & 0.685 \\
\hline White & 24 & 7.458 & 7.009 & & \\
\hline \multicolumn{6}{|l|}{ Education } \\
\hline No 4-year degree & 8 & 5.375 & 3.378 & 0.640 & 0.534 \\
\hline 4-year degree & 17 & 8.352 & 8.193 & & \\
\hline Post-graduate degree & 7 & 6.429 & 6.383 & & \\
\hline \multicolumn{6}{|l|}{ Income } \\
\hline$\$ 50,000-\$ 74,000$ & 7 & 5.571 & 3.867 & 0.805 & 0.458 \\
\hline$\$ 75,000-\$ 99,000$ & 9 & 9.333 & 6.874 & & \\
\hline Over $\$ 100,000$ & 14 & 7.033 & 7.405 & & \\
\hline \multicolumn{6}{|l|}{ Number of Children } \\
\hline 0 & 4 & 2.250 & 2.630 & 0.858 & 0.501 \\
\hline 1 & 9 & 6.556 & 6.502 & & \\
\hline 2 & 8 & 7.875 & 8.079 & & \\
\hline 3 & 6 & 9.333 & 5.465 & & \\
\hline 4 or more & 5 & 8.600 & 6.229 & & \\
\hline
\end{tabular}

The independent variable race had two categories: white $(N=24)$ and non-white $(\mathrm{N}=8)$. The dependent variable was the pre-separation depression level. There were no significant differences between white and non-white wives in pre-separation depression $(F(1,30)=.168$, $p=.685)$.

Education was divided into three categories: no four-year degree $(N=8)$, with four-year degree $(N=17)$, and with post graduate degree $(N=7)$. The dependent variable was the preseparation depression level. There were no significant differences between the three levels of education in pre-separation depression $F(2,27)=.640, p=.534$.

The independent variable was income was divided into three categories: military wives with combined incomes of $\$ 50,000-\$ 74,000(N=7)$, military wives with combined incomes of $\$ 75,000-\$ 99,000(N=9)$, and lastly, military wives with incomes of over $\$ 100,000(N=14)$. The 
dependent variable was the pre-separation depression level There were no significant differences between the three income levels on pre-separation depression $F(2,27)=0.805, p=.458$.

The number of children had five categories: military wives with no children $(N=4)$, military wives with one child $(N=9)$, military wives with two children $(N=8)$, military wives with three children $(N=6)$, and lastly, military wives with four or more children $(N=5)$. The dependent variable was the pre-separation depression level. Regardless of the number of children, there were no significant differences in pre-separation depression $F(4,27)=.858, p=.501$.

As shown in Table 8, a one-way ANOVA was conducted to evaluate the differences between race, educational attainment, family income, or number of children and the level of post-separation depression. Race, educational attainment, family income or number of children was divided into the same categories as used in the pre-separation analyses.

There were no significant differences between white (N-24) and non-white wives $(\mathrm{N}=8)$ in post-separation depression $F(1,30)=1.10, p=.301$. There were no significant differences between the three levels of education attainment (no 4 year degree, 4 years degree, and post graduate education) on post-separation depression $F(3,26)=1.402, p=.238$. There were no significant differences between the income levels in post-separation depression $F(2,27)=1.200$, $p=.317$. Regardless of the number of children, there were no significant differences in postseparation depression $F(4,27)=.521, p=.721$.

In sum, the results indicate that there were no differences between participants by race, education, income, or the number of children in either pre- or post-separation depression scores. 
TABLE 8. Differences in Post-Separation Depression by Group.

\begin{tabular}{|c|c|c|c|c|c|}
\hline \multicolumn{6}{|c|}{ Depression } \\
\hline & $\mathbf{N}$ & Mean & $S D$ & $\mathbf{F}$ & $\mathbf{p}$ \\
\hline \multicolumn{6}{|l|}{ Race } \\
\hline Non-White & 8 & 6.125 & 5.276 & 1.107 & 0.301 \\
\hline White & 24 & 8.875 & 6.707 & & \\
\hline \multicolumn{6}{|l|}{ Education } \\
\hline No 4-year degree & 8 & 4.875 & 5.793 & 1.509 & 0.238 \\
\hline 4-year degree & 17 & 9.059 & 6.270 & & \\
\hline Post-graduate degree & 7 & 9.857 & 6.962 & & \\
\hline \multicolumn{6}{|l|}{ Income } \\
\hline$\$ 50,000-\$ 74,000$ & 7 & 5.714 & 3.302 & 1.200 & 0.317 \\
\hline$\$ 75,000-\$ 99,000$ & 9 & 10.444 & 5.940 & & \\
\hline Over $\$ 100,000$ & 14 & 7.214 & 7.628 & & \\
\hline \multicolumn{6}{|l|}{ Number of Children } \\
\hline 0 & 4 & 9.250 & 9.215 & 0.521 & 0.721 \\
\hline 1 & 9 & 5.778 & 5.630 & & \\
\hline 2 & 8 & 9.625 & 6.781 & & \\
\hline 3 & 6 & 7.667 & 4.967 & & \\
\hline 4 or more & 5 & 10.000 & 7.583 & & \\
\hline
\end{tabular}

\section{Research Question 2}

The second research question (RQ2): Do military wives have resiliency when separated from their active duty husbands? A paired-sample t-test was conducted to compare pre- and postseparation resiliency levels among military wives. Table 9 shows the mean during pre-separation resiliency $(M=3.934)$, and post-resiliency $(M=3.909)$ was not statistically significant $(t=-0.40$, $p=0.690$ ). The result indicates that there was no significant difference between the level of resiliency pre- and post- separation.

TABLE 9. Differences in Pre- and Post-Separation Resiliency.

\begin{tabular}{lclcc}
\hline & Mean & $\boldsymbol{S D}$ & $\boldsymbol{t}$ & $\boldsymbol{p}$ \\
\hline Resiliency (Pre-separation ) & 3.934 & .670 & & \\
Resiliency (Post-separation) & 3.909 & .643 & -0.403 & 0.690 \\
\hline
\end{tabular}




\section{Research Question 3}

The third research question (RQ3): Is short-term separation associated with a decrease in relationship satisfaction among wives of active-duty military? A paired sample $t$-test was conducted to compare pre- and post- separation relationship satisfaction levels among military wives. Table 10 shows the mean differences during pre-separation relationship satisfaction $(M=4.267)$, and post-separation relationship satisfaction $(M=4.223)$ was not statistically significant $(t=-0.58, p=0.566)$. The result indicates that there was no difference between relationship satisfaction pre-and post- separation.

TABLE 10. Differences in Pre- and Post-Relationship Satisfaction.

\begin{tabular}{lcccc}
\hline & Mean & SD & $\boldsymbol{t}$ & $\boldsymbol{p}$ \\
\hline Relationship Satisfaction (Pre-separation) & 4.267 & .670 & & \\
Relationship Satisfaction (Post-separation) & 4.223 & .643 & -0.580 & 0.566 \\
\hline
\end{tabular}

\section{Research Question 4}

The fourth research question (RQ4): Are stress levels in military wives in response to separation related to levels of social support or resiliency? A Pearson correlation coefficient was computed to assess the relationship between the level of stress with separation and social support. Table 11 shows that there was no significant relationship between social support and stress levels $(r=-0.241, p=.184)$. Resiliency was strongly negatively correlated with perceived stress $(r=-0.566, p=.00)$. This means that military wives with higher resiliency reported less perceived stress post-separation, which would be predicted based on the literature and theory informing this study. 
TABLE 11. Post-Separation Survey Descriptive Statistics and Inter-Correlations for Social Support, Resiliency and Perceived Stress.

\begin{tabular}{lccc}
\hline & Social Support & Resiliency & Perceived Stress \\
\hline Social Support & 1.00 & 0.318 & -0.241 \\
Resiliency & & 1.00 & $-0.566^{* *}$ \\
Perceived Stress & & & 1.00 \\
\hline
\end{tabular}

$* \mathrm{p}<.05, * * \mathrm{p}<0.01$

Table 12 shows that post-separation social support accounted for only $5.8 \%$ of the variance in post-separation stress. Although the sample size in this study $(\mathrm{N}=32)$ did not have sufficient power to conduct linear regression as it requires 65 participants $(1-\beta=.95)$, a linear regression analysis was conducted based on the original data analysis plan. Findings revealed that the level of social support was not a predictor of stress scores $\left(R^{2}=0.058, p=.184\right)$.

TABLE 12. Linear Regression: Social Support as a Predictor of Stress.

\begin{tabular}{cccccc}
\hline & & \multicolumn{4}{c}{ Coefficients } \\
\cline { 3 - 6 } & $\boldsymbol{R}^{\mathbf{R}}$ & Social Support & Sig. & Constant & Sig. \\
\hline 0.241 & 0.058 & -0.147 & 0.184 & 3.512 & $<0.001$ \\
\hline
\end{tabular}

Table 13 shows that post-separation resiliency accounted for $32 \%$ of the variance in postseparation stress. A linear regression analysis revealed that the level of resiliency is a significant predictor of stress scores $\left(R^{2}=0.320, p=.001\right)$ even though the sample size was too small.

TABLE 13. Linear Regression: Resiliency as a Predictor of Stress.

\begin{tabular}{cccccc}
\hline & & \multicolumn{4}{c}{ Coefficients } \\
\cline { 3 - 6 } $\boldsymbol{R}$ & $\boldsymbol{R}^{\mathbf{2}}$ & Resiliency & Sig. & Constant & Sig. \\
\hline 0.566 & 0.320 & -0.586 & 0.001 & 5.012 & $<0.001$ \\
\hline
\end{tabular}

Figure 2 (Stress vs. Social Support with Best-Fit Line) and Figure 3 (Stress vs. Resiliency with Best-Fit Line) provide a visual depiction of social support and resiliency in relation to stress 
levels. Figure 2 shows that the data was dispersed, consistent with the finding reported in Table 11. Figure 3 shows that resiliency scores were clustered close to the best fit line, consistent with the results reported in Table 12 .

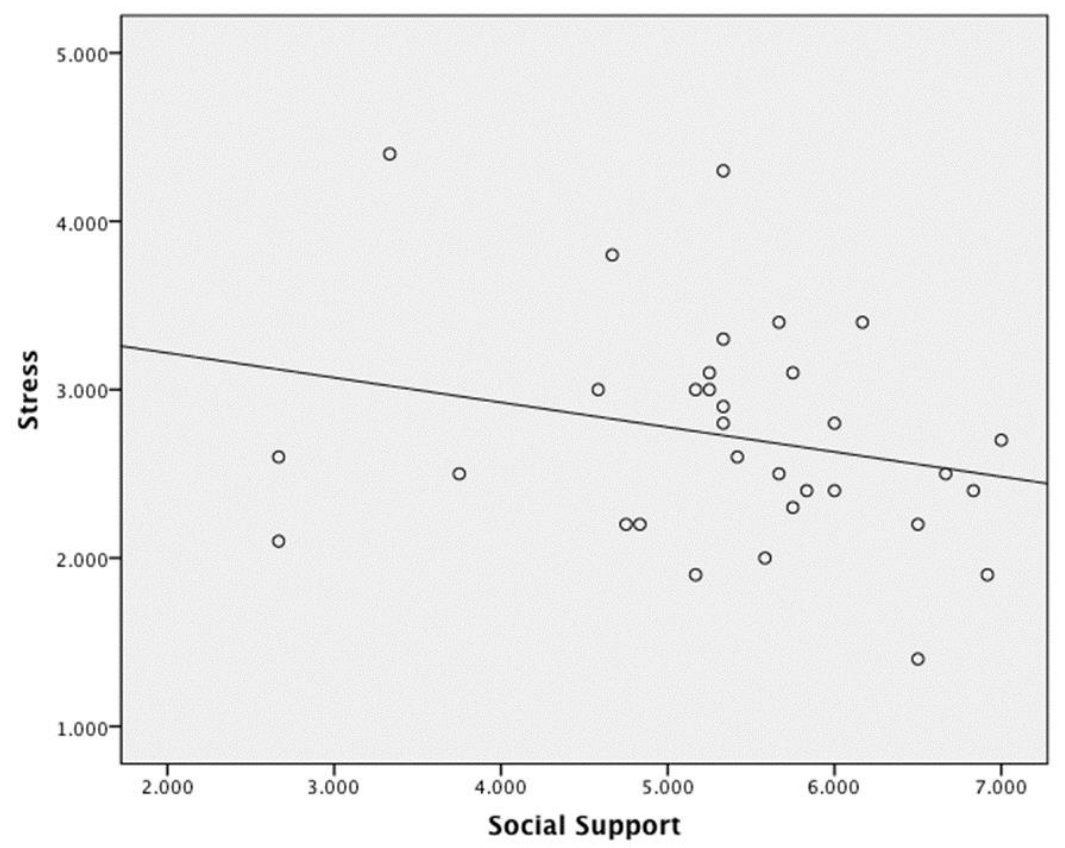

FIGURE 2. Stress vs. Social Support with Best-Fit Line.

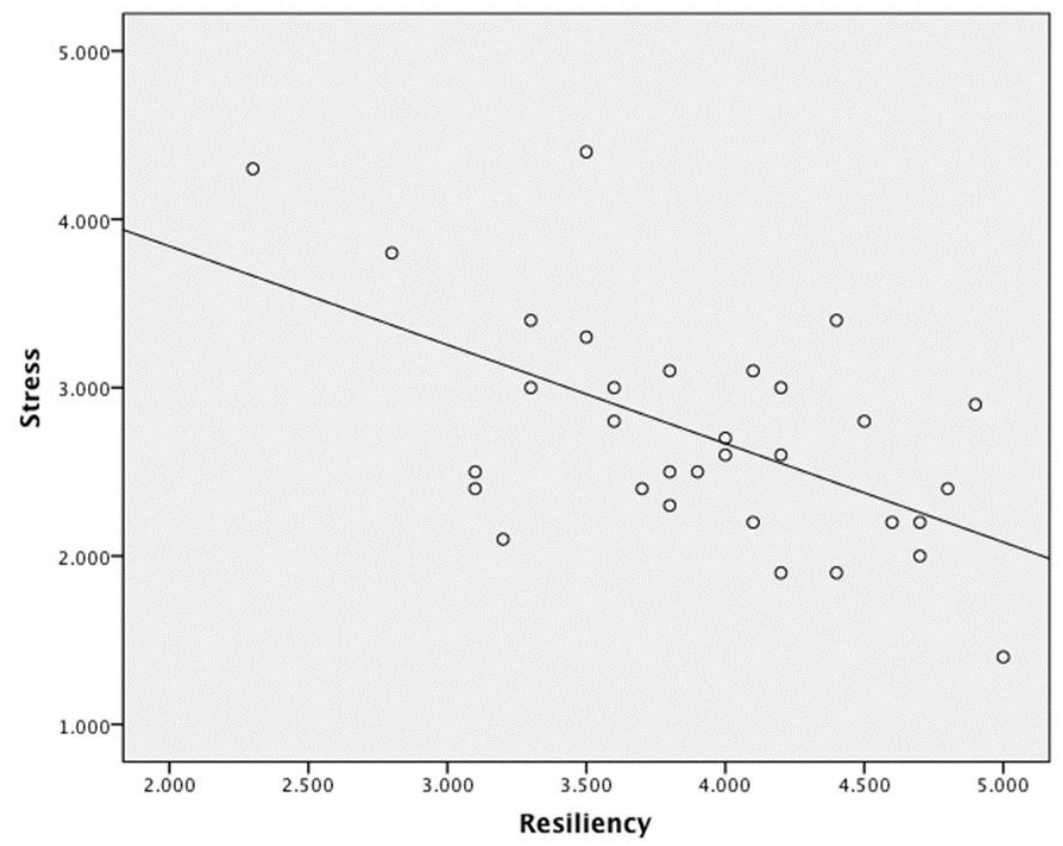

FIGURE 3. Stress vs. Resiliency with Best-Fit Line. 


\section{Research Question 5}

The fifth research question (RQ5): Do socio-demographic characteristics, social support, resiliency, perceptions of stress, or relationship satisfaction predict depression in the wives of active-duty military personnel? Pearson's correlation coefficients were computed for the military wives' socio-demographic characteristics (age, number of separations, length of separation, and length of marriage), post- separation social support, post-separation resiliency, post separation stress, and post separation relationship level versus post-separation depression. Pearson's correlations were used due to the small sample size to indicate relationships rather than prediction.

Table 14 shows the correlations matrix between frequency of communication and each of the post-separation study variables. Weighted communication frequencies were computed to assign some sense of the intimacy of communication. Communications via letters were assigned a weight of one (1); texting, a two (2); email, a three (3); phone communications, a four (4); and communications via Skype were assigned a weight of five (5). Since most wives reported communicating with their husbands seven days a week, there was a very little range in the communication frequency. In particular, the communication frequency variable expressed no concept of the quality or duration of the communication. Although no information was reported about the frequency or duration of communications within a given day, military wives did report the modes of communication they used. No significant relationships between the weighted communication frequencies and the study variables were found. 
TABLE 14. Correlations of Social Support, Resiliency, Perceived Stress, Relationship Satisfaction, and Depression with Frequency of Communication.

\begin{tabular}{lcc}
\hline \multicolumn{1}{c}{ Variable } & $\boldsymbol{r}$ & $\boldsymbol{p}$ \\
\hline Social support & -0.013 & 0.944 \\
Resiliency & 0.194 & 0.286 \\
Perceived Stress & 0.051 & 0.780 \\
Relationship Satisfaction & 0.210 & 0.250 \\
Depression & -0.041 & 0.825 \\
\hline
\end{tabular}

** Correlation is significant at the $1 \%$ level

* Correlations is significant at the $5 \%$ level

Table 15 shows the correlations between variables post-separation. All correlations were in the direction predicted by the literature. This analysis indicates a strong relationship between post-separation resiliency and post-separation depression $(r=-0.631, p<.001)$, documenting the theoretical link between resiliency and depression. For relationship satisfaction ( $r=-0.483, p=0.006$ ), a strong negative association was found between decreased relationships satisfaction and increased depression. Military wives with lower relationship satisfaction reported higher levels of depression. For stress $(r=0.763, p<.001)$, a strong correlation was found between higher stress and higher depression. This finding was as predicted by the literature of the strong relationship between stress and depression. Age, number of separations, length of separation, length of marriage, time living with the husband, and social support had no significant relationships with post-separation depression. 
TABLE 15. Correlations of Age, Number of Separations, Length of Separation, Length of Marriage, Time Living with Husband, Social Support, Perceived Stress, and Relationship Satisfaction with Post-Separation Depression.

\begin{tabular}{lcc}
\hline \multicolumn{1}{c}{ Variable } & $\boldsymbol{r}$ & $\boldsymbol{p}$ \\
\hline Age & -0.284 & 0.122 \\
Number of separations & -0.063 & 0.736 \\
Length of separation & 0.084 & 0.651 \\
Length of marriage & 0.123 & 0.511 \\
Time living with husband & -0.246 & 0.183 \\
Social support & -0.297 & 0.105 \\
Resiliency & $-0.631^{* *}$ & $<0.001$ \\
Perceived Stress & $0.763^{* *}$ & $<0.001$ \\
Relationship Satisfaction & $-0.483^{* *}$ & 0.006 \\
\hline
\end{tabular}

** Correlation is significant at the $1 \%$ level

* Correlations is significant at the $5 \%$ level

\section{Summary}

This chapter provided a description of the demographic characteristics of the 32 military wives, and the presentation of the data results. The responses to the pre- separation and postseparation surveys were examined using descriptive statistics, including frequencies, means, and standard deviations. The focus of the study was to determine whether short-term separation is associated with changes in the behavioral health of military wives.

Chapter 5 will include an interpretation of the data and a conclusion. The findings will be presented in a manner that extends the knowledge base contained within the accompanying literature review. 


\section{CHAPTER 5: DISCUSSION}

This chapter discusses the findings and the implications of the study. The chapter will begin with an integration of the findings with the literature. Each of the five research questions are discussed. The implications for nursing practice, limitations of this study, as well as recommendations for future research are also presented.

The purpose of this research was to examine the effect of short-term separation on the behavioral health of military wives. The five research questions addressed in this study were:

1) Does post-separation depression vary based on socio-demographics characteristics?

2) Do military wives have resiliency when separated from their active-duty military husbands?

3) Is short-term separation associated with decrease in relationship satisfaction among military wives of active-duty military?

4) Are stress levels in military wives in response to separation related to levels of social support or resiliency?

5) Do socio-demographic characteristics, social support, resiliency, perception of stress, and/or relationship satisfaction predict depression in military wives?

\section{Findings Related to the Literature}

The average age of the participants was 33 years old, which is consistent with the literature that $74 \%$ of the military wives range from between 18 to 34 years old. This is due to the fact that nearly half of active duty service members are younger than 26 , which means that military spouses as a demographic are predominantly young (Department of Defense, 2007; Lester et al., 2010). The average number of separations was two, with eight months as the 
average length of separation. Among the 32 participants, only four had no children, but the remaining military wives had 1-4 children living with them. Also, more than half of the participants (53\%) had a four-year college degree. These sociodemographic characteristics of this sample were not typical of military wives, in that most military wives are minority, lack of a college education, have lower incomes and experience a lack of social support In this study, the military wives were a healthy, young, educated, high income or resource rich group compared to other military wives or their civilian counterparts. According to National Defense Research Institute, RAND (2005), military wives are more likely to have young children at home; also, they are more likely to have graduated from high school and to have some college education than their civilian counterparts (National Defense Research Institute, RAND, 2005). These factors may have influenced the way of dealing with separation as well as negating developing behavioral health issues.

The findings of this study are consistent with the literature (U.S. Department of Health and Human Services, Office of the Surgeon General, Substance Abuse and Mental Health Services Administration, 2001) - namely, that depression is not dependent upon racial differences. The results for education and income are consistent with the findings of Centers for Disease Control (CDC, 2010) that people with less education and economic stability are more likely to experience depression. This sample was highly educated, and none were below the poverty level. Since having children equates to having responsibilities, the more children the family has the more responsibilities they have. A study of British parents in the Archives of Pediatrics and Adolescent Medicine (2010) found that more than one-third of mothers seem have experienced symptoms of depression during the period from their child's birth until 12 years of 
age. The study specifically stated that $13 \%$ of mothers have episodes of depression (Dave, et al. 2010). But since the results of this study showed that the number of children did not make a difference among military wives and their depression scores, it could be said that the combination of factors (e.g., strong social support, income and education, and the fact that the short-term separation was for education) negated the effects of the number of children. In this sample, sociodemographic characteristics were not associated with depression scores either preor post-separation.

\section{Resilience}

Although the findings from this study do not support prior findings that resiliency level changes over time, there may be an explanation. First, military wives may have different levels of ability to manage the unique demands of military life, especially given the average length of marriage was 10 years. Further, some wives seem able to handle challenges more easily and address these problems based on their life experiences and support systems. Furthermore, the duration of separation may have been too short or the nature of the separation insufficiently stressful. The cause of the separation in this study was for the husband to obtain a military education, a prerequisite for the husband to get promoted to the next higher rank. Perhaps when the active-duty husband is gone for 12 weeks or more, the potential for more family issues may increase, causing a decreased level of resiliency. In addition, perhaps the nature of the separation did not cause a need for more resiliency than normal.

Military wives are getting more involved in military sponsored resiliency training program and relied on each other, friends and neighbors for support, usually during separation and deployment. It also appears that military wives acknowledge the problem associated with 
separation and build resiliency with the help of formal training provided by the military. During this separation, contact with the wives was continued, and the military wives contacted their active-duty husbands an average of 6.34 times per day via telephone (97\%), texting (94\%), email (71\%), Skype (71\%), and letter (3\%). This frequency of contact may have negated any effect of the actual physical separation enabling both the military wives and their husbands to enact their roles within the families. This finding has implications for future intervention where deployed military personnel needs to have access to methods to contact their spouses.

Morse (2006) and Pincus et al. (2001) found that the longer the husband is away, the more independent the wife may become as she creates new schedules and ways of doing things. Also, separations longer than six months may significantly alter the ability of military wives to successfully cope with problems and their ability to increase resiliency. Further research should examine the impact of short-term separations on military wives' level of resiliency using different populations, such as enlisted military wives or in situations where the short-term separation is more stressful (i.e., higher risk to the husband).

This study found that military wives with higher levels of resiliency reported less stress post-separation. Military wives' life circumstances at the time of separation affected the degree to which emotions, such as stress, were experienced. Again the nature of the separation may account for the lower stress experienced by these wives. The findings were consistent with the research conducted on resiliency (Charney, 2004, 2006; Ozbay, Johnson, Dimoulas, Charney \& Southwick, 2007). Resilient individuals are able to adjust to difficult events as they happen and without complications(Scott, 2014). There are ways by which individuals can strengthen their resiliency, and the military as an organization is a resiliency-enhancing environment, even for 
wives. Military wives have many ways to increase their stress tolerance while separated from

their husband, such as by taking an active role in strengthening and preparing themselves (e.g., participating in a Family Readiness Group, attending military readiness training).

Thus, resiliency becomes very helpful in military wives' ability to balance their needs and responsibilities as well as counteracting the stress. The ability of military wives to build resilience is fundamental in establishing a healthy sense of well-being.

\section{Relationship Satisfaction}

The findings of this study do not support prior research regarding the effects of shortterm military separation on relationship satisfaction. This discrepancy has several potential reasons. The separations of the couples in this study were short, and the separation was only for military training and not for overseas combat operations. The separation involved active-duty husbands leaving their military wives for a period of 12 weeks to attend higher education. The hope of early return of the military husband made the separation easier, and the relationship more intact especially given the high frequency of contact.

Research has shown that couples who reported more effective communication showed the highest satisfaction with their relationships (Russo, 2013). The majority of military wives are younger in age; and in this study, age ranged from 22 to 48 . More than $90 \%$ of military wives communicated to their husband using telephone and text, more than $70 \%$ used emails and Skype, and $3 \%$ used letter writing to communicate with their husband. Thus, as a group these wives were not out of contact with their husbands despite being physically separated. 
And lastly, the wife may be able to continue her daily life, due to her belief that the military-induced separation involves little risk. And there may be little disruption to her daily life, given the frequent communication with her husband regarding family issues.

This study revealed that the level of relationship satisfaction does not change after nine weeks of separation, as although they were physically apart, they stayed consistently connected though phone calls, emails, and other forms of communications, thereby maintaining a level of relationship satisfaction.

\section{Social Support}

The results of this study illustrated that there was no significant correlation between social support and level of stress, which is not consistent with research on social support. There may be several reasons for the lack of a significant relationship. First, the sample in the current study had very low perceived stress and very high social support. Second, the availability of good social support helped military wives to mediate the stress of the military lifestyle, which has been shown in other research (Rosen \& Moghadam, 1990). Lastly, military wives with supportive families and friends had an easier time adjusting to military life and maintaining family satisfaction consistent with previous research (Orthner \& Rose, 2005, 2009).

This study found that stress is independent of social support, which means that the varying degrees of stress that military wives experienced during the short term were unrelated to social support. The results of this study were similar to the research findings of Skomorovsky (2014), who conducted examined the roles of deployment (separation) and social support. The study revealed that social support from family, nonmilitary friends, and military partners were independent from stress and affect military wives' psychological well-being differently. 


\section{Stress and Depression}

Sociodemographic characteristics and social support were not found to be associated with post-separation depression. Previous research showed that sociodemographic factors such as age, gender, marital status, education, and income have consistently been identified as important factors in explaining the variability in depression (Akhtar-Danesh \& Landeen, 2007). However, as the military wives in this study comprised a highly homogeneous sample (i.e., mostly white, highly educated and with high incomes), it can be assumed that they were a resource rich group whose resources enabled them to avoid developing depression. Consistent with previous research these findings document that younger, more educated people with higher incomes have a lower incidence of depression than older do women in poverty. A future study about short-term separation with a mixture of different sociodemographics, including enlisted military wives and LGBT military couples, would likely yield a different result. The finding that military wives with lower relationship satisfaction and higher perceived stress reported higher levels of depression is consistent with the literature (Harmen, 2005; Bruno, 2014; Hall-Flavin, 2014). Many factors are associated with depression (e.g., medical conditions, substance abuse, mental illness), including stress. Depression occurs when effective coping mechanisms erode; and for many adults, the vicious cycle of stress becomes a recurring cause of depression (Black, 1993; Blank et al., 2012). When a stress response fails to shut off and reset after a difficult situation has passed, it can lead to depression for those who are susceptible.

Studying the effects of separation in relation to depression, social support, resiliency, stress and relationship satisfaction yielded insights into the life matters that affect women to 
various extents across different settings. The combination of all these variables can cause a build-up of behavioral problems eventually resulting in a crisis or non-crisis.

\section{Relationships of These Findings to the Theoretical Model}

This study attempted to test the modified ABCX theoretical model as the basis for this research, but a true test of the model was not possible because of the low sample size. The findings, as expected, partially supported the modified theoretical model, Post-separation resiliency, relationship satisfaction (existing resources), and measures of perception of stress (stress) predicted crisis/non-crisis (depression). But the length of separation (stressor event), socio-demographics, and social support (existing support) was not associated with depression. Therefore any conclusions about model fit are extremely speculative.

\section{Implications of This Study}

\section{Nursing Research and Practice}

The separation of active-duty service members from their family is a major facet of military life. This study provided preliminary findings about the behavioral problems that military wives face in relation to short-term separation. This is especially important for military nurses that are providing care to military service-members, military families and beneficiaries. These findings will provide knowledge and understanding that can assist in modifying the type of care health care providers provide to this population.

This study could also serve as a foundation for future studies to promote development and utilization of innovative programs that address the needs of military wives. For example, the importance of contact to decrease negative consequences of separation was documented in this study. Thus, programs that can facilitate daily contact with spouses through technology may be 
useful in meeting the needs of military wives. For some military wives, this might require supplying such technology. The knowledge gained from this study can be used to design studies that further narrow gaps in the literature about short-term separation. The lessons learned from this study can guide future researchers on this topic in designing more valid and generalizable quantitative studies that are more transparent, coherent, and credible.

\section{Policy Development}

Having this research known to military leaders will increase public awareness, thus additional applied research can be initiated, such as a program with the sole focus of addressing and promoting the development of programs designed for military wives.

To lessen the stress of separation, families would benefit from programs that support advanced preparation regarding separation management. Military programs that prepare for separation already exist, although sometimes families don't partake in them because participation is not mandatory (Drummet, Coleman \& Cable, 2003, p. 284). Future research may interview military wives to determine the strengths and limitations of such programs to determine refinements as needed.

\section{Strengths and Limitations of This Study}

The greatest strength of this study relative to some previous studies was the study was a quantitative study with widely accepted measures for the different concepts. All the measures used had previously been demonstrated as having excellent reliability and validity, making it easier to test the hypotheses for this type of research design (correlational).

The major limitation of the study was the small number of participants: a total of 34 persons for the sample participated in the study. A (total of 68 pre- and post- separation surveys) 
were collected for analysis. All findings from this study should be interpreted with caution due to the small sample size inherent in pilot studies. The unforeseen difficulty in obtaining a large enough number of participants limits the generalizability of the findings.

The reason for the smaller than hoped for sample size was because the first iteration of data collection was halted due to complaints submitted by one of the participant's husband to the BAMC-IRB. An audit of survey records and documents was conducted by the BAMC-IRB, and no major violations were found. Upon the researcher's consultation with his dissertation committee, the data collection was halted permanently, and a closure report was submitted and approved by the responsible IRB. The small number of data collected necessitated the use of a less robust data analysis techniques (e.g., no multiple regression procedures), which limited the ability to answer the research questions regarding predictors of depression.

The use of self-report questionnaires means that the information provided by respondents cannot be independently verified. Finally, the participants were not a mixture of both enlisted and officer wives, therefore the results of this study cannot extrapolate to the effects of separations on enlisted wives facing either short- or long-term separation. It is also a limitation that military husband and military same sex couples were not represented in this study.

\section{Recommendations for Future Research}

Future research using this same theoretical model should be conducted with a larger sample size and appropriate statistical techniques. Future research could include LGBT couples to compare their experiences with heterosexual couples, and the effects of short-term separation. Further investigation is recommended for military wives of the United States Army Reserve (USAR) officers due to the fact that majority of them reside off-post and mixed with the civilian 
community compared to active-duty family. With the younger demographics of military wives, it will be interesting to know, if different methods of data collection such as emails, Monkey survey, text, and other electronic methods will yield a better response rate of conducting survey among military wives.

\section{Summary}

In conclusion, this study provided preliminary data of the effect of short-term separation on the behavioral health of military wives. Although it only partially supported the modified ABCX model, the results do show some relationships and these can be further studied with larger samples. Post-separation resiliency, relationship satisfaction (existing resources), perceptions of stress (stress) accumulated as stressors can result in depression (crisis). The length of separation (stressor event), socio-demographics, social support (existing resources) does not predict the probability of depression in this study. This may be due to a very small sample size and may be different with a larger and adequate sample size. 
APPENDIX A:

INSTITUTIONAL REVIEW BOARD APPROVAL 


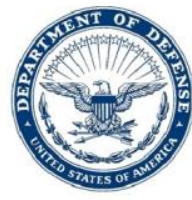
ATTENTION OF:

\section{DEPARTMENT OF THE ARMY \\ BROOKE ARMY MEDICAL CENTER \\ 3851 ROGER BROOKE DR.}

FORT SAM HOUSTON, TX 78234

MCHE-CI

February 13, 2014

$\begin{array}{ll}\begin{array}{l}\text { MEMORANDUM FOR: } \\ \text { FROM: }\end{array} & \begin{array}{l}\text { MAJ Pedro Oblea, NC, USA } \\ \text { Brooke Army Medical Center (BAMC) Institutional Review Board }\end{array} \\ \text { PROJECT TITLE: } & \begin{array}{l}{[394036-1] \text { Effect of Short-term Separation on Behavioral Health of Military }} \\ \text { Wives }\end{array} \\ \text { REFERENCE \#: } & \begin{array}{l}\text { C.2014.032d } \\ \text { SUBMISSION TYPE: }\end{array} \\ \text { New Project } \\ \text { ACTION: } & \text { APPROVED } \\ \text { APPROVAL DATE: } & \text { February 13, 2014 } \\ \text { EXPIRATION DATE: } & \text { February 13, 2015 } \\ \text { REVIEW TYPE: } & \text { Expedited Review }\end{array}$

1. Congratulations! The Brooke Army Medical Center (BAMC) Institutional Review Board (IRB) reviewed and APPROVED your aforementioned protocol and supporting documents on February 13, 2014.

The research is judged to constitute minimal risk. The protocol has been assigned control number C.2014.032d. Please refer to this designation in all correspondence.

Your protocol was reviewed for regulatory compliance under Expedited Review, in accordance with 32CFR§219.110(b) Federal Registry Category (7). Applicable OHRP (under 45CFR46), FDA (under 21CFR $\$ 0$ and 56) and HIPAA (45CFR§160 and 164) regulations were also consulted, as appropriate.

2. This submission has received Expedited Review based on the applicable federal regulation.

a. The protocol is approved to enroll up to 600 subjects.

b. An informed consent process has been approved in accordance with (IAW) 32 CFR§219.116. A waiver of the documentation of written informed consent has been approved IAW 32 CFRß219.117(c)(2). Each subject will be provided with a written statement (Research Information Sheet) regarding the research. The stamped, IRB approved written statement (Research Information Sheet) will be used for enrolling subjects.

c. The Health Insurance Portability Accountability Act has been determined not to be applicable to this study.

d. No funding is requested from the Department of Clinical Investigation.

3. All documents labeled "*FINAL" located within the Designer Page and Board Documents sections of IRBNet are to be utilized throughout the course of the strudy.

4. A Research Monitor is not required; protocol is no greater than minimal risk. 
5. You are required to report all unanticipated problems involving risks to subjects or others (UPIRSOs) and Serious Adverse Events (SAEs) to the IRB. Any unanticipated adverse events must be reported to the Human Protection Administrator within 24 hours by phone at (210) 916-2598 or (210) 916-0606 or by email at BAMC_IRB_AE@amedd.army.mil.

6. Protocol C.2014.032d will automatically expire on February 13, 2015. If you plan to continue beyond this date, the required continuing review progress report is due to the BAMC IRB no later than six weeks prior to the protocol expiration date. The IRB will attempt to assist you by sending a reminder; however, submission of the continuing review report is your responsibility. Failure to submit the report on time will result in the expiration of your protocol and a requirement to cease all research activities until the entire protocol can be resubmitted.

7. Please be sure to maintain all records in accordance with the terms set forth in your protocol. You are required to have all records, including informed consent and HIPAA documents, available for review by the IRB or other federal agencies.

8. Any changes to your protocol, including any changes in personnel, may not be made without prior IRB approval. Please forward a request for any changes, along with their rationale, to the BAMC IRB for review and approval.

9. Please inform the IRB when the protocol is completed or changes status and forward any significant findings.

10. Please ensure that you remain in compliance with BAMC Memo 70-1. Review and approval of abstract and/or manuscript submissions should be made through the Department of Clinical Investigation prior to any release. Contact Ileana King-Letzkus (210) 916-2000 for additional details.

11. If at any time you have questions regarding your responsibilities as a Principal Investigator, please contact Stacey Young-McCaughan at (210) 916-2104 or stacey.young-mccaughan.civ@mail.mil. On behalf of the entire IRB, we wish you much success with your research protocol. We look forward to reviewing the progress of your study in the coming months. 
APPENDIX B:

INSTITUTIONAL REVIEW BOARD CLOSURE REPORT 


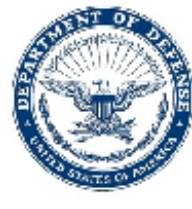

MCHE-Cl

\section{DEPARTMENT OF THE ARMY \\ BROOKE ARMY MEDICAL CENTER \\ 3551 ROGER BROOKE DR.}

FORT SAM HOUSTON, TX 78234
REPLY TO OF:

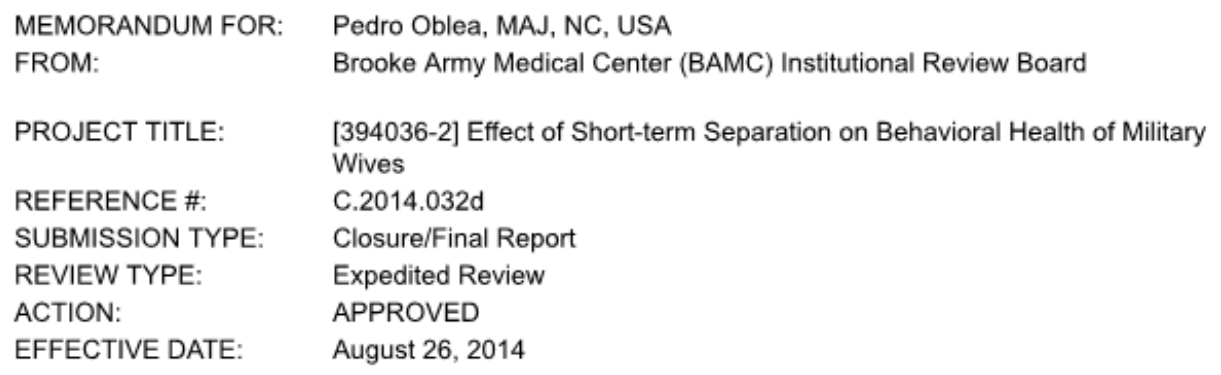

1. Thank you for submitting the Closure/Final Report for the above research study. The Brooke Army Medical Center (BAMC) Institutional Review Board has reviewed and APPROVED your submission under the Expedited Pathway, in accordance with 32CFR219.110. This action will be reported in the September 3, 2014 IRB minutes. No further action on submission 394036-2 is required at this time.

2. The following item was reviewed and approved in this submission based on the applicable federal regulation(s):

- Closure/Final Report - P35 Closure Report-Oblea (UPDATED: 07/30/2014)

3. If you have any questions, the POC is Brenda C. Torres at (210) 916-2598 or brenda.c.torres2.civ@mail.mil. Please include your project title and reference number in all correspondence with this committee.

This document has been electronically signed in accordance with all applicable regulations, and a copy is retained within our records. 
APPENDIX C:

INSTITUTIONAL REVIEW BOARD AUDIT RESULT 


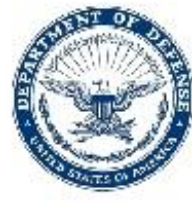

MCHE-Cl

\section{DEPARTMENT OF THE ARMY \\ BROOKE ARMY MEDICAL CENTER \\ 3551 ROGER BROOKE DR.}

FORT SAM HOUSTON, TX 78234
REPLY TO OF:

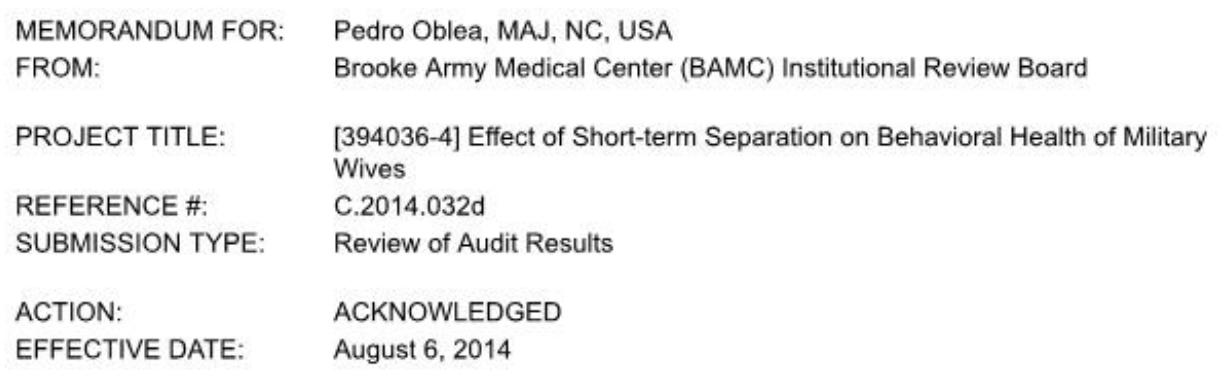

1. Thank you for submitting the Other materials for the above research study. The Brooke Army Medical Center (BAMC) Institutional Review Board has ACKNOWLEDGED your submission. No further action on submission $394036-4$ is required at this time.

2. The following item was acknowledged in this submission:

- Assessment of the Protocol "Effect of Short-term Separation on Behavioral Health of Military Wives" IRB Reference \# C.2014.032d, IRBNet \# 394036-1

3. If you have any questions, the POC is Brenda C. Torres at (210) $916-2598$ or brenda.c.torres2.civ@mail.mil. Please include your project title and reference number in all correspondence with this committee.

This document has been electronically signed in accordance with all applicable regulations, and a copy is retained within our records. 


\section{APPENDIX D:}

COVER LETTER FOR MILITARY WIVES 
[Date]

Dear Military Wives,

My name is MAJ Pedro N. Oblea, Jr., I am one of the faculty at the AMEDDC\&S, Captains Career Course, that your active duty husband is about to attend. I am also a doctoral student from University of Arizona. While I was deployed with the $27^{\text {th }}$ Brigade Support Battalion, $1^{\mathrm{St}}$ Cavalry Division in Iraq as a Brigade Nurse, my soldiers often spoke of the stress their spouses were experiencing. As a result, I have focused my doctoral studies on better understanding and documenting the stress associated with separations, both short term and long term.

I have a research questionnaire approved by the leadership at the AMEDDC\&S, Captains Career Course as well as the Brooke Army Medical Center Institutional Review Board to survey spouses of Captains Career Course students, that's the reason of contacting you is to offer you the opportunity to participate in my research study.

If you agreed to participate, enclosed in this letter are:

- Research Information Sheet with more information about the study and your participation. You can keep this sheet for reference.

- Survey Questionnaire which you will complete and return to me if you decide to participate.

- Self-addressed stamped enveloped

- Resources for Military Families in Need of Assistance for your reference, if needed.

You can choose to complete the questionnaire or not; your decision to participate or not will not have any impact on your husband status at the Captains Career Course class. Your husband has been notified that I am contacting you about participating in my study. If you do decide to participate in this study and complete the questionnaire, your husband will not see your answers. If you have any questions or concerns, I can be reached by phone at (210) 221-7548 or (254) 383-9367 (preferred cell). If you have any questions about the research approval, the BAMC IRB Department of Clinical Investigation is also available to speak with you. Their phone number is (210) 916-0606 or (210) 916-2598.

Thank you very much.

Respectfully,

Pedro N. Oblea, Jr., RN, BSN, MS

MAJ, AN

Doctoral Student University of Arizona 


\section{APPENDIX E:}

LETTER TO ACTIVE DUTY HUSBAND 
[Date]

CPT Active Duty Husband,

My name is MAJ Pedro N. Oblea, Jr., I will be one of your faculty at the AMEDDC\&S, Captains Career Course you are scheduled to attend. I am also a doctoral student from University of Arizona. While I was deployed with the $27^{\text {th }}$ BSB as a Brigade Nurse, my staff often spoke of the stress their spouses were experiencing. As a result, I have focused my doctoral studies on better understanding and documenting the stress associated with separations, both short term and long term.

I have a research questionnaire approved by the leadership at the AMEDDC\&S, Captains Career Course as well as the Brooke Army Medical Center Institutional Review Board to survey spouses of your Captains Career Course class and I will be contacting your wife to offer her the opportunity to participate in my research study.

Your wife can choose to complete the questionnaire or not; her decision to participate or not will not have any impact on your status at the Captains Career Course class. If you have any questions or concerns, I can be reached by phone at (210) 221-7548 or (254) 383-9367 (preferred cell). If you have any questions about the research approval, the BAMC IRB Department of Clinical Investigation is also available to speak with you. Their phone number is (210) 916-0606 or (210) 916-2598. Your wife will also be given this information.

Thank you very much.

Respectfully,

Pedro N. Oblea, Jr.

MAJ, AN

Small Group Leader/Instructor

Captains Career Course 


\section{APPENDIX F:}

HUMAN PROTECTION APPROVAL (MILITARY) 

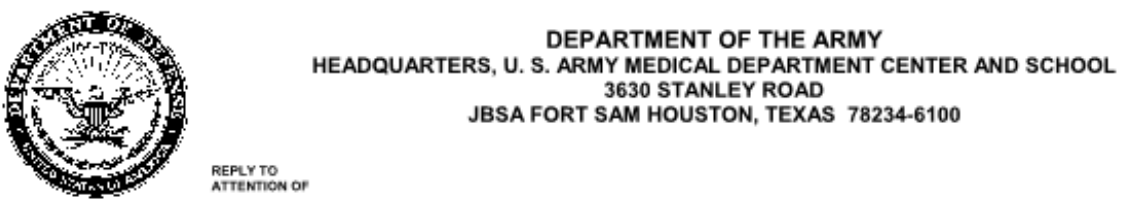

MCCS-HC-A

9 Oct 2013

MEMORANDUM FOR MAJ Pedro N. Oblea Jr., AMEDD C\&S Captains Career Course Branch, JBSA-Fort Sam Houston, TX

SUBJECT: Effects of Short-Term Separation on Military Wives on Behavioral Health

1. Your proposed research study has been approved by the Academy of Health Sciences (AHS) Dean and 32d Medical Brigade Commander for conduct with the AMEDD C\&S subject population identified in your protocol.

2. Please note that you are not authorized to begin research until receiving Institution Review Board (IRB) approval. Once granted, please provide a copy of your IRB approval to this office for record management purposes.

3. You may be required to provide the IRB a copy of this memorandum.

4. If substantial changes are made to your protocol involving AHS personnel or resources, please notify this office for reassessment. Please provide a copy of your IRB continuing review approval and any approved Protocol Amendments if the study extends past one year, as well as the IRB closure report approval once complete.

5. The undersigned can be reached at 210-221-7780 or renee.e.cole.mil@mail.mil for further questions or assistance. Thank you and good luck!

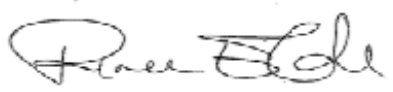

RENEE E. COLE

Major, SP, USA

Human Protections Administrator

Academy of Health Sciences 
APPENDIX G:

RESEARCH INFORMATION SHEET 


\section{UNITED STATES ARMY MEDICAL COMMAND BROOKE ARMY MEDICAL CENTER RESEARCH INFORMATION SHEET}

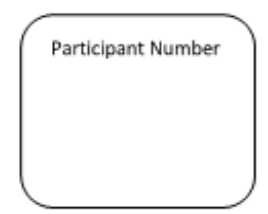

Finding better ways to better care for military beneficiaries is part of the mission of Brooke Army Medical Center. Research is done to find ways to deliver better care. To be sure your rights and welfare are protected while taking part in a research project, an Institutional Review Board (IRB) made up of doctors, nurses and non-medical people from the community reviews all studies to ensure they are appropriate and any risk is minimized.

Title of Study: Effect of short-term separation on behavioral health of military wives.

Study Investigator: Major Pedro N. Oblea, Jr., RN, BSN, MS

What is the Purpose of the Study? Separations are the norm in military life, and little is known about impact of these separations on the behavioral health of military wives. The war is winding down and longer separations due to deployment will hopefully decrease, but shortterm separation of three months or less of service members from their families due to training or special missions will continue. Long-term separations are well documented as a cause of behavioral health concerns for military spouses but the effect of short-term separations has not been assessed. This study will provide information on the effect of short-term separation on military wives and will contribute to this previously neglected area of research. The results of the study will add to the literature and become the background for developing programs for prevention and early intervention for military wives.

Why was I Selected to Participate? You are one of up to 600 military wives being invited to participate in this research project due to the fact that in few days you will be separated from your active duty husband due to his attendance at the Captains Career Course. Your decision to participate or not will in no way affect your husband's schooling.

What is Done in the Study? You are being asked to complete two questionnaires, one now just prior to your husband's departure to school, and another that will be mailed to you just prior to his return home. Each questionnaire will take approximately 20 minutes of your time. A stamped, addressed envelope will be provided for you to mail back your completed

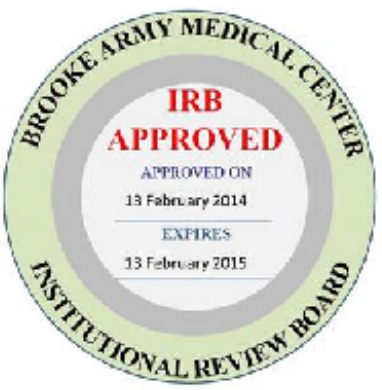


APPENDIX H:

PRE-SEPARATION SURVEY QUESTIONNAIRES 


\section{(PART 1: Pre-Test Survey)}

(NOTE: the PART II of this survey is the BDI-II, attached in a separate sheet) Identification Number:

\section{How do you feel today?}

Are you currently an enlisted or a commissioned member of the US military? (Yes) (No)

Are you pregnant? (Yes) (No)

Are you accompanying your active duty husband to the Captains Career Course at Fort Sam Houston, AMEDD Center and School? (Yes) (No)

Are you a wife of a military officer belonging to the United States Army Reserve or National Guard? (Yes) (No)

1. What is today's date?

2. What is your age?

3. Previous history of separation.

Number of (active duty husbands) deployments during marriage.

Length of typical separations from your husband.

4. What is your ethnicity? Please check all that apply.

$\circ$ White

- Hispanic or Latino

- Black or African American

- Native American or American Indian

- Asian/Pacific Islander

○ Other

5. Please list number of years of education.

○ Some High school

○ GED

- High School Diploma

- Some College

- Associate Degree

- 4 year college degree

- Master's degree

- Doctoral degree 
6. How long have you been married?

7. Indicate employment status:

- Employed full time

- Employed part time

o Homemaker

○ Student

○ Retired

○ Unable to work

8. How long have you been living with your husband?

9. What is your current combined household income per year?

- Under $\$ 39,000$

○ $\$ 40,000-\$ 49,000$

○ $\$ 50,000-\$ 74,000$

- $\$ 75,000-\$ 99,000$

- Over $\$ 100,000$

10. How many children do you have?

o None

○ 1

$\circ 2$

○ 3

- 4 or more

Ages of children: (if applicable)

11. What is your primary language?

○ English

○ Spanish

○ Other, please specify:

12. Have you had any of the following? Please check/circle all that are applicable.
- Anxiety disorder
- Posttraumatic stress disorder (PTSD)
- Obsessive compulsive disorder
- Panic disorder
○ Social phobia
- Alcohol/Substance dependence
○ Please list any serious medical illness (i.e., heart disease, stroke, cancer, HIV/AIDS, diabetes, Parkinson's disease). Please list:
○ Do you have any family history of depression? (Yes) (No)
○ Do you have a personal history of depression? (Yes) (No)
○ Are you currently taking anti-depressants? (Yes) (No)
$\circ$ Are currently engaged in therapy or counseling? (Yes) (No) 
The following will ask about your support network, feelings, and emotions. Please answer the questions the best you can. If you have any questions, please contact Major Pedro N. Oblea at (254) 383-9367.

\begin{tabular}{|c|c|c|c|c|c|c|c|}
\hline $\begin{array}{l}\text { *Social Support: Read each } \\
\text { statement carefully and } \\
\text { indicate how you feel by } \\
\text { circling the number in the } \\
\text { column to the right. }\end{array}$ & $\begin{array}{c}\text { Very } \\
\text { Strongly } \\
\text { Disagree }\end{array}$ & $\begin{array}{l}\text { Strongly } \\
\text { Disagree }\end{array}$ & $\begin{array}{c}\text { Mildly } \\
\text { Disagree }\end{array}$ & Neutral & $\begin{array}{l}\text { Mildly } \\
\text { Agree }\end{array}$ & $\begin{array}{l}\text { Strongly } \\
\text { Agree }\end{array}$ & $\begin{array}{c}\text { Very } \\
\text { Strongly } \\
\text { Agree }\end{array}$ \\
\hline $\begin{array}{l}\text { 13. There is a special person } \\
\text { around when I am in } \\
\text { need. }\end{array}$ & 1 & 2 & 3 & 4 & 5 & 6 & 7 \\
\hline $\begin{array}{l}\text { 14. There is a special person } \\
\text { with whom I can share } \\
\text { my joys and sorrows. }\end{array}$ & 1 & 2 & 3 & 4 & 5 & 6 & 7 \\
\hline $\begin{array}{l}\text { 15. My family really tries to } \\
\text { help me. }\end{array}$ & 1 & 2 & 3 & 4 & 5 & 6 & 7 \\
\hline $\begin{array}{l}\text { 16. I get the emotional help } \\
\text { and support I need from } \\
\text { my family. }\end{array}$ & 1 & 2 & 3 & 4 & 5 & 6 & 7 \\
\hline $\begin{array}{l}\text { 17. I have a special person } \\
\text { who is a real source of } \\
\text { comfort to me. }\end{array}$ & 1 & 2 & 3 & 4 & 5 & 6 & 7 \\
\hline $\begin{array}{l}\text { 18. My friends really try to } \\
\text { help me. }\end{array}$ & 1 & 2 & 3 & 4 & 5 & 6 & 7 \\
\hline $\begin{array}{l}\text { 19. I can count on my } \\
\text { friends when things go } \\
\text { wrong. }\end{array}$ & 1 & 2 & 3 & 4 & 5 & 6 & 7 \\
\hline $\begin{array}{l}\text { 20. I can talk about my } \\
\text { problems with my } \\
\text { family. }\end{array}$ & 1 & 2 & 3 & 4 & 5 & 6 & 7 \\
\hline $\begin{array}{l}\text { 21. I have friends with } \\
\text { whom I can share my } \\
\text { joys and sorrows. }\end{array}$ & 1 & 2 & 3 & 4 & 5 & 6 & 7 \\
\hline $\begin{array}{l}\text { 22. There is a special person } \\
\text { in my life who cares } \\
\text { about my feelings. }\end{array}$ & 1 & 2 & 3 & 4 & 5 & 6 & 7 \\
\hline $\begin{array}{l}\text { 23. My family is willing to } \\
\text { help me make decisions. }\end{array}$ & 1 & 2 & 3 & 4 & 5 & 6 & 7 \\
\hline $\begin{array}{l}\text { 24. I can talk about my } \\
\text { problems with my } \\
\text { friends. }\end{array}$ & 1 & 2 & 3 & 4 & 5 & 6 & 7 \\
\hline
\end{tabular}

*With full permission to use in this study from Dr. Greg Zimet, Professor of Pediatrics and Psychology, Indiana University School of Medicine. 


\begin{tabular}{|l|c|c|c|c|c|}
\hline $\begin{array}{l}* * \text { Resiliency: Indicate your response to the } \\
\text { following by circling the number in the column } \\
\text { to the right. Over the past month, }\end{array}$ & $\begin{array}{c}\text { Not } \\
\text { true at } \\
\text { all }\end{array}$ & $\begin{array}{c}\text { Rarely } \\
\text { true }\end{array}$ & $\begin{array}{c}\text { Sometimes } \\
\text { true }\end{array}$ & $\begin{array}{c}\text { Often } \\
\text { True }\end{array}$ & $\begin{array}{c}\text { True nearly } \\
\text { all the time }\end{array}$ \\
\hline 25. I am able to adapt when changes occur. & 0 & 1 & 2 & 3 & 4 \\
\hline 26. I can deal with whatever comes my way. & 0 & 1 & 2 & 3 & 4 \\
\hline $\begin{array}{l}\text { 27. I try to see the humorous side of things when } \\
\text { I am faced with problems. }\end{array}$ & 0 & 1 & 2 & 3 & 4 \\
\hline $\begin{array}{l}\text { 28. Having to cope with stress can make me } \\
\text { stronger. }\end{array}$ & 0 & 1 & 2 & 3 & 4 \\
\hline $\begin{array}{l}\text { 29. I tend to bounce back after illness, injury, or } \\
\text { other hardships. }\end{array}$ & 0 & 1 & 2 & 3 & 4 \\
\hline $\begin{array}{l}\text { 30. I believe I can achieve my goals, even if } \\
\text { there are obstacles. }\end{array}$ & 0 & 1 & 2 & 3 & 4 \\
\hline $\begin{array}{l}\text { 31. Under pressure, I stay focused and think } \\
\text { clearly. }\end{array}$ & 0 & 1 & 2 & 3 & 4 \\
\hline 32. I am not easily discouraged by failure. & 0 & 1 & 2 & 3 & 4 \\
\hline $\begin{array}{l}\text { 33. I think of myself as a strong person when } \\
\text { dealing with life's challenges and difficulties. }\end{array}$ & 0 & 1 & 2 & 3 & 4 \\
\hline $\begin{array}{l}\text { 34. I am able to handle unpleasant or painful } \\
\text { feelings like sadness, fear and anger. }\end{array}$ & 0 & 1 & 2 & 3 & 4 \\
\hline
\end{tabular}

**All rights reserved. No part of this document may be reproduced or transmitted in any form, or by any means, electronic or mechanical, including photocopying, or by any information storage or retrieval system, without permission in writing from Dr. Davidson at mail@cd-risc.com. Copyright 2001-2013 by Kathryn M. Connor, MD, and Jonathan RT Davidson, MD.

\begin{tabular}{|c|c|c|c|c|c|}
\hline $\begin{array}{l}\text { ***Perceptions of Stress: The questions in this scale ask } \\
\text { you about your feelings and thought during THE LAST } \\
\text { MONTH. In each case, please indicate your response by } \\
\text { circling the number representing HOW OFTEN you felt or } \\
\text { thought a certain way. }\end{array}$ & Never & Almost & Sometimes & $\begin{array}{l}\text { Fairly } \\
\text { Often }\end{array}$ & $\begin{array}{l}\text { Very } \\
\text { Often }\end{array}$ \\
\hline $\begin{array}{l}\text { 35. In the last month, how often have you been upset } \\
\text { because of something that happened unexpectedly? }\end{array}$ & 0 & 1 & 2 & 3 & 4 \\
\hline $\begin{array}{l}\text { 36. In the last month, how often have you felt that you were } \\
\text { unable to control the important things in your life? }\end{array}$ & 0 & 1 & 2 & 3 & 4 \\
\hline $\begin{array}{l}\text { 37. In the last month, how often have you felt nervous and } \\
\text { "stressed"? }\end{array}$ & 0 & 1 & 2 & 3 & 4 \\
\hline $\begin{array}{l}\text { 38. In the last month, how often have you felt, confident } \\
\text { about your ability to handle your personal problems? }\end{array}$ & 0 & 1 & 2 & 3 & 4 \\
\hline $\begin{array}{l}\text { 39. In the last month, how often have felt that things were } \\
\text { going your way? }\end{array}$ & 0 & 1 & 2 & 3 & 4 \\
\hline $\begin{array}{l}\text { 40. In the last month, how often have you found that you } \\
\text { could not cope with all the things that you had to do? }\end{array}$ & 0 & 1 & 2 & 3 & 4 \\
\hline $\begin{array}{l}\text { 41. In the last month, how often have you been able to } \\
\text { control irritations in your life? }\end{array}$ & 0 & 1 & 2 & 3 & 4 \\
\hline $\begin{array}{l}\text { 42. In the last month, how often have you felt that you were } \\
\text { on top of things? }\end{array}$ & 0 & 1 & 2 & 3 & 4 \\
\hline $\begin{array}{l}\text { 43. In the last month, how often have you felt been angered } \\
\text { because of things that were outside of your control? }\end{array}$ & 0 & 1 & 2 & 3 & 4 \\
\hline $\begin{array}{l}\text { 44. In the last month, how often have you felt difficulties } \\
\text { were piling up so high that you could not overcome } \\
\text { them? }\end{array}$ & 0 & 1 & 2 & 3 & 4 \\
\hline
\end{tabular}


****Relationship Assessment: Please mark on the answer sheet the letter for each item which best answers that item for you.

45. How well does your partner meet your needs?

$\begin{array}{lllll}\text { A } & \text { B } & \text { C } & \text { D }\end{array}$

Poorly

Average

E

Extremely well

46. In general, how satisfied are you with your relationship?

$\begin{array}{lllll}\text { A } & \text { B } & \text { C } & \text { D } & \text { E }\end{array}$

Unsatisfied Average Extremely Satisfied

47. How good is your relationship compared to most?

$\begin{array}{lllll}\text { A } & \text { B } & \text { C } & \text { D }\end{array}$

Poor Average Excellent

$\begin{array}{llll}\text { 48. How often do you wish you hadn't gotten in this relationship? } & \\ \text { A } & \text { B } & \text { C } & \text { D }\end{array}$

$\begin{array}{llll}\text { A } & \text { B } & \text { D } & \text { E } \\ & \text { Average } & \text { Very often }\end{array}$

49. To what extent has your relationship met your original expectations?

$\begin{array}{lllll}\text { A } & \text { B } & \text { C } & \text { D } & \text { E }\end{array}$

Hardly at all Average

E Completely

50. How much do you love your partner?

$\begin{array}{lllll}\text { A } & \text { B } & \text { C } & \text { D } & \text { E }\end{array}$

Not much

Average

E

51. How many problems are there in your relationship?

$\begin{array}{lllll}\text { A } & \text { B } & \text { C } & \text { D }\end{array}$

Very few Average Very many

****Will full permission to use in this study from Dr. Susan S. Hendrick, PhD, Department of Psychology, Texas

Tech University. 
APPENDIX I:

POST-SEPARATION SURVEY QUESTIONNAIRES 
(PART 1: Post-Test Survey)

(NOTE: the PART 2 of this survey is the BDI-II, attached in a separate sheet) Identification Number:

\section{How do you feel today?}

The following questions ask about you

1. What is today's date?

2. How frequently did you and your husband communicate while he was in school attending the Captains Career Course? (via telephone, Skype, face to face) number of days per week on average

3. How did you communicate with your husband? Check all that apply.

e-mail

telephone

Skype

text messaging

letters

Instagram

4. Length of separation.

- 8 weeks

- 9 weeks

- 9 weeks plus

$\circ$ (number of weeks) 
The following will ask about your support network, feelings, and emotions. Please answer the questions the best you can. If you have any questions, please contact Major Pedro N. Oblea at (254) 383-9367.

\begin{tabular}{|c|c|c|c|c|c|c|c|}
\hline $\begin{array}{l}\text { * Social Support: Read each } \\
\text { statement carefully and } \\
\text { indicate how you feel by } \\
\text { circling the number in the } \\
\text { column to the right. }\end{array}$ & $\begin{array}{c}\text { Very } \\
\text { Strongly } \\
\text { Disagree }\end{array}$ & $\begin{array}{l}\text { Strongly } \\
\text { Disagree }\end{array}$ & $\begin{array}{c}\text { Mildly } \\
\text { Disagree }\end{array}$ & Neutral & $\begin{array}{l}\text { Mildly } \\
\text { Agree }\end{array}$ & $\begin{array}{l}\text { Strongly } \\
\text { Agree }\end{array}$ & $\begin{array}{c}\text { Very } \\
\text { Strongly } \\
\text { Agree }\end{array}$ \\
\hline $\begin{array}{l}\text { 5. There is a special person } \\
\text { around when I am in } \\
\text { need. }\end{array}$ & 1 & 2 & 3 & 4 & 5 & 6 & 7 \\
\hline $\begin{array}{l}\text { 6. There is a special person } \\
\text { with whom I can share } \\
\text { my joys and sorrows. }\end{array}$ & 1 & 2 & 3 & 4 & 5 & 6 & 7 \\
\hline $\begin{array}{l}\text { 7. My family really tries to } \\
\text { help me. }\end{array}$ & 1 & 2 & 3 & 4 & 5 & 6 & 7 \\
\hline $\begin{array}{l}\text { 8. I get the emotional help } \\
\text { and support I need from } \\
\text { my family. }\end{array}$ & 1 & 2 & 3 & 4 & 5 & 6 & 7 \\
\hline $\begin{array}{l}\text { 9. I have a special person } \\
\text { who is a real source of } \\
\text { comfort to me. }\end{array}$ & 1 & 2 & 3 & 4 & 5 & 6 & 7 \\
\hline $\begin{array}{l}\text { 10. My friends really try to } \\
\text { help me. }\end{array}$ & 1 & 2 & 3 & 4 & 5 & 6 & 7 \\
\hline $\begin{array}{l}\text { 11. I can count on my friends } \\
\text { when things go wrong. }\end{array}$ & 1 & 2 & 3 & 4 & 5 & 6 & 7 \\
\hline $\begin{array}{l}\text { 12. I can talk about my } \\
\text { problems with my } \\
\text { family. }\end{array}$ & 1 & 2 & 3 & 4 & 5 & 6 & 7 \\
\hline $\begin{array}{l}\text { 13. I have friends with whom } \\
\text { I can share my joys and } \\
\text { sorrows. }\end{array}$ & 1 & 2 & 3 & 4 & 5 & 6 & 7 \\
\hline $\begin{array}{l}\text { 14. There is a special person } \\
\text { in my life who cares } \\
\text { about my feelings. }\end{array}$ & 1 & 2 & 3 & 4 & 5 & 6 & 7 \\
\hline $\begin{array}{l}\text { 15. My family is willing to } \\
\text { help me make decisions. }\end{array}$ & 1 & 2 & 3 & 4 & 5 & 6 & 7 \\
\hline $\begin{array}{l}\text { 16. I can talk about my } \\
\text { problems with my } \\
\text { friends. }\end{array}$ & 1 & 2 & 3 & 4 & 5 & 6 & 7 \\
\hline
\end{tabular}

*With full permission to use in this study from Dr. Greg Zimet, Professor of Pediatrics and Psychology, Indiana University School of Medicine. 


\begin{tabular}{|l|c|c|c|c|c|}
\hline $\begin{array}{l}\text { ** Resiliency: Indicate your response to the } \\
\text { following by circling the number in the column } \\
\text { to the right. } \\
\text { Over the past month, }\end{array}$ & $\begin{array}{c}\text { Not } \\
\text { True at } \\
\text { all }\end{array}$ & $\begin{array}{c}\text { Rarely } \\
\text { true }\end{array}$ & $\begin{array}{c}\text { Sometimes } \\
\text { true }\end{array}$ & $\begin{array}{c}\text { Often } \\
\text { True }\end{array}$ & $\begin{array}{c}\text { True nearly } \\
\text { all the time }\end{array}$ \\
\hline 17. I am able to adapt when changes occur. & 0 & 1 & 2 & 3 & 4 \\
\hline 18. I can deal with whatever comes my way. & 0 & 1 & 2 & 3 & 4 \\
\hline $\begin{array}{l}\text { 19. I try to see the humorous side of things when I } \\
\text { am faced with problems. }\end{array}$ & 0 & 1 & 2 & 3 & 4 \\
\hline $\begin{array}{l}\text { 20. Having to cope with stress can make me } \\
\text { stronger. }\end{array}$ & 0 & 1 & 2 & 3 & 4 \\
\hline $\begin{array}{l}\text { 21. I tend to bounce back after illness, injury, or } \\
\text { other hardships. }\end{array}$ & 0 & 1 & 2 & 3 & 4 \\
\hline $\begin{array}{l}\text { 22. I believe I can achieve my goals, even if there } \\
\text { are obstacles. }\end{array}$ & 0 & 1 & 2 & 3 & 4 \\
\hline $\begin{array}{l}\text { 23. Under pressure, I stay focused and think } \\
\text { clearly. }\end{array}$ & 0 & 1 & 2 & 3 & 4 \\
\hline 24. I am not easily discouraged by failure. & 0 & 1 & 2 & 3 & 4 \\
\hline $\begin{array}{l}\text { 25. I think of myself as a strong person when } \\
\text { dealing with life's challenges and difficulties. }\end{array}$ & 0 & 1 & 2 & 3 & 4 \\
\hline $\begin{array}{l}\text { 26. I am able to handle unpleasant or painful } \\
\text { feelings like sadness, fear and anger. }\end{array}$ & 0 & 1 & 2 & 3 & 4 \\
\hline
\end{tabular}

**All rights reserved. No part of this document may be reproduced or transmitted in any form, or by any means, electronic or mechanical, including photocopying, or by any information storage or retrieval system, without permission in writing from Dr. Davidson at mail@cd-risc.com. Copyright 2001-2013 by Kathryn M. Connor, MD, and Jonathan RT Davidson, MD.

\begin{tabular}{|l|c|c|c|c|c|}
\hline $\begin{array}{l}\text { ****erceptions of Stress: The questions in this scale ask you } \\
\text { about your feelings and thought during THE LAST MONTH. In } \\
\text { each case, please indicate your response by circling the number } \\
\text { representing HOW OFTEN you felt or thought a certain way. }\end{array}$ & Never & Almost & Sometimes & $\begin{array}{c}\text { Fairly } \\
\text { Often }\end{array}$ & $\begin{array}{c}\text { Very } \\
\text { Often }\end{array}$ \\
\hline $\begin{array}{l}\text { 27. In the last month, how often have you been upset because } \\
\text { of something that happened unexpectedly? }\end{array}$ & 0 & 1 & 2 & 3 & 4 \\
\hline $\begin{array}{l}\text { 28. In the last month, how often have you felt that you were } \\
\text { unable to control the important things in your life? }\end{array}$ & 0 & 1 & 2 & 3 & 4 \\
\hline $\begin{array}{l}\text { 29. In the last month, how often have you felt nervous and } \\
\text { "stressed"? }\end{array}$ & 0 & 1 & 2 & 3 & 4 \\
\hline $\begin{array}{l}\text { 30. In the last month, how often have you felt, confident about } \\
\text { your ability to handle your personal problems? }\end{array}$ & 0 & 1 & 2 & 3 & 4 \\
\hline $\begin{array}{l}\text { 31. In the last month, how often have felt that things were } \\
\text { going your way? }\end{array}$ & 0 & 1 & 2 & 3 & 4 \\
\hline $\begin{array}{l}\text { 32. In the last month, how often have you found that you could } \\
\text { not cope with all the things that you had to do? }\end{array}$ & 0 & 1 & 2 & 3 & 4 \\
\hline $\begin{array}{l}\text { 33. In the last month, how often have you been able to control } \\
\text { irritations in your life? }\end{array}$ & 0 & 1 & 2 & 3 & 4 \\
\hline $\begin{array}{l}\text { 34. In the last month, how often have you felt that you were on } \\
\text { top of things? }\end{array}$ & 0 & 1 & 2 & 3 & 4 \\
\hline $\begin{array}{l}\text { 35. In the last month, how often have you felt been angered } \\
\text { because of things that were outside of your control? }\end{array}$ & 0 & 1 & 2 & 3 & 4 \\
\hline $\begin{array}{l}\text { 36. In the last month, how often have you felt difficulties were } \\
\text { piling up so high that you could not overcome them? }\end{array}$ & 0 & 1 & 2 & 3 & 4 \\
\hline
\end{tabular}

***With full permission to use in this study from Dr. Sheldon Cohen, Department of Psychology, Carnegie Mellon University. 
****Relationship Assessment: Please mark on the answer sheet the letter for each item which best answers that item for you.

37. How well does your partner meet your needs?

$\begin{array}{lllll}\text { A } & \text { B } & \text { C } & \text { D } & \text { E } \\ \text { Poorly } & & \text { Average } & & \text { Extremely well }\end{array}$

38. In general, how satisfied are you with your relationship?

$\begin{array}{lllll}\text { A } & \text { B } & \text { C } & \text { D } & \text { E }\end{array}$

Unsatisfied Average Extremely Satisfied

39. How good is your relationship compared to most?

$\begin{array}{lllll}\text { A } & \text { B } & \text { C } & \text { D } & \text { E }\end{array}$

Poor Average Excellent

$\begin{array}{llll}\text { 40. How often do you wish you hadn't gotten in this relationship? } & \\ \text { A } & \text { B } & \text { C } & \text { D }\end{array}$

Never Average Very often

41. To what extent has your relationship met your original expectations?

$\begin{array}{lllll}\text { A } & \text { B } & \text { C } & \text { D } & \text { E }\end{array}$

Hardly at all Average Completely

42. How much do you love your partner?

$\begin{array}{lllll}\text { A } & \text { B } & \text { C } & \text { D } & \text { E }\end{array}$

Not much Average Very much

43. How many problems are there in your relationship?

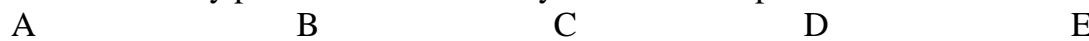

Very few Average Very many

**** With full permission to use in this study from Dr. Susan S. Hendrick, Department of Psychology, Texas Tech University. 


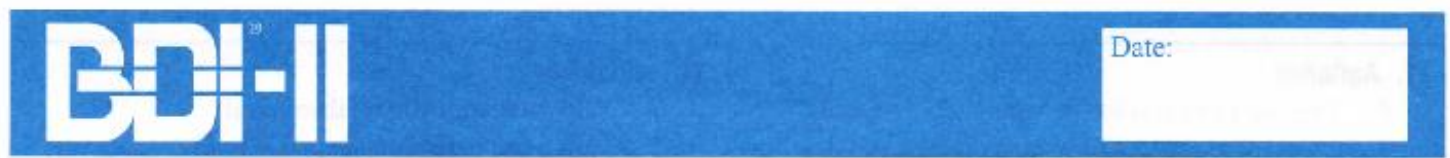

Name:

Marital Status:

Age:

Sex:

Occupation:

Education:

Instructions: This questionnaire consists of 21 groups of statements. Plcase read each group of statements carefully, and then pick out the one statement in each group that best describes the way you have been feeling during the past two weeks, including today. Circle the number beside the statement you have picked. If several statements in the group seem to apply equally well, circle the highest number for that group. Be sure that you do not choose more than one statement for any group, including Item 16 (Changes in Sleeping Pattern) or Item 18 (Changes in Appetite).

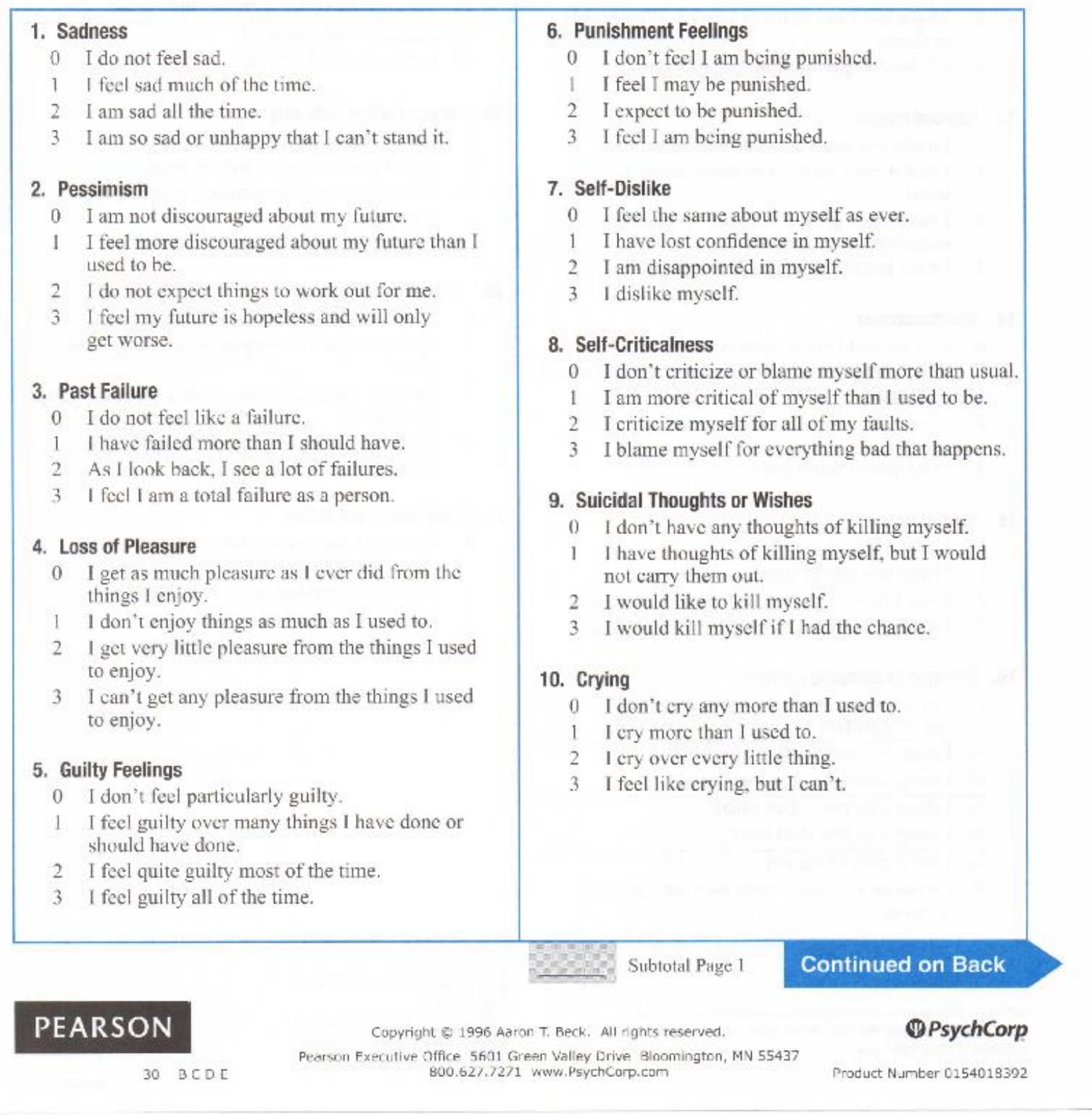


APPENDIX J:

RESOURCES FOR MILITARY WIVES 
Please Note: I will not be immediately reviewing your answers on the questionnaire. If you need assistance due to depression or maybe you have had thoughts of hurting yourself, please call someone for help. The resources listed below are just a few of many organizations that assist military beneficiaries with behavioral problems.

\section{Resources for Military Families in Need of Help}

1. http://www.militaryonesource.mil/

Military OneSource offers non-medical counseling services online, via telephone or face-toface. Eligible individuals may receive non-medical counseling addressing issues requiring shortterm attention (800-342-9647)

2. http://www.militaryhomefront.dod.mil/

DOD's website for official Military Community and Family Policy (MC\&FP) program information, policy and guidance designed to help troops and their families, leaders, and service providers.

3. http://www.militaryfamily.org/

National Military Family Association. Provides education and information regarding rights, benefits, and services for military families.

4. www.couragetocareforme.org/offline/

Courage To Care For Me. Provides fact sheets on timely health topics relevant to military life developed by military health experts at Uniformed Services University of the Health Sciences.

5. http://www.mentalhealthamerica.net/reunions/info.cfm

Mental Health America is proud to champion Operation Healthy Reunions, a first-of-its-kind program that provides education and helps to bust the stigma of mental health issues among soldiers, their families, and medical staff to ensure that a greater number of military families receive the prompt and high-quality care they deserve. In partnership with the leading military organizations, Mental Health America distributes educational materials on such topics as reuniting with your spouse and children, adjusting after war, depression, and post-traumatic stress disorder (PTSD).

6. Contact your local Military Treatment Facilities or your local Family Readiness Group (FRG) for any help or assistance.

7. National Suicide Prevention Lifeline: 1-800-273-TALK (8255).

8. For emergencies, call 911 or go to the nearest hospital emergency room. 
APPENDIX K:

APPROVAL LETTER FOR THE USE OF INSTRUMENTS 


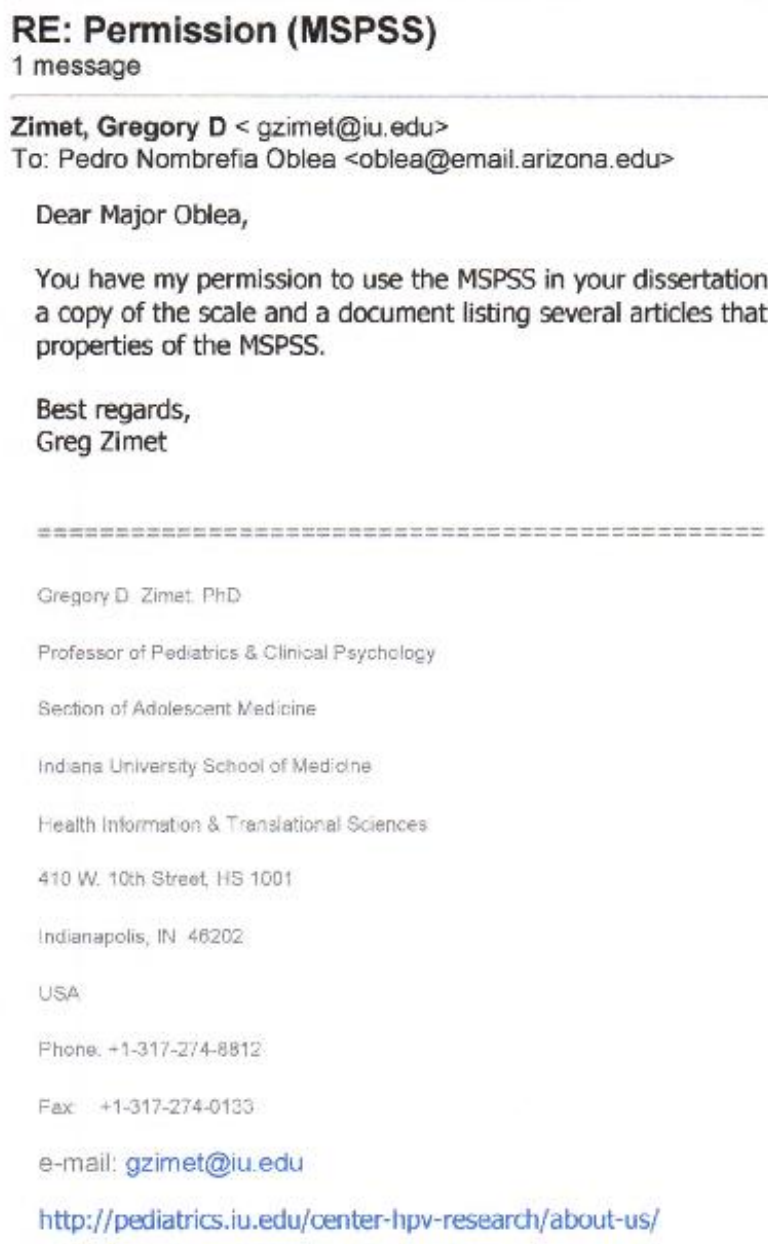

From: Pedro Nombrefia Oblea [oblea@email.arizona.edu]

Sent: Saturday, September 14, 2013 6:56 PM

To: Zimet, Gregory D

Subject: Permission (MSPSS)

Dr. Zimet,

I am a doctoral student from University of Arizona writing my dissertation tentatively titled "Effect of Short-Term Separation on Military Wives on Behavioral Health", under the direction of my dissertation committee chaired by Dr. Terry A. Badger.

https://mail.google.com/mail/u/0/?ui=2\&ik=f729b442b3\&view=pt\&search=inbox\&th=141... 9/16/2013 


\section{RE: Request Form from: Pedro N. Oblea \\ 1 message}

Jonathan Davidson, M.D. $<$ jonathan.davidson@iduke.edu> Wed, Aug 28, 2013 at 4:02

To: Pedro Nombrofia Oblea <oblea@email arizona.edu>

Dear Pedro:

Thank you for your reply and for sending payment. I am pleased to enclose a copy of the CD-RISC 10 and manual for your project. As indlcated in the agreement, we do ask that the copyright statement accompany the scale in your survey, and that the name of the scale also be clearly evident.

We wish you well on your study and thank you again for choosing the CD-RISC. Please let me know if you have any questions.

Kind regards,

Jonathan Davidson

From: Pedro Nombrefia Oblea [oblea@email.arizona.edu]

Sent: Wednesday, August 28, 2013 4:31 PM

To: Jonathan Davidson, M.D.

Subject: Re: Request Form from: Pedro N. Oblea

Dr. Davidson,

I will use your scale as is. No modification. I sent a \$30 check this morning. Attached is the request form. Ihank you very much.

Pedro

On Mon, Aug 26, 2013 at 9:28 PM, Jonathan Davidson, M.D. jonathan.davidson@duke.edu> wrote:

Dear Pedro:

Thank you for your reply. We would only be able to approve use of the scale as we have developed it. Any alterations in the scoring and choice of ratings makes it impossible to

https:/mail.google.com/mail/u/0/?ui-2\&ik-1729b442b3\&view-pt\&search-inbox\&th=140... 8/29/2013 
X7. THE UNIVERSITY 3. OF ARIZONA.

Pedro Nombrefia obleac obleademall,arlzona,edus

\section{RE: Permission to use Percieved Stress Scale}

1 message

Sheldon Cohen< scohen@smu,cd:

Won, Sep 16, 2013 at 7:52 AM

To: Fedro Nombrefia Oblea <oblea@email.arizona.edu>

Pedro, You are welcome to use the PSS in vour dissertation. Best o: luck. $5 \mathrm{C}$

From: Pedro Nombrefia Oblea [mailto:oblcaịcmail.alizena,odu]

Sent: Monday, September 16, 2013 8:21 Aim

To: Ellen Conser; Slieldon Cohen

Subject: Peithission to use Fercieved Stress Scale

Dr. Cohelv/Ms. Ellen Conser,

I am a dontoral student from Univessity of Arizona writing my dissertation tentatively titled "Effect of ShortTerm Separation on Mjlitary Wives on Behavioral Health", under the direction of my dissertation (x)'virrittee chaired by Dr. Terry A. Baóger. I would like your permission to use your PSS Scale in my research.

Thar:k you very mush.

Very Respectfuly,

Pẹd' N, Obleta, Jr. RN, BSN, MS

Major, Uritod Statos Army

Cell No. (254)383-8367 
University of Arizona Mail - RE: Request for permission (Relationship Asessment Scale) Page 1 of 2

TA THE UNIVERSITY

Pedro Nombrefia Oblea< oblea@email.arizona.edu>

\section{RE: Request for permission (Relationship Asessment Scale) 1 message}

Hendrick, $\mathbf{S}<$ s.hendrick@ttu.edu>

To: Pedro Nombrefia Oblea coblea@email.arizona.edu>

Fri, Aug 30, 2013 at 4:00 PM

Major Oblea,

You have my full permission to use the RAS in your work. Because I also work in the oncology area, I would be very interested in receiving a copy of your dissertation when it is completed. If you need any articles relevant to the RAS, please let me know. Best wishes in this important work.

Susan Hendrick

Susan S. Hendrick, PhD

Paul Whitfield Horn Professor of Psychology

Department of Psychology

Texas Tech University

Campus

From: Pedro Nombrefia Oblea [mailto:oblea@email.arizona.edu]

Sent: Friday, August 30, 2013 1:49 PM

To: Hendrick, S

Subject: Request for permission ( Relationship Asessment Scale)

Dr. Hendrick, I am a doctoral student from University of Arizona writing my dissertation tentatively titled "Effect of Short-
Term Separation on Military Wives on Behavioral Health", under the direction of my dissertation committee
chaired by Dr. Terry A. Badger.

I would like to ask for your permission to reproduce or use your survey instrument in my research study. I am willing to pay the fee for the use of the instrument.

https: $/ /$ mail.google.com $/ \mathrm{mail} / \mathrm{u} / 0 /$ ui $=2 \& \mathrm{ik}=\mathrm{f} 729 \mathrm{~b} 442 \mathrm{~b} 3 \&$ view $=$ pt\&search=inbox $\&$ th $=140 \ldots \quad 8 / 30 / 2013$ 
INVOICE

BILL TO:

ATTN: ACCOUNTS PAYABLE

PEDRO OBLEA JR

6924 AUTUMN VIEW

CONVERSE, TX 78109

\section{PEARSON}

LOCATED AT:

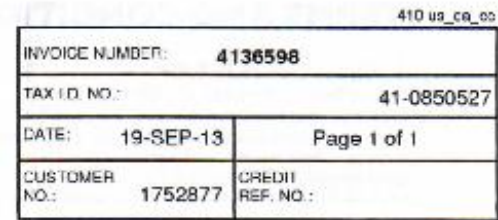

PEDRO OELEA JF

6924 AUTUMN VIEW

CONVERSE, TX 78109

Reference Number: -3916621

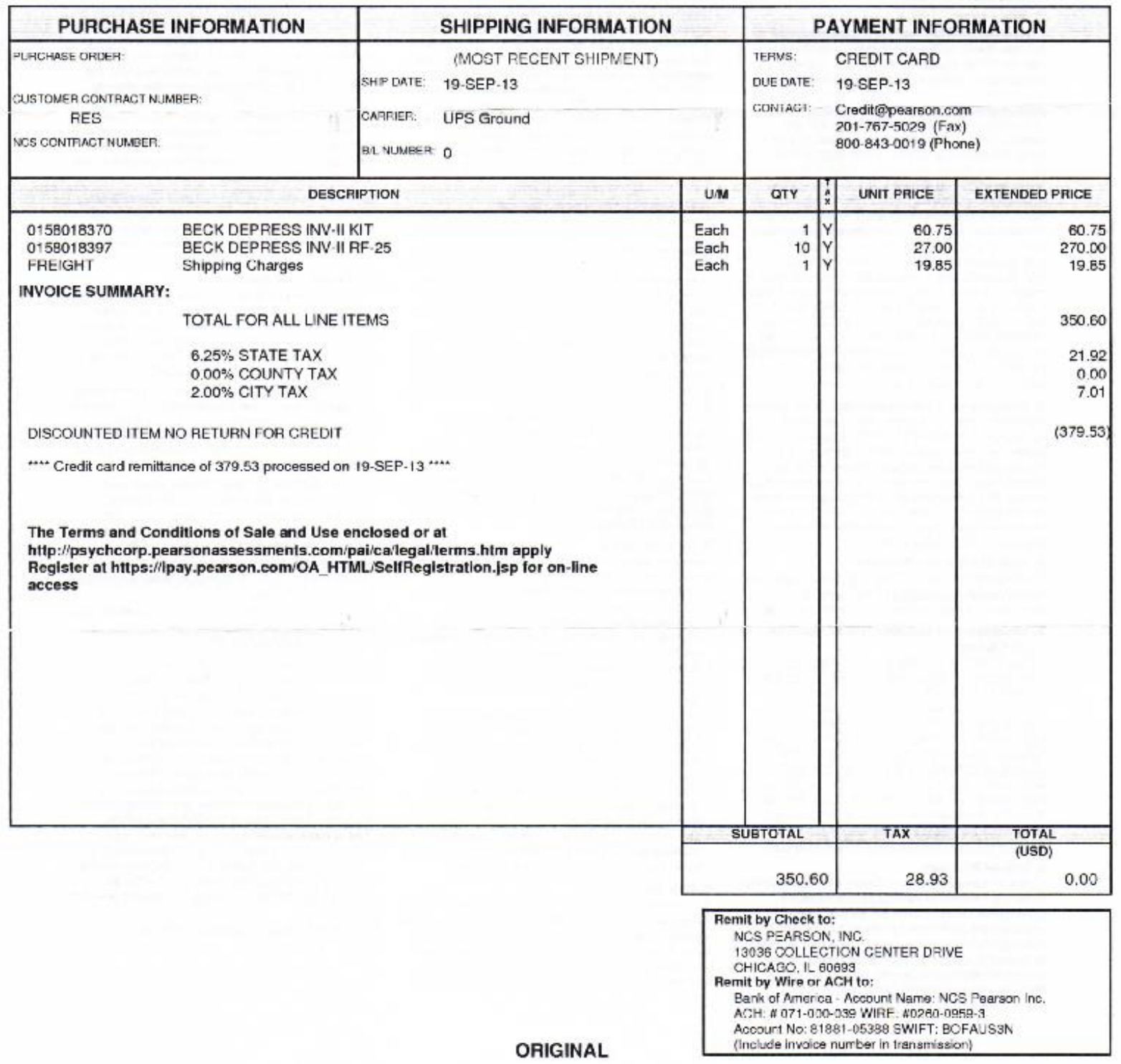




\section{REFERENCES}

Aguirre, B. (2007). Dialectics of vulnerability and resilience. Georgetown Journal of Poverty Law and Policy, 14(39), 1-18.

Allen, E. S., Rhoades, G. K., Stanley, S. M., \& Markman, H. J. (2010). Hitting home: Relationships between recent deployment, posttraumatic stress symptoms, and marital functioning for Army couples. Journal of Family Psychology, 24, 280-288.

American Psychological Association. (2006). The road to resilience. Retrieved March 20, 2009, from http://www.apahelpcenter.org/featuredtopics/feature.php?id=6.

Andres, M. (2014). Distress, support, and relationship satisfaction during military-induced separations: a longitudinal study among spouses of Dutch deployed military personnel. Psychological Services, 11(1), 22-30. http://dx.doi.org/10.1037/a0033750

Angrist, J. D., \& Johnson, J. H. (2000). Effects of work-related absences on families: Evidence from the Gulf War. Industrial and Labor Relations Review, 54(1), 41-58.

Badger, T. A. (1996). Family members' experiences living with depression. Western Journal of Nursing Research, 18(2), 149-171.

Badger, T. A., Braden, C. J., \& Mishel, M. H. (2001). Depression burden, self-help interventions and side effect experience in women receiving treatment for breast cancer. Oncology Nursing Forum, 28, 567-574.

Badger, T. A., \& Lazenby, M. (in press). Depression. In C. Brown (Ed.) A guide to oncology symptom management. Pittsburgh, PA: Oncology Nursing Society Press.

Bambauer, K. Z., Zhang, B., Maciejewski, P. K., Sahay, N., Pirl, W. F., Block, S. D., \& Prigerson, H. G. (2006). Mutuality and specificity of mental disorders in advanced cancer patients and caregivers. Social Psychiatry and Psychiatric Epidemiology, 41(10), 819824. http://dx.doi.org/10.1007/s00127-006-0103-x

Bandura, A. (1982). Self-efficacy mechanism in human agency. American Psychologist, 37(2), 122-147.

Beck, A. T., Steer, R. A., Ball, R., \& Ranieri, W. (1996, December). Comparison of Beck Depression Inventory I-A and II in psychiatric outpatients. Journal of Personality Assessment, 67(3), 588-597. http://dx.doi.org/10.1207/s1532775ipa6703_13

Beck, A. T., Steer, R. A., \& Brown, G. K. (1996). Manual for the Beck Depression Inventory II. San Antonio, TX: Psychological Corporation. 
Beck, A. T., Steer, R. A., \& Carbin, M. G. (1988). Psychometric properties of the Beck Depression Inventory: Twenty-five years of evaluation. Clinical Psychology Review, $8(1), 77-100$.

Black, W. B. (1993). Military-induced family separation: A stress reduction intervention. Social Work, 38(3), 273-280. http://dx.doi.org/10.1093/sw/38.3.273

Blank, C., Adams, L. A., Kittelson, B., Connors, R. A., \& Padden, D. L. (2012). Coping behaviors used by Army wives during deployment separation and their perceived effectiveness. Journal of American Academy of Nurse Practitioners, 24(11), 1-9. http://dx.doi.org/10.1111/j.1745-7599.2012.00766.x

Blankinship, K. (2013). How to cope with being a military wife. Retrieved from www.ehow.com/print/how_7675078_cope-being-military-wife.html

Blehar, M. C., \& Keita, G. P. (2003). Women and depression: A millennial perspective. Journal of Affective Disorders, 74(2003), 1-4. http://dx.doi.org/10.1016/S0165-0327(02)00425-1

Blount, B. W., Curry, A., \& Lubin, G. I. (1992). Family separations in the military. Military Medicine, 157(2), 76-80.

Bonanno, G. (2004). Loss, trauma, and human resilience: Have we underestimated the human capacity to thrive after extremely aversive events? American Psychologist, 59, 20-28.

Boss, P. (1988). Family stress management. Newbury Park, CA: Sage.

Browne, I. (1999). Latinas and African American women at work: Race, gender, and economic inequality. New York, NY: Russell Sage Foundation.

Burrell, L. M., Adams, G. A., Durand, D. B., \& Castro, C. A. (2006). The impact of military lifestyle demands on well-being, army and family outcomes. Armed Forces \& Society, 33(1), 43-58. http://dx.doi.org/10.1177/0002764206288804

Bruno, K. (2014). Stress and depression. Retrieved from www.webmd.com/depression/features/stress-depression

Caldwell, E. (2010, November 9). Depression linked to altered activity of circadian rhythm gene. Research News. Retrieved from http://researchnews.osu.edu/archive/circgenes.htm

Campbell, L. C., Clauw, D. J., \& Keefe, F. J. (2003). Persistent pain and depression: A biopsychosocial perspective. Biological Psychiatry, 54(3), 399-409.

Canty-Mitchell, J., \& Zimet, G. D. (2000). Psychometric properties of the Multidimensional Scale of Perceived Social Support in urban adolescents. American Journal of Community Psychology, 28, 391-400. 
Cassano, P., \& Fava, M. (2002). Depression and public health, An overview. Journal of Psychosomatic Research, 53, 849-857.

Centers for Disease Control and Prevention. (2010, October 1). Current depression among adults, United States, 2006 and 2008. Morbidity and Mortality Weekly Report, 59(38), 12291235. Retrieved from www.cdc.gov/features/dsdepressison/index/html

Centers for Disease Control and Prevention. (2011, September 2). Mental illness surveillance among adults in the United States. Morbidity and Mortality Weekly Report, 60, 1-29.

Chartrand, M. M., \& Siegel, B. (2007). At war in Iraq and Afghanistan: Children in US military families. Ambulatory Pediatrics, 7(1), 1-2.

Charney, D. S. (2004). Psychobiological mechanism of resilience and vulnerability: implications for successful adaptation to extreme stress. American Journal of Psychiatry, 161, 195216.

Charney, D. S. (2006). In session with Dennis S. Charney, MD: Resilience to stress. Primary Psychiatry, 13(8), 39-41.

Charter, R.A. (2003). Study Samples Are Too Small to Produce Sufficiently Precise Reliability Coefficients. The Journal of General Psychology, 130, 117-129.

Chawla, N., \& Solinas-Saunders, M. (2011). Supporting military parent and child adjustments to deployments and separations with filial therapy. American Journal of Family Therapy, 39, 179-192. http://dx.doi.org/10.1080/01926187.2010.531647

Child Trends Data Bank. (2014, August). Parental depression: indicators on children and youth. DataBank, 1-16.

Cohen, S., Kamarck, T., \& Mermelstein, R. (1983). A global measure of perceived stress. Journal of Health and Social Behavior, 24,385-396.

Cohen, S., \& Williamson, G. (1988). Perceived stress in a probability sample of the United States. In S. Spacapan, \& S. Oskamp (Eds.), The social psychology of health. Newbury Park, CA: Sage.

Connor, K. M., \& Davidson, J. R. T. (2003). Development of a new resilience scale: The Connor-Davidson Resilience Scale (CD-RISC). Depression and Anxiety, 18, 76-82. http://dx.doi.org/10.1002/da.10113.

Converse, P. D., Wolfe, E. W., \& Oswald, F. L. (2008). Response rates for mixed-mode surveys using mail and e-mail/web. American Journal of Evaluation, 29(1), 99-107. 
Conway, K. P., Compton, W., Stinson, F. S., \& Grant, B. F. (2006, February). Lifetime comorbidity of DSM-IV mood and anxiety disorders and specific drug use disorders; Results from the National Epidemiologic Survey on alcohol and related conditions. Journal of Clinical Psychiatry, 67(2), 247-257.

Coolbaugh, K. W., \& Rosenthal, A. (1992). Family separations in the Army (Technical Report 964). Retrieved from Army Research Institute for Behavioral and Social Sciences: www.hqda.army.mil/ari

Cuijpers, P., Geraedts, A. S., Van Oppen, P., Anderson, G., Markowitz, J. C., \& Van Straten, A. (2011). Interpersonal psychotherapy for depression: A meta-analysis. American Journal of Psychiatry, 168(6), 581-592. http://dx.doi.org/10.1176/appi.ajp.2010.10101411

Dave, S., Petersen, I., Sherr, L., \& Nazareth, I. (2010, November). Incidence of maternal and paternal depression in primary care: a cohort study using a primary care database. Archives of Pediatrics \& Adolescent Medicine, 164(11), 1038-1044. http://dx.doi.org/10.1001/archpediatrics.2010.184

Defense Manpower Data Center. (2005). The changing profile of the Army. Retrieved from www.armyg1.army.mil/hr/docs/demographics/changingprofilefinalcopy.pdf

Delgado, P. L. (2000). Depression: The case for monoamine deficiency. Journal of Clinical Psychiatry, 61(Suppl. 6), 7-11.

Department of Defense. (2007). Demographics 2007: Profile of the military community. Retrieved from www.militaryonesources.mil/12038/MOS/Reports/2007\%20demographics.pdf

Department of Defense. (2012). 2011 Demographics: Profile of the military community. Retrieved from www.militaryonesource.mil/12038/MOS/reports/2011_demographics_reports.pdf

Department of the Army. (2009). Soldier family in action. U.S. Army Posture Statement. Retrieved from www.army.mil/aps/09/addenda/addenda_h.html

Department of Defense. (2011, February). Deployment overview. Military Deployment Guide, 310.

Depressive and Bipolar Support Alliance. (2006). The state of depression in America. Retrieved from www.dballiance.org/pfs/wplowres.pdf

Devane, C. L., Chiao, E., Franklin, M., \& Kruep, E. J. (2005, October). Anxiety disorders in the 21st century: Status, challenges, opportunities, and comorbidity with depression. American Journal of Managed Care, 11(12), 344-353. 
Drummet, A. R., Coleman, M., \& Cable, S. (2003). Military family under stress: Implications for family education. Family Relations, 52(3), 279-287. http://dx.doi.org/10.1111/j.17413729.2003.00279.xwww.military.com/deployment/deploymentoverview.html

Easterling, B., \& Knox, D. (2010, July 20). Left behind: How military wives experience the deployment of their husbands. Journal of Family Life, 1-22. Retrieved from www.journaloffamilylife.org/print/node/580.html

Eaton, K. M., Hoge, C. W., Messer, S. C., Whitt, A. A., Cabrera, O. A., McGurk, D., \& Castro, C. A. (2008). Prevalence of mental health problems, treatment need, and barriers to care among primary care-seeking spouses of military service members involved in Iraq and Afghanistan deployments. Military Medicine, 173(11), 1051-1056.

Fawcett, J. (2005). Contemporary nursing knowledge: Analysis and evaluation of nursing models and theories (2nd ed.). Philadelphia, PA: F.A. Davis.

Field, A. (2009). Discovering statistics using SPSS (3rd ed.). Thousand Oaks, CA: Sage.

Fincham, J. E. (2008). Response rates and responsiveness for surveys, standards, and the journal. American Journal of Pharmaceutical Education, 72(2), 1-3.

Finley, M. C. (2004). Coast Guard families experiencing deployment: Stressors, coping strategies and supports. (Doctoral dissertation). Retrieved from ProQuest Information and Learning Company. (Accession Order No. 3127866).

Frank, R. G., Goldman, H. H., \& McGuire, T. G. (2009). Trends in mental health cost growth: An expanded role for management. Health Affairs, 28(3), 649-659. Retrieved from http://dx.doi.org/10.1377/hlthaff.28.3.649

Friedman, M. M., Bowden, V. R., \& Jones, E. G. (2003). Family nursing: Research, theory, and practice (5th ed.). Upper Saddle River, NJ: Prentice Hall.

Gable, S. L., Reis, H. T., Impett, E. A., \& Asher, E. R. (2004). What do you do when things go right? The intrapersonal and interpersonal benefits of sharing positive events. Journal of Personality and Social Psychology, 87, 228-245.

Galson, S. K. (2009, March-April). Surgeon general's perspectives: Mental health matters. Public Health Reports, 124, 189-191.

Giese-Davis, J., Collie, K., Rancourt, K. M., Neri, E., Kraemer, H. C., \& Spiegel, D. (2010). Decrease in depression symptoms is associated with longer survival in patients with metastatic breast cancer: A secondary analysis. Journal of Clinical Oncology, 29(4), 413420. http://dx.doi.org/10.1200/JCO.2010.28.4455 
Goetzel, R. Z., Hawkins, K., Ozminkowski, R. J., \& Wang, S. (2003). The health and productivity cost burden of the "top 10" physical and mental health conditions affecting six large U.S. employers in 1999. Journal of Occupational Environmental Medicine, $45(1), 5-14$.

Gorman, L. A., Blow, A. J., Ames, B. D., \& Reed, P. L. (2011). National Guard families after combat: Mental health, use of mental health services, and perceived treatment barriers. Psychiatric Services, 62(1), 28-34. http://dx.doi.org/10.1176/app1.ps.62.1.28

Greenberg, P. E., \& Birnbaum, H. G. (2005). The economic burden of depression in the U.S.: Societal and patient perspectives. Expert Opinion on Pharmacotherapy, 6(3), 369-376.

Hall-Flavin, D. K. (2014). Stress management. Retrieved from www.mayoclinic.org

Hammen, C. (2005). Stress and depression. Annual Review of Clinical Psychology, 293-319.

Hankin, B. L., Abramson, L. Y., Miller, N., \& Haefel, G. J. (2004). Cognitive vulnerabilitystress theories of depression: Examining affective specificity in the prediction of depression versus anxiety in three prospective studies. Cognitive Therapy and Research, 28(3), 309-345.

Harrell, M. C., Lim, N., Castaneda, L. W., \& Golinelli, D. (2004). Working around the military family: Challenges to military spouse employment and education. Santa Monica, CA: RAND Corporation.

Hayes, S. C., Hayes, L. J., \& Reese, H. W. (1988). Finding the philosophical core: A review of Stephen C. Pepper's world hypotheses: A study in evidence. Journal of the Experimental Analysis of Behavior, 50(1), 97-111. http://dx.doi.org/10.1901/jeab.1988.50-97

Hendrick, S. S. (1988). A generic measure of relationship satisfaction. Journal of Marriage and Family, 50, 93-98.

Herbert, J. D., \& Forman, E. M. (2011). The evolution of cognitive behavior therapy: The rise of psychological acceptance and mindfulness. In J. D. Herbert \& E. M. Forman (Eds.), Acceptance and mindfulness in cognitive behavior therapy: Understanding and applying the new therapies (pp. 3-25). Hoboken, NJ: Wiley.

Higginbotham, E., \& Romero, M. (1997). Women and work: Exploring race, ethnicity, and class. Thousand Oaks, CA: Sage.

Hill, D. (1968). Depression: Disease, reaction, or posture? American Journal of Psychiatry, 125(4), 445-457.

Hosek, J., Asch, B., Fair, C. C., Martin, C., \& Mattock, M. (2002). Married to military: The employment and earnings of military wives compared with those of civilian wives. Santa Monica, CA: RAND Corporation. 
Huebner, A. J., \& Mancini, J. A. (2005). Adjustments among adolescents in military families when a parent is deployed. Final report to the Military Family Research Institute and Department of Defense Quality of Life Office. Retrieved from www.mfri.purdue.edu/content/reports/adjustments\%20among\%20605.pdf

Hunter, E. J. (1982). Families under the flag: A review of military family literature. New York, NY: Praegers Publishers.

Institute of Medicine - National Research Council. (2009). Depression in parents, parenting, and children: Opportunities to improve identification, treatment, and prevention. Retrieved from www.nap.edu/catalog.php?record_id-12565

Isay, R. A. (1968). The submariners' wives syndrome. Psychiatric Quarterly, 42(4), 647-652. http://dx.doi.org/10.1007/BF01564308

Jacob, V., Chattopadhay, S. K., Sipe, T. A., Thota, A. B., Byard, G. J., \& Chapman, D. P. (2012). Economics of collaborative care for management of depressive disorders: A community guide systematic review. American Journal of Preventive Medicine, 42(5), 539-549. http://dx.doi.org/10.1016/j.amepre.2012.01.011

Jacobsen, P. B., \& Jim, H. S. (2008). Psychosocial interventions for anxiety and depression in adult cancer patients: Achievements and challenges. Cancer Journal for Clinicians, 58(4), 214-230. http://dx.doi.org/10.3322/CA.2008.0003

Jensen, P. S., Martin, D., \& Watanabe, H. (1996). Children's response to parental separation during Operation Desert Storm. Journal of the American Academy of Child and Adolescent Psychiatry, 35(4), 433-441.

Kaplowitz, M. D., Hadlock, T. D., \& Levine, R. (2004). A comparison of web and mail survey response rates. Public Opinion Quarterly, 68(1), 94-101.

Keller, A., Litzelman, L., Wisk, L. E., Maddox, T., Cheng, E. R., Creswell, P. D., \& Witt, W. P. (2012). Does the perception that stress affects health matter? The association with health and mortality. Health Psychology, 31(5), 677-684. http://dx.doi.org/10.1037/a0026743

Kelley, M. L. (1994). The effects of military-induced separation on family factors and child behavior. American Journal of Orthopsychiatry, 64(1), 103-111. http://dx.doi.org/10.1037/h0079499

Kessler, R. C. (2003). Epidemiology of women and depression. Journal of Affective Disorders, 74(1), 5-13. http://dx.doi.org/10.1016/S0165-0327 (02)00426-3

Kessler, R. C., Berglund, P., Demier, O., Jin, R., Koretz, D., Merikangas, K. R., \& Wang, P. S. (2003). The epidemiology of major depressive disorder: Results from the National Comorbidity Survey Replication (NCS-R). Journal of American Medical Association, 289(23), 3095-3105. 
Kline, P. (1986). A handbook of test construction: Introduction to psychometric design. New York: Methune \& Company.

Knapp, T. S., \& Newman, S. J. (1993). Variables related to the psychological well-being of Army wives during the stress of an extended military separation. Military Medicine, $158(2), 77-80$.

Leahy, R. (2010, October 30). The cost of depression. The Huffington Post. Retrieved from www.huffingtonpost.com/robert-leahy-phd/the-cost-of-depression_b_770805.html

Lee, M. (2009). A path analysis on elder abuse by family caregivers: Applying the ABCX model. Journal of Family Violence, 24(1), 1-9.

Leitz, C. (2013). Family resilience in the context of high risk situations. New York, NY: Springer.

Lepine, J. P., \& Briley, M. (2011). The increasing burden of depression. Neuropsychiatric Disease and Treatment, 7(1), 3-7. http://dx.doi.org/10.2147/NDT.S19617

Lester, P., Peterson, K., Reeves, J., Knauss, L., Glover, D., Mogil, C., \& Beardslee, W. (2010, April). The long war and parental combat deployment: Effects on military children and at-home spouses. Journal of the American Academy of Child and Adolescent Psychiatry, 49(4), 310-320. http://dx.doi.org/10.1016/j.jaac.2010.01.003

Leyva, M. (2003). Married to the military: A survival guide for military wives, girlfriends, and women in uniform. New York, NY: Fireside.

Lim, N., Golinelli, D., \& Cho, M. (2007). Working around the military, revisited: Spouse employment in 2000 census data. Retrieved from www.rand.org/pubs/monographs/2007/RAND_MG566.pdf

Lin, N., Simeone, R. S., Ensel, W. M., \& Kuo, W. (1979). Social support, stressful life events, and illness: A model and an empirical test. Journal of Health and Social Behavior, 20, 108-119.

Long, P. (1986). Growing up military. Psychology Today, 20(12), 31-37.

Luthar, S. S. (2006). Resilience in development: A synthesis of research across five decades. In D. Cichetti \& D. J. Cohen (Eds.). Developmental psychopathology: Risk, disorder, and adaptation. New York, NY: Wiley

Mansfield, A. J., Kaufman, J. S., Marshall, S. W., Gaynes, B. N., Morrissey, J. P., \& Engel, C. C. (2010). Deployment and the use of mental health services among U.S. Army wives. New England Journal of Medicine, 362(2), 101-109.

http://dx.doi.org/10.1056/NEJMoa0900177 
Markowitz, J. C., \& Weissman, M. M. (2004). Interpersonal psychotherapy: Principles and applications. World Psychiatry, 3(3), 136-139.

Martinez, L. (2011, November 11). U.S. Veterans: By the numbers. ABC News. Retrieved from www.abcnews.go.com

McCubbin, H. I., \& Patterson, J. M. (1983a). Family stress and adaptation to crises: A double ABC model of family behavior. In D. H. Olson, \& B. C. Miller (Eds.), Family studies review yearbook (pp. 87-107). Beverly Hills, CA: Sage.

McCubbin, H. I., \& Patterson, J. M. (1983b). The family stress process: The double ABCX model of adjustment and adaptation. Marriage and Family Review, 6(1-2), 7-37. http://dx.doi.org/10.1300/J002v06n01_02

McCubbin, H. I., \& Patterson, J. M. (1983c). The family stress process. Marriage and Family Review, 6(1), 7-37.

McCubbin, H. I., Joy, C. B., Cauble, A. E., Comeau, J. K., Patterson, J. M., \& Needle, R. H. (1980). Family stress and coping: A decade review. Journal of Marriage and Family, 42(4), 855-871.

McCubbin, M. A., \& McCubbin, H. I. (Eds.). (1987). Family stress theory and assessment. Family assessment inventories for research and practice (pp. 3-22). Madison, WI: University of Wisconsin-Madison.

McDowell, I. (2006). Measuring health: A guide to rating scales and questionnaires. New York, NY: Oxford University Press.

McLeland, K. C., Sutton, G. W. \& Schumm, W. R. (2008). Marital satisfaction before and after deployments associated with the global war on terror. Psychological Reports, 103, 836844.

McNulty, P. A. (2003). Does deployment impact the health care use of military families stationed in Okinawa, Japan? Military Medicine, 168(6), 465-470.

Medway, F. J., Davis, K. E., Cafferty, T. P., Chappell, K. D., \& O’Hearn, R. E. (1995). Family disruption and adult attachment correlates of spouse and child reactions to separations and reunion due to Operation Desert Storm. Journal of Social and Clinical Psychology, 14(2), 97-118. http://dx.doi.org/10.1521/jscp.1995.14.2.97

Mental Health America. (2013). Depression in women. Retrieved from www.nmha.org/index.cfm?objectid=C7DF952E-1372-4D20-C8A3DDCD5459D07B

Mewes, A. (2011). Intro to Army life: A handbook for spouses and significant others entering the Army lifestyle. Boise, ID: Aloha Publishing. 
Misono, S., Weiss, N. S., Fann, J. R., Redman, M., \& Yueh, B. (2008). Incidence of suicide in persons with cancer. Journal of Clinical Oncology, 26(29), 4731-4738.

http://dx.doi.org/10.1200/JCO.2007.13.8941

Molaison, V. A. (1990). Family and chronic stress: A test of the ABCX model in families caring for disabled adults (Unpublished doctoral dissertation). The University of Maryland, College Park, MD.

Monat, A, \& Lazarus, R. S. (1991). Stress and coping: An anthology (3rd ed.). New York, NY: Columbia University Press.

Morgan, H. (2001). Depression in men. Australian Family Physician, 30(3), 206-217.

Morse, J. (2006). New emotional cycles of deployment for service members and their families. U.S. Department of Defense: Deployment Health and Family Readiness Library. San Diego, CA. Retrieved from http://deploymenthealthlibrary.fhp.osd.mil/Product/RetrieveFile?prodId=241

Muriel McQueen Fergusson Center for Family Violence Research at the University of New Brunswick and the Resolve Violence and Abuse Research Centre at the University of Manitoba. (2000). Report on the Canadian Forces-Response to woman abuse in the military families. Retrieved from www.springtideresources.org/sites/all/files/womanabuse-in-military-families.pdf

National Alliance on Mental Illness. (2009, October). Women and depression, Fact sheet. National Alliance on Mental Illness Fact Sheet, 1-3. Retrieved from www.nami.org

National Cancer Institute. (2013). NCI dictionary of cancer terms. Retrieved from http://www.cancer.gov/dictionary?cdrid=440116

National Defense Research Institute, RAND. (2005). Working around the military: Challenges of military spouse employment. Retrieved from www.rand.org

National Institute of Mental Health. (2013). Women and depression: Discovering hope. Retrieved from www.nimh.nih.gov/health/publications/women-and-depressiondiscovering-hope/index/shtml

Nemade, R., Reiss, N. S., \& Dombeck, M. (2013). Psychology of depression - Psychodynamic theories. Retrieved from http://info.epmhmr.org/poc/view_doc.php?type=doc\&id=13003\&cn=5

Netuveli, G., Wiggins, R. D., Montgomery, S. M., Hildon, Z., \& Blane, D. (2008). Mental health and resilience at older ages: Bouncing back after adversity in the British Household Panel Survey. Journal of Epidemiology and Community Health, 62(11), 987-991. 
Noble, R. E. (2005). Depression in women. Metabolism, Clinical and Experimental, 54(5), 4952. http://dx.doi.org/10.1016/j.metabol.2005.01.014

Nunnally, J.C.\& Bernstein, I.H. (1994). Psychometric theory (3rd ed.). New York: McGraw-Hill.

Nutt, D. J. (2008). Relationship of neurotransmitters to the symptoms of major depression. Journal of Clinical Psychiatry, 69(1), 4-7.

Office of the Deputy Under Secretary of Defense. (2008). Demographics 2008. Profile of the military community. Retrieved from www.cs.mhf.dod.mil

Olfson, M., Marcus, S. C., Druss, B., Elinson, L., Tanielian, T., \& Pincus, H. A. (2002). National trends in the outpatient treatment of depression. Journal of the American Medical Association, 287(2), 203-209. http://dx.doi.org/10.1001/jama.287.2.203

Ozbay, F., Fitterling, H., Charney, D., \& Southwick, S. (2008). Social support and resilience to stress across the lifespan: A neurobiologic framework. Current Psychiatric Reports, 10(4), 304-310.

Patterson, J. M. (1988). Families experiencing stress: I. The family adjustment and adaptation response model; II. Applying the FAAR model to health-related issues for intervention and research. Family Systems Medicine, 6(2), 202-237.

Patterson, J. M., \& McCubbin, H. I. (1983). The impact of family life events and changes on health of a chronically ill child. Family Relations, 32(2), 255-264.

Peebles-Kleiger, M. J., \& Kleiger, J. H. (1994). Re-integration stress for Desert Storm families: Wartime deployments and family trauma. Journal of Trauma Stress, 7(2), 173-194.

Pincus, S., House, R., Christenson, J., \& Adler, L. (2004). The emotional cycle of deployment: A military family perspective. Retrieved from www.hooah4health.com/deployment/familymatters/emotionalcycle.htm\#

Reed, P. G., \& Crawford-Shearer, N. B. (Eds.). (2008). From a plethora of paradigms to parsimony in worldviews. Perspectives on nursing theory (5th ed., pp. 216-220). Philadelphia, PA: Wolters Kluwer Health/ Lippincott Williams \& Wilkins.

Regier, D. A., Rae, D. S., Narrow, W. E., Kaebler, C. T., \& Schatzberg, A. F. (1998). Prevalence of anxiety disorders and their co-morbidity with mood and addictive disorders. British Journal of Psychiatry, 1998(173), 24-28.

Riggs, B. A. (1990). Routine work-related absence: The effects on families. Marriage and Family Review, 15(3-4), 147-160. http://dx.doi.org/10.1300/J002v15n03_09

Russo, F. (2013). The key to happy relationships? It's not all about communication. Retrieved from www.heartland.time.com 
Salgado-Delgado, R., Osorio, A. T., Saderi, N., \& Escobar, C. (2011, June 6). Disruption of circadian rhythms: A crucial factor in the etiology of depression. Depression Research and Treatment, 2011, 1-9. http://dx.doi.org/10.1155/2011/839743

Saltzman, W. R., Lester, P., Beardslee, W. R., Layne, C. M., Woodward, K., \& Nash, W. P. (2011). Mechanisms of risk and resilience in military families: Theoretical and empirical basis of a family-focused resilience enhancement program. Clinical Child Family Psychology Review, 14, 213-230. http://dx.doi.org/10.1007/s10567-011-0096-1

Schneider, F. W., Coutts, L., Gruman, J. A., \& Coutts, L. M. (Eds.). (2005). Applied social psychology: Understanding and addressing social and practical problems (1st ed.). Thousand Oaks, CA: Sage.

Schumm, W. R., Bell, D. B., \& Gade, P. A. (2000). Effects of a military overseas peacekeeping deployment on marital quality, satisfaction, and stability. Psychological Reports, 87(3), 815-821. http://dx.doi.org/10.2466/pr0.2000.87.3.815

Scott, E. (2014). The traits, benefits and development of emotional resilience. Retrieved from www.stress.about.com/od/understandingstress/a/resileince.htm

Segall, D. O. (1994). The reliability of linearly equated tests. Psychometrika, 59, 361-375.

Segal, M. W., \& Harris, J. J. (1993). What we know about military families [White paper]. Retrieved from DTIC Online Information for the Defense Community: www.oai.dtic.mil/oai?vern=getRecord\&metadataPrefix=html\&identifier=ADA271989

Sharp, L. K., \& Lipsky, M. S. (2002). Screening for depression across the lifespan: A review of measures for use in primary care settings. American Family Physician, 66(6), 1001-1008.

Silver, R. L., \& Wortman, C. B. (1980). Coping with undesirable life events. In J. Garber, \& M. E. Seligman (Eds.), Human Helplessness (pp. 279-375). New York, NY: Academic Press.

Smith, M. J., \& Liehr, P. R. (2008). Theory of family stress and adaptation. In G. LoBiondoWood (Ed.), Middle range theory for nursing (2nd ed., pp. 225-241). New York, NY: Springer.

Spiegel, D., Giese-Davis, J., Taylor, C. B., \& Kraemer, H. (2006). Stress sensitivity in metastatic breast cancer: Analysis of the hypothalamic-pituitary-adrenal axis function. PsychoNeuroendocrinology, 31(10), 1231-1244. http://dx.doi.org/10.1016/j.psyneuen.2006.09.004

Stahl, S. M. (1997). Psychopharmacology of antidepressants (1st ed.). London, England: Martin Dunitz. 
Steel-Fisher, G. K., Zaslavsky, A. M., \& Blendon, R. J. (2008). Health-related impact of deployment extensions on spouses of active duty Army personnel. Military Medicine, 173(3), 221-229.

Storch, E. A., Roberti, J. W., \& Roth, D. A. (2004). Factor, structure, concurrent validity, and internal consistency of the Beck Depression Inventory-second edition in sample of college students. Depression \& Anxiety, 19(3), 189-189. http://dx.doi.org/10.1002/da.20002

Stoudemire, A., Frank, R., Kamlet, M., \& Blazer, D. (1986). The economic burden of depression. General Hospital Psychiatry, 8(6), 387-394.

Suter, P., Suter, W. N., \& Johnston, D. (2008). Depression revealed: The need for screening, treatment, and monitoring. Home Healthcare Nurse, 26(9), 543-550.

TRICARE. (2012). Evaluation of the TRICARE program: Access, cost and quality. Fiscal Year 2012 report to Congress. Retrieved from www.tricare.mil/hpae/_docs/2012eval/files/assets/basic_html/toc.html

Ursano, R. J., Holloway, H. C., Jones, D. R., Rodriguez, A. R., \& Belenky, G. L. (1989). Psychiatric care in the military community: Family and military stressors. Hospital Community Psychiatry, 40(12), 1284-1289.

US Department of Health and Human Services, Office of the Surgeon General, Substance Abuse and Mental Health Services Administration. (2001). Mental health: culture, race, and ethnicity: a supplemental to mental health: a report of the Surgeon General. Retrieved from www.surgeongeneral.gov/library/mentalhealth/cre

Vaishnavi, S., Connor, K., \& Davidson, J. R. T. (2007). An abbreviated version of the ConnorDavidson Resilience Scale (CD-RISC), the CD-RISC2: Psychometric properties and applications in psychopharmacological trials. Psychiatry Research, 152(2-3), 293-297.

Verdeli, H., Baily, C., Vousoura, E., Belser, A., Singla, D., \& Manos, G. (2011, August). The case for treating depression in military spouses. Journal of Family Psychology, 25(4), 488-496. http://dx.doi.org/10.1037/a0024525

Vitaterna, M. H., Takahashi, J. S., \& Turek, F. W. (2013). Overview of circadian rhythms. Retrieved from www.pubs.niaaa.nih.gov/publications/arh25-2/85-93.htm

Vormbrock, J. K. (1993). Attachment theory as applied to wartime and job-related marital separation. Psychological Bulletin, 114(1), 122-144. http://dx.doi.org/10.1037//00332909.114.1.122

Walsh, F. (2013). Handbook of family resilience. New York, NY: Springer. 
Walker, A. J. (1985). Reconceptualizing family stress. Journal of Marriage and Family, 47(4), 827-837.

Warner, C. H., Appenzeller, G. N., Warner, C. M., \& Grieger, T. (2009). Psychological effects of deployments on military families. Psychiatric Annals, 39(2), 56-63.

Watt, S., Simpson, C., McKillop, C., \& Nunn, V. (2002). Electronic course surveys: Does automating feedback and reporting give better results? Assessment \& Evaluation in Higher Education, 27(4), 325-337. http://dx.doi.org/10.1080/0260293022000001346

Whitchurch, G., \& Constantine, L. (2009). Systems theory. In P. Boss, W. Doherty, R. LaRossa, W. Schumm \& S. Steinmetz (Eds.), Sourcebook of family theories and methods: A contextual approach (pp. 325 - 352).

Williams, S. B., O’Connor, E. A., Edder, M., \& Whitlock, E. P. (2009, April 1). Screening for child and adolescent depression in primary care settings: A systematic evidence review for the US Preventive Services Task Force. Pediatrics, 123(4), 716-735. http://dx.doi.org/10.1542/peds.2008-2415

Wilson, E. (2009, November 12). Military wives speak out on health care. Family Matters Blog, Armed Forces Press Service, US Department of Defense, 1-3. Retrieved from www.afps.dodlive.mil

World Health Organization. (2002). Prevention and promotion in mental health. Mental Health: Evidence and Research, 1-46.

World Health Organization. (2012a). Depression. Retrieved from www.who.int/mental_health/management/depression/definition/en

World Health Organization. (2012b). Depression. Retrieved from www.who.int/topics/depression/en/

World Health Organization. (2012c). World suicide prevention day. Retrieved from www.who.int/mediacentre/events/annual/world_suicide_prevention_day/en/

Yonkers, K. A., Wisner, K. L., Stewart, D. E., Oberlander, T. F., Dell, D. L., Stotland, N., \& Lockwood, C. (2009, September). The management of depression during pregnancy: A report from the American Psychiatric Association and the American College of Obstetricians and Gynecologists. Obstetrics \& Gynecology, 114(3), 703-713. http://dx.doi.org/10.1097/AOG.0b013e3181ba0632

Yun, G. W., \& Trumbo, C. W. (2000). Comparative response to survey executed by post, e-mail, and web form. Journal of Computer-Mediated Communications, 6. Retrieved from http://jcmc.indiana.edu/vol6/issue1/yun.html 
Zimet, G. D., Dahlem, N. W., Zimet, S. G., \& Farley, G. K. (1988). The Multidimensional Scale of Perceived Social Support. Journal of Personality Assessment, 52, 30-41.

Zimet, G. D., Powel, S. S., Farley, G. K., Werkman, S., \& Berkoff, K. A. (1990). Psychometric characteristics of the Multidimensional Scale of Perceived Social Support. Journal of Personality Assessment, 55, 610-617.

Zubin, J., \& Spring, B. (1977). Vulnerability: A new view on schizophrenia. Journal of Abnormal Psychology, 86(2), 103-126. 